Georgetown University Law Center

Scholarship @ GEORGETOWN LAW

2018

The Fault Is Not in Our Stars: Avoiding an Arms Race in Outer

Space

David A. Koplow

Georgetown University Law Center, koplow@law.georgetown.edu

This paper can be downloaded free of charge from:

https://scholarship.law.georgetown.edu/facpub/2083

https://ssrn.com/abstract=3058132

David A. Koplow, The Fault Is Not in Our Stars: Avoiding an Arms Race in Outer Space, 59 Harv. Int'I L.J. 331 (2018)

This open-access article is brought to you by the Georgetown Law Library. Posted with permission of the author. Follow this and additional works at: https://scholarship.law.georgetown.edu/facpub

Part of the Air and Space Law Commons 


\title{
The Fault Is Not in Our Stars: Avoiding an Arms Race in Outer Space
}

\author{
David A. Koplow*
}

\begin{abstract}
Men at some time are masters of their fates; The fault, dear Brutus, is not in our stars, But in ourselves, that we are underlings.
\end{abstract}

William Shakespeare, Julius Caesar, act 1, sc. 2

The world is on the precipice of a new arms race in outer space, as China, Russia, the United States, and others undertake dramatic new initiatives in anti-satellite weaponry. These accelerated competitive efforts at space control are highly destabilizing because developed societies have come to depend so heavily upon satellite services to support the entire civilian economy and the modern military apparatus; any significant threat or disruption in the availability of space assets would be massively, and possibly permanently, disruptive.

International law regarding outer space developed with remarkable rapidity in the early years of the Space Age, but the process of formulating additional treaties and norms for space has broken down over the past several decades; no additional legal instruments have emerged that could cope with today's rising threats. This Article therefore proposes three initiatives. Although none of them can suffice to solve the emerging problems, they could, perhaps, provide additional diplomacy, reinvigorating the prospects for rapprochement in space. Importantly, each of these three ideas has deep roots in other sectors of arms control, where they have served both to restore a measure of stability and to catalyze even more ambitious agreements in the longer term.

The first proposal is for a declaratory regime of "no first use" of specified space weapons; this would do little to directly alter states' capabilities for space warfare, but could serve as a "confidence-building measure," to temper their most provocative rhetoric and practices. The second concept is a "limited test ban," to interdict the most dangerous debris-creating developmental tests of new space weapons. Third is a suggestion for shared "space situational awareness," which would create an international apparatus enabling all participants to enjoy the benefits of greater transparency, reducing the possibilities for secret malign or negligent behavior. In each instance, the Article describes the proposal and its variations, assesses its possible contributions to space security, and displays the key precedents from other arms-control successes.

The Article concludes by calling for additional, further-reaching space diplomacy, in the hope that these relatively modest initial measures could provoke more robust subsequent negotiations.

* Professor of Law, Georgetown University Law Center. The author is deeply indebted to the following experts, colleagues, and friends who reviewed earlier drafts of this manuscript and provided invaluable critique and suggestions: Allison K. Astorino-Courtois, Arthur E. Baer, Jr., Jack M. Beard, Martin C. Faga, Joanne Irene Gabrynowicz, Mark A. Gubrud, Henry R. Hertzfeld, Peter Hulsroj, Raymond Jeanloz, Barry Kellman, Al Mauroni, Scott Pace, Victoria Samson, James B. (Bart) Wager Jr., and Brian Weeden. Staff members at the Georgetown Law Library provided essential support in research, cite checking, and editing: Mabel Shaw, Jeremy McCabe, Peter Runfola, and Emma Chapman. The author was previously employed by the U.S. Department of Defense, but the views expressed here do not necessarily reflect the official policy or position of the Department or the U.S. Government. 


\section{INTRODUCTION}

The world today is wobbling on the precipice of a threatening new arms race in outer space, a development that would be simultaneously dangerous and expensive, as well as eminently avoidable. China, Russia, the United States, and others are conducting an expanded array of tests of anti-satellite ("ASAT") weapons and associated capabilities and technologies; fresh funding is surging into the field; and increasingly bellicose rhetoric emanates from military and civilian authorities. No shots have yet been fired in anger, but the exoatmospheric environment is no longer a sanctuary from predatory arms competition, and unless international legal and political corrective action is undertaken promptly, the hazards will surely escalate.

The stakes are already high here, because the United States and other developed countries have become so heavily dependent upon satellites to support the full range of civilian and military activities. Denial or serious degradation of those space functions could be catastrophic, inflicting immediate and possibly irreversible economic, social, and security losses. Indeed, satellite-enabled services have become so ubiquitous that most people no longer notice them, remaining passively unaware of how thoroughly our daily activities, and our responses to military crises, have become reliant upon a secure, predictable regime of outer space-and how imperiled that stability has now become.

Worse yet, the world's traditional mechanisms for responding to emergent security threats have failed here, with the global diplomatic and political institutions and routines proving feckless over a period of decades. Although the early years of the Space Age were remarkably fertile in generating new treaties and international norms for regulating the safe and productive exploitation of space, that process has ground to a halt, and no fresh concepts have emerged that command the international consensus among spacefaring states to avoid or mitigate the new dangers.

This Article seeks to circumvent that impasse, by proposing three modest initiatives for arms control in outer space. None of these schemes is revolutionary or definitive; even in concert, they would not suffice to solve the security problems generated by revolutionary ASAT developments. But they can be useful nonetheless in reenergizing the stultified global diplomatic dialogue, jump-starting a more robust international process.

The three proposals assembled here are: a "no first use" pledge; a limited test ban agreement; and a mechanism for shared monitoring of outer space. Importantly, each of these concepts has antecedents elsewhere in arms control, where they have proven successful both in contributing in a modest, immediate way to enhanced security and in catalyzing progress toward more ambitious subsequent measures. Indeed, this is often the way arms control proceeds: via initial baby steps that can lead to something more profound. This Article's essential proposition is to apply that traditional arms-control 
incrementalism to outer space, restoring a process of sensible, measured responses to urgent security threats.

The Article proceeds as follows. After this Introduction, Part I presents the current quagmire of outer space in three dimensions. First, it explores the growing U.S. and global dependence upon space, to make clear how much we have come to derive economic and military value from orbiting resources, and accordingly how vulnerable we have become to perturbations in satellite operations. Second, it describes the threat: the explosion of ASAT and related counter-space activities, especially by the three leading spacefaring countries but now increasingly emulated by others. The past decade has "changed the game" regarding space security in alarming ways. Third, it analyzes the failure of the international law-making institutions to cope with this new adversity, and it concludes that the existing panorama of diplomatic initiatives is wholly inadequate to suppress the erupting problems.

Next, the Article presents my three proposals. Part II discusses the idea of an agreement for no first use of ASAT weapons - an undertaking not to be the first to introduce space warfare into any future combat. Part III displays the possibilities for a new limited ASAT test ban regime-an agreement to refrain from explosive testing in space of the most aggravating types of weapons. Part IV explains the idea of shared "space situational awareness" ("SSA")—a commitment to augment countries' collective abilities to understand what is actually happening in outer space and to respond to distant events. In each Part, the Article describes what the proposal entails, what the various options and sub-elements could consist of, and how the idea would contribute to security. Importantly, each Part also explains the relevant precedents, identifying how the concept has previously played out in the realms of the control of nuclear, chemical, biological or other weapons, suggesting analogies for outer space.

Finally, the Article offers some concluding thoughts, trying to project how these initial incremental steps might lead to more ambitious and comprehensive measures of arms control in outer space. That sort of more enduring solution is long-distant and hard to conceive at this point, but the urgency of the problem should energize the world to pursue it vigorously.

\section{The Current Quagmire in Outer Space}

This Part discusses, in three steps, where the world now stands regarding the deficit of arms control in outer space, how we got into the current predicament, and why the usual spectrum of global responses is so inadequate to deal with the new threats. 


\section{A. The World's Large and Growing Use of, and Dependence upon, Space}

Space is now thoroughly integrated into terrestrial ecosystems, especially in the United States and other economically advanced societies, but to a growing degree everywhere. Indeed, satellites have been insinuated into every aspect of modern life, but sometimes with a subtlety that obscures their true impact. ${ }^{1}$

On the civilian side, satellites enable many of the communications (phone, text, email, internet, television) and banking operations (credit card purchases, ATMs) that have become the primary modes of social interaction and the lifeblood of the world's economy. For industrial purposes, networked supervisory control and data acquisition ("SCADA") systems enable operators to coordinate peripheral manufacturing and other operations, and the emerging internet of things will similarly revolutionize consumer behavior. Global Positioning System (“GPS”) satellites guide and track cars, airplanes, and, soon, drones that will deliver household packages. Earthmonitoring spacecraft enable farmers to supervise their crops, foresters to direct firefighters, and flood control authorities to anticipate river flows. Satellites help save lives by supporting disaster relief and search and rescue missions. In each of these functions, the invisible, speed-of-light, and inexpensive links must be ubiquitous and $100 \%$ reliable - any gaps in coverage or transitory outages provoke exasperation and confusion, as people seem to notice the service mechanisms only when they are interrupted. ${ }^{2}$

The United States is the world's pre-eminent explorer and exploiter of commercial and civil space, but a broad array of other countries is fully invested in satellite operations, and even the impoverished world is racing

1. See generally Elbridge Colby, Ctr. for a New Am. Sec., from Sanctuary to Battlefield: A Framework for U.S. Defense and Deterrence Strategy for Space (2016); Theresa Hitchens \& Joan Johnson-Freese, Atlantic Council Strategy, Strategy Paper No. 5, Toward a New National Security Space Strategy (2016); Joan Johnson-Freese, Space Warfare in the 21st Century (2017); 1 Bhavya Lal et al., Inst. for Def. Analyses, ida Paper P-5242, Global Trends in Space (2015) thereinafter IDA]; Bruce W. MacDonald Et al., Foreign Policy Inst., Crisis Stability in Space: China and Other Challenges (2016); Comm. on Nat'l Sec. Space Def. \& Prot., Nat'l Research Council, National Security Space Defense and Protection (2016) [hereinafter NRC REPORT]; SPACE SECURITY Index (Jessica West ed., 13th ed. 2016); Jack M. Beard, Soft Law's Failure on the Horizon: The International Code of Conduct for Outer Space Activities, 38 U. PA. J. INT'L L. 335 (2017).

2. See MacDonald et AL., supra note 1, at 5-6; NRC Report, supra note 1, at 3, 10-11, 14, 27-28; SPACE SECURITY INDEX, supra note 1, at 46-53, 69-80 (surveying wide range of uses of space by various actors, and noting growth in global space industry); GPS Allows for Better, Faster Tsunami Warnings, Homeland Security News Wire (Feb. 18, 2016), http://www.homelandsecuritynewswire.com/ dr20160218-gps-allows-for-better-faster-tsunami-warnings; Angela Fritz, This New Weather Satellite Isn't Just Good for the U.S._-It's Good for the World, WASH. Post (Nov. 19, 2016), https://wapo.st/2FVgqDJ (highlighting the value of satellites for weather forecasting); U.S.-EU Satellite Data Arrangement Aids in Hurricane Harvey and Hurricane Irma Efforts, U.S. DeP'T of STATE (Sept. 6, 2017), https://www.state .gov/r/pa/prs/ps/2017/09/273826.htm; Rebecca Spyke Keiser, Assoc. Deputy Adm'r for Pol'y Integration, NASA, A Day Without Space: Economic Security Ramifications (Dec. 9, 2011), https:// www.nasa.gov/pdf/609548main_Space\%20Enterprise\%20Council\% 20Briefing\%20Final\%20Package $\% 20$ Dec\%209\%20updated.pdf; see also NASA, SpINOFF (2017) (collecting dozens of instances of collateral benefits from space operations). 
toward similar market penetration. No fewer than eleven states are now capable of launching satellites; fifty-nine countries operate their own orbiters, and every community derives multiple types of benefits from space assets. The annual global space economy has been estimated as a $\$ 340$ billion enterprise. ${ }^{3}$

On the military side, the degree of exploitation of space is, if anything, even greater. Today, the U.S. military demands ever-increasing bandwidth for secure, real-time communications between central authorities and fielded forces on land, sea, and air. Satellites provide crucial strategic and tactical reconnaissance about the location and status of enemy and friendly assets and about after-action battle damage assessment. Other satellites supply the strategic and tactical warning of enemy ballistic missile launches and cue anti-missile system responses. The same GPS network that provides the foundation for Waze and other civilian navigation aids also enables military aircraft, ships, and trucks to know their locations and plot their courses, and it steers many "smart bombs" with their characteristic stunning accuracy.

3. See Communication from the Commission to the European Parliament, the Council, the European Economic and Social Committee and the Committee of the Regions: Space Strategy for Europe, COM (2016) 705 final (Oct. 26, 2016) (presenting European Commission views about how space matters for Europe); DEAN CHENG, Heritage Found., Responding to the Chinese Space Challenge (2017); Anthony H. Cordesman, Ctr. for Strategic \& Int'l Studies, Chinese Space Strategy and Developments 7 (2016) (reporting China's use of space assets for land resource assessment, environmental quality monitoring, emergency responses, and other functions); IDA, supra note 1, at 2.3-2.6, 3.1-3.14 (noting that eighty countries engage in space-based activities and 170 countries hold financial interests in satellites); NRC Report, supra note 1, at 13, 16-19; Kevin Pollpeter et al., U.S.-China Econ. \& Sec. Rev. Comm'n, China Dream, Space Dream: China's Progress in Space Technologies and ImplicaTIONS FOR THE UNITED STATES 19-22 (2015) (presenting China's views on space weapons and arms control); Satellite Indus. Ass'n, State of the Satellite Industry Report 7-8 (2017); Space SECURITY INDEX, supra note 1, at 46-50 (noting several countries' pursuit of satellite-based navigation systems, and fifty countries' investments in Earth observation satellites); $i d$. at 53 (reporting that fifty-six countries own or operate active satellites); id. at 56-57 (comparing states' civilian space budgets); $i d$. at 73-74 (noting countries' efforts to grow their commercial space sectors); Justin Anderson et al., International Space Negotiations, Emerging Space Powers, and U.S. Efforts to Protect the Military Use of Space, 7 SPACE \& Def. 6, 7-22 (2014) (discussing military space programs of India, Brazil, and South Africa); William J. Lynn, III, A Military Strategy for the New Space Environment, 34 WASH. Q. 7, 8 (2011) (reporting that eleven states now operate twenty-two launch sites, and more than sixty nations have a presence in space); Daniel Stacey, India Looks for Its Own Elon Musk to Win the Space Race with China, Wall ST. J. (June 23, 2017), https://www.wsj.com/articles/india-shoots-for-the-moon-chasing-influence-closer-to-home1498210205 (reporting that India plans to spend over $\$ 6$ billion on its space program over the next five years); Michael Raska, The Real Star Wars: Improving Satellite Defences (Rajaratnam Sch. Of Int'l Studies, Working Paper No. CO16032, 2016), https://www.rsis.edu.sg/wp-content/uploads/2016/02/CO16032 .pdf (reporting that sixty-seven percent of the economy of the United Kingdom is dependent on spacebased communications, and that $\$ 1.6$ trillion of U.S. business revenues in 2015 were heavily influenced by satellites); Tristan Kenderdine, Coordinating China's Satellite Constellations, AsIA \& PAC. POL'y Soc. (July 20, 2017), https://www.policyforum.net/coordinating-chinas-satellite-constellations/ (discussing the role of space assets in China's Belt and Road Project); David Martin, The Battle Above (CBS News 60 Minutes broadcast Apr. 26, 2015), http://www.cbsnews.com/news/rare-look-at-space-command-satellitedefense-60-minutes-2/; UCS Satellite Database, UnION of ConCERned SCIENTISTs, http://www.ucsusa .org/nuclear-weapons/space-weapons/satellite-database\#.WX91SoTyuos (last visited Nov. 16, 2017). 


\section{Satellites provide current and forecasted weather data, essential for military and civilian operations alike. ${ }^{4}$ \\ To date, other countries remain a step or two behind the United States in the integration of space into military operations, but many of them are com- mitted to following the same trajectory, to exploit the manifest war-fighting benefits of space. ${ }^{5}$}

4. See Colby, supra note 1 , at 4-5, 8 (surveying the "[v]ital [i]mportance of [s]pace to the United States" and concluding that "[t]he United States has therefore built an enormously expensive and delicate architecture of space assets upon which it greatly relies for its military preeminence-and left it increasingly vulnerable to adversary attack or disablement"); MACDONALD ET AL., supra note 1, at 5-6; NRC REPORT, supra note 1, at 3, 19-21; SPACE SECURITY INDEX, supra note 1, at 80-85 (surveying the range of space-based U.S. military force enhancements); Beard, supra note 1, at 337-39; Lynn, supra note 3, at 7, 10 (then-Deputy Secretary of Defense asserting, "Space systems enable our modern way of war. They allow our warfighters to strike with precision, to navigate with accuracy, to communicate with certainty, and to see the battlefield with clarity. Without them, many of our most important military advantages evaporate .... [T]oday we rely on space for almost everything we do"); Martin, supra note 3 (citing a budget of $\$ 25$ billion per year for U.S. military and intelligence space programs); Michael Nayak, CubeSat Proximity Operations: The Natural Evolution of Defensive Space Control into a Deterrence Initiative, SPACE Rev. (Jan. 18, 2016), http://www.thespacereview.com/article/2902/1 (citing William Shelton, then the Commander of the U.S. Air Force Space Command, asserting, "From satellite-based surveillance to communications, mapping and weather technologies ... every US military action depends on space capabilities").

5. See Worldwide Threat Assessment of the U.S. Intelligence Community: Hearing Before the S. Select Comm. on Intelligence, 115th Congress 8-9 (2017) (opening statement of Daniel R. Coats, Dir. of Nat'l Intelligence) (forecasting that Russia will double or triple the number of its satellites by 2025, "China intends to continue increasing its space-based military and intelligence capabilities," and both countries "will continue to pursue a full range of [anti-satellite ("ASAT")] weapons as a means to reduce US military effectiveness"); CoRdesman, supra note 3, at 5, 8-9, 13-19 (discussing China's reliance upon satellites for a wide range of military applications); ERIC Heginbotham ET AL., RAND Corp., The U.S.-ChinA Military Scorecard: Forces, Geography, and the Evolving Balance of Power, 1996-2017, at 228-32 (2015) (comparing U.S. and Chinese use of military space systems); STEve Lambakis, Nat'L InSt. Pub. Pol’y, Foreign Space Capabilities 9-15 (2017) (comparing U.S. and other military satellite systems); Pollpeter ET AL., supra note 3, at 8 (reporting Chinese military statements that "whoever controls space controls the Earth”), 73-86 (describing China’s military space programs); SPACE SECURITY INDEX, supra note 1 , at 80-83, 87-90 (discussing use of military satellites by the United States, Russia, China, India, the European Union, and others). Regarding Russia's military space programs, see U.S. Def. Intelligence Agency, Russia Military Power 35-37 (2017) thereinafter DiA] (describing Russia's space and counter-space military capabilities, including more than 130 spacecraft); U.S.-CHINA Econ. \& Sec. Rev. Comm'n, 2015 Report to Congress 281, 283 (2015) (concluding that "Beijing believes space superiority would be critical to almost every component of its military operations . . .."). Regarding China's military space programs, see Cassandra Steer, Global Commons, Cosmic Commons: Implications of Military and Security Uses of Outer Space, 18 GEO. J. INT'L AfF. 9 (2017); David Axe, Russia Is Using Space Power in Its Attack on Syria, DaIly BEAST (Dec. 16, 2015, 1:00 AM), https://www .thedailybeast.com/russia-is-using-space-power-in-its-attack-on-syria (observing that Russia claims to have positioned ten satellites over Syria to support its military operations); Ruth Eglash \& William Booth, Israel to Launch One of the Most Advanced Missile Defense Systems in the World, With U.S. Help, WASH. PosT (Mar. 3, 2016), http://wapo.st/2prlpG5 (asserting that Israel's defense system will be able to hit orbiting satellites as well as ballistic missiles); Clay Dillow, Is China's Race to Space a Military Ploy?, CNBC (Feb. 18, 2016, 9:31 AM), https://www.cnbc.com/2016/02/18/chinas-space-missions-in-2016tied-to-military-ambitions.html (estimating China's space program as spending two to three billion dollars per year, but still being decades behind the U.S. program). Regarding other countries' military space programs, see Vivek Raghuvanshi, India Kick-Starts Military Satellite Programs, Def. News (June 19, 2017), https://www.defensenews.com/space/2017/06/19/india-kick-starts-military-satellite-pro grams/ (discussing India's surging space and ASAT programs); S. Korea's Military Seeks Five Indigenous Spy Satellites by 2023, Yonhap News AGEnCY (Aug. 25, 2017, 3:00PM), http://english.yonhapnews.co.kr/ news/2017/08/25/0200000000AEN20170825007300315.html. See also Anderson et al., supra note 3. 
Therefore, it is impossible to overestimate the role of space in modern life; the benefits from satellites are multiple and diverse and will surely continue to expand in the coming years. But there is also a dark side to this phenomenally successful exploitation. That is, as countries pour more functions into satellites, they have simultaneously reduced some of their capacities for performing some of those operations in the "old fashioned" way; the alternative routines have atrophied. Collectively, we have declined to sustain all of the now-redundant, less-efficient systems of land lines, postal services, and paper maps; in the same vein, it now seems quaintly anachronistic to train naval officers and civilian ship captains to discern their position via sextant, when all-weather GPS devices are so much quicker and more accurate. ${ }^{6}$

Over time, therefore, the modern "use" of satellites has evolved into a "reliance" upon them, which has graduated into a "dependence," and eventually generated a "vulnerability." Potential adversaries, aware of the technology patterns of the United States (and other), have come to appreciate the suggestion that satellites may now be the Achilles heel of the American civilian economy and its mighty military apparatus. If deft ASAT operations could deprive the United States of its space services, an attacker might be able to swiftly obtain a crippling advantage. ${ }^{7}$

Even in that apocalyptic scenario, the United States would not be destroyed or disarmed-an immensely powerful fighting force and a robust infrastructure would still be largely intact. But the ability to fight effectively, in the manner that the military has now been trained to prosecute,

6. But see Colby, supra note 1 , at 15 (discussing Department of Defense efforts to reduce reliance upon GPS and other space assets); SPACE SECURITY INDEX, supra note 1, at 98 (reporting that in 2015, the U.S. Navy resumed training in the use of sextants for celestial navigation, in response to the vulnerability of GPS signals); Josh Hrala, The Scary, Practical Reason the US Navy Is Once Again Teaching Celestial Navigation, SCI. AlerT (Feb. 12, 2016), https://www.sciencealert.com/the-scary-practical-reason-the-navy-isonce-again-teaching-celestial-navigation (citing Thomas Gibbons-Neff, After Two Decades, Sailing by the Stars Is Back at the Naval Academy, WASH. PosT (Oct. 13, 2015), http://wapo.st/2DGq1Mt); Jonathan Saul, Cyber Threats Prompt Return of Radio for Ship Navigation, Reuters (Aug. 9, 2017, 2:38AM), https:// www.reuters.com/article/us-shipping-gps-cyber/cyber-threats-prompt-return-of-radio-for-ship-naviga tion-idUSKBN1ANOHT.

7. Nayak, supra note 4, at 2 (noting that foreign policy analysts cite the U.S. dependence upon space as an "Achilles heel," and quoting one Chinese analyst referring to it as America's "soft ribs," saying "for countries that can never win a war with the United States by using the method of tanks and planes, attacking the U.S. space system may be an irresistible and most tempting choice"); see Worldwide Threat Assessment of the US Intelligence Community Before the S. Armed Servs. Comm., 114th Cong. 9 (2016) (statement of James R. Clapper, Dir. of Nat'l Intelligence) ("Foreign military leaders understand the unique advantages that space-based systems provide to the United States. Russia [sic] senior leadership probably views countering the US space advantage as a critical component of warfighting."); Andrew H. Boyd, Satellite and Ground Communication Systems: Space and Electronic Warfare Threats to the United States Army, Land Warfare Papers, Nov. 2017, at 1 ("One of the U.S. Army's most critical vulnerabilities is its overreliance on SATCOM, on which most of its mission command systems depend."); see also MACDONALD ET AL., supra note 1, at 7 ("It is no wonder that China's [military] wants the capability to interrupt the rivers of information and services that U.S. space assets provide."); POLLPETER ET AL., supra note 3, at 8, 109-11 (discussing how China's growing counter-space capabilities pose a threat to the U.S. military); Alessandro Shimabukuro, No Deal in Space: A Bargaining Model Analysis of U.S. Resistance to Space Arms Control, 30 SPACE POL'Y 13, 14 (2014) (reporting that the vulnerability of U.S. satellite systems has inspired fears of a "Space Pearl Harbor"). 
would be compromised, and an economy that has grown accustomed to instantaneous communications and choreographed just-in-time delivery and payment would find it very difficult to adapt to circumstances that were routine not that long ago. If deprived of its space assets, the U.S. military might be reduced to fighting as it did in the pre-digital era; the American firepower in the 1950s and 1960s was surely staggering, but it would pale in comparison to what the Pentagon has created in recent decades. ${ }^{8}$

That growing (or, now, full-grown) U.S. investment in satellites, and the understanding that "a day without space" would be a very bad day, indeed, have perversely reinforced the strong incentives for potential enemies to pursue counter-space capabilities. There is a measure of reciprocity in this relationship, as China, Russia, and others also deploy their own satellites, treading the same path toward reliance, dependence, and vulnerability. The same pressures and incentives that have driven the United States to place valuable assets into space will doubtless inspire others to make some similar choices. But for at least the next decade, and perhaps beyond, a major asymmetry remains: the United States is much more highly invested in space, both in the sheer number of military and civilian satellites and in the diversity and ubiquity of their uses. ${ }^{9}$

In sum, all states share an interest in a sustainable, peaceful, and unthreatened regime for space, but some countries, especially the United States, share it more.

8. Martin, supra note 3 (quoting Gen. John Hyten, then the head of Air Force Space Command, saying that without space assets, "What happens is you go back to World War II. You go back to industrial age warfare"); see James A. Lewis, Reconsidering Deterrence for Space and Cyberspace, in ANTISatellite Weapons, Deterrence and Sino-American Space Relations 61, 66 (Michael Krepon \& Julia Thompson eds., 2013) (explaining that, unlike nuclear weapons, space weapons do not pose an "existential" threat to the United States, but they nonetheless pose significant problems for deterrence); Jeffry Lin \& P.W. Singer, China to Launch Powerful Hyperspectral Satellite, Popular SCI. (Jan. 25, 2016), https://www.popsci.com/china-to-launch-worlds-most-powerful-hyperspectral-satellite\#page-2; David Logsdon et al., Roundtable Discussion, A Day without Space: Economic and National Security Ramifications (Oct. 16, 2008), http://marshall.org/wp-content/uploads/2013/08/Day-without-Space-Oct-16-2008 .pdf [https://web.archive.org/web/20170817161004/http://marshall.org/wp-content/uploads/2013/08/ Day-without-Space-Oct-16-2008.pdf]. But see Gregory Kulacki, The United States, China, and Anti-Satellite Weapons, All Things Nuclear Blog (Sept. 7, 2016, 9:47 AM), http://allthingsnuclear.org/gkulacki/the-united-states-china-and-anti-satellite-weapons ("China's military dependence on satellites may be greater than that of the United States."). See generally JoHnSON-FrEESE, supra note 1, at 96-99.

9. See Heginbotham et al., supra note 5, at 228-32 (comparing U.S. and Chinese orbital infrastructures); LAMBAKIS, supra note 5, at 1-2 (stressing U.S. military reliance upon space assets); BRUCE W. MacDonald, Council on Foreign Relations, China, Space Weapons, and U.S. Security 3-4 (2008); Pollpeter ET AL., supra note 3, at 116 (forecasting that if current trends continue, China will have as much to lose as it has to gain from the management or mismanagement of space); SPACE SECURITY INDEX, supra note 1, at 80-82, 87-89 (comparing U.S., Chinese, Russian, and other military space programs, including those in Iran, North Korea, India, Japan, and the European Union); Brian Chow, Stalkers in Space: Defeating the Threat, STRATEgIC STUD. Q., Summer 2017, at 82; Shimabukuro, supra note 7, at 15, 17 (presenting charts comparing U.S. and Chinese satellite numbers). But see MACDoNALD ET AL., supra note 1, at 7, 16, 20 (forecasting that the absolute U.S. advantages in space will increase over time, but the margin of U.S. advantage seems likely to diminish); Michael Nacht, The United States and China in Space, in ANTi-Satellite Weapons, supra note 8, at 101, 103. 


\section{B. The Incipient Arms Race in Space}

Humans have demonstrated remarkable creativity and persistence in developing a plethora of space weapons. For purposes of this Article, the full array of counter-space or space-control activities and apparatus is under evaluation. The technology (as developed, tested, and deployed, or at least as conceptualized) includes kinetic-energy interceptors (developing a physical mass of some sort to be sent into space, to collide with a target or to explode nearby, shattering both vehicles); directed-energy systems (exploring the use of high energy lasers, microwave systems, or other concepts, to burn holes in targeted satellites, blind their sensors, or otherwise damage or destroy them); or cyber mechanisms (inventing capabilities to interfere with uplinks and downlinks, to disrupt the space vehicle's normal functions, or even to commandeer it). ${ }^{10}$ Critical elements of these systems could be based on Earth, on aircraft, or on satellites. Moreover, an attacker contemplating a challenge to a rival's space system could elect to target whatever appeared to be the weakest, most vulnerable component: the satellite itself, the ground station that controls and communicates with it, or the electronic or other links between them.

With all those variables, it is not surprising that the world has seen arms races in space before, but what is surprising is that we have always managed to avoid the worst, most expensive, and most destabilizing versions. In fact, the history of ASAT weaponry is virtually as old as the history of satellitesboth the United States and the Soviet Union began exploring mechanisms for attacking enemy orbiters in the 1950s and 1960s. ${ }^{11}$ By the 1970s and

10. Space SeCURITY INDEX, supra note 1, at 99-104 (discussing a variety of mechanisms for attacking satellites); Martin, supra note 3; see НEgInbOTHAM ЕT AL., supra note 5, at 237-41 (analyzing the risks that U.S. counter-space programs could pose for China); TODD HARrison ET AL., CTR. FOR STRAtegic \& Int'l Studies, Implications of Ultra-Low-Cost Access to Space; Air Univ., Maxwell Air Force Base, Fast Space: Leveraging Ultra low-Cost Space Access for 21st Century Challenges 10-18 (2017); Stephen Shea et al., Terror on High: Deterring ASAT, SpaCE \& Def., Spring 2015, at 59, 60-63 (discussing alternative mechanisms for attacking satellites); Mike Gruss, DoD Will Spend $\$ 2$ Billion on Space Control This Year, SpaCE News (Mar. 23, 2016), http://spacenews.com/dod-willspend-2-billion-on-space-control-this-year/; Patricia Lewis \& David Livingstone, The Cyber Threat in Outer Space, Bull. Атомic Scientists (Nov. 21, 2016), https://thebulletin.org/cyber-threat-outer-space101 78; Jana Robinson, Governance Challenges at the Intersection of Space and Cyber Security, Space Rev. (Feb. 15, 2016), http://www.thespacereview.com/article/2923/1 (emphasizing the conjunction of space and cyber security); Christopher Stone, Rethinking the National Security Space Strategy: Part 3, Space Rev. (Feb. 8, 2016), http://www.thespacereview.com/article/2918/1.

11. See Brian Weeden, Secure World Found., Through a Glass, Darkly: Chinese, AmeriCan, And Russian Anti-Satellite Testing in Space 20-23, 29-30 (2014); Michael Krepon \& Sonya Schoenberger, Stimson Ctr., A Comparison of Nuclear and Anti-Satellite Testing, 1945-2013, in ANTI-SATEllite Weapons, supra note 8, at 131-37; John Pike \& Eric Stambler, Anti-Satellite Weapons and Arms Control, in 2 Encyclopedia of Arms Control and Disarmament 991, 992-94 (Richard Dean Burns ed., 1993); Steven Weber \& Sidney Drell, Attempts to Regulate Military Activities in Space, in U.S.-SoviET Security Cooperation: AChievements, Failures, Lessons 373, 378-88 (Alexander George et al. eds., 1988); Bart Hendrickx, Naryad-V and the Soviet Anti-Satellite Fleet, 69 Space Chron. 1 (2016); Anatoly Zak, The Hidden History of the Soviet Satellite-Killer, Popular Mechanics (Nov. 1, 2013) thereinafter Zak, Hidden History], http://www.popularmechanics.com/space/satellites/a9620/the-hidden-historyof-the-soviet-satellite-killer-16108970/; Anatoly Zak, Spacecraft: Military: IS Anti-Satellite System, Rus- 
1980s, each superpower had thoroughly tested and evaluated multiple concepts, and each had deployed an ASAT weapon with "operational" status. ${ }^{12}$ The principal U.S. enterprise employed a guided missile to be launched into space by a rapidly-ascending F-15 Eagle fighter jet; it was successfully tested in 1985 against a defunct Solwind satellite, spectacularly obliterating the target. ${ }^{13}$

However, a remarkable hiatus then followed, as both countries refrained from further overt ASAT-test operations. No treaty required this restraint; there was not even an explicit non-legally-binding agreement on unilateral moratoria. But the next two decades were relatively free of salient ASAT developments, as each side seemingly assessed that further acceleration in that direction was contrary to its interests. ${ }^{14} \mathrm{~A}$ common refrain was that space had been "militarized, but not weaponized," meaning that multiple military operations were conducted through satellites, but that no weapons (capable of attacking satellites or targets on Earth) had yet been operationally deployed into space. ${ }^{15}$

That complacency was rudely shattered in 2007, when China dramatically entered the ASAT testing business. Beijing authorities launched an SC-19 interceptor aboard a multi-stage solid-fuel missile from the Xichang Satel-

SIAN SPACE WEB (Dec. 24, 2012) [hereinafter Zak, Spacecraft], http://www.russianspaceweb.com/is.html. [https://web.archive.org/web/20130115035516/http://www.russianspaceweb.com/is.html]. See generally Laura Grego, Union of Concerned Scientists, A History of Anti-Satellite Programs (2012); Paul B. Stares, The Militarization of Space: U.S. Policy, 1945-1984, at 47-58, 106-34 (1985); Michael Krepon, Opinion, Is Space Warfare's Final Frontier?, SpACE News (July 24, 2017), http:// spacenews.com/op-ed-is-space-warfares-final-frontier/ (assessing that today the world is entering its third round of intensified military competition in space).

12. STARES, supra note 11, at 135-56, 201-15; see GREGO, supra note 11, at 3-5; NRC REPORT, supra note 1, at 9; WEEDEN, supra note 11, at 22-23, 29-31; Hendrickx, supra note 11; Weber \& Drell, supra note 11, at 388-424; Zak, Hidden History, supra note 11; Zak, Spacecraft, supra note 11.

13. Weeden, supra note 11, at 25; see Todd Harrison et al., Ctr. For Strategic \& Int'L Stud., Escalation and Deterrence in the Second Space Age 2-4 (2017); Pike \& Stambler, supra note 11 , at 993-94.

14. David Axe, When It Comes to War in Space, U.S. Has the Edge, Reuters (Aug. 10, 2015), http:// blogs.reuters.com/great-debate/2015/08/09/the-u-s-military-is-preparing-for-the-real-star-wars/ (characterizing the era as an "unofficial moratorium" against weapons in space); see GrEgo, supra note 11, at 5-8; Pike \& Stambler, supra note 11, at 991-92. This period was not entirely free from weapons-related developments in space. In the 1980s, the Reagan administration's pursuit of the Strategic Defense Initiative triggered fears of a "Star Wars" program for weaponization of space, and in 1997, the United States tested its MIRACL laser as an anti-satellite weapon. The United States also developed its Counter Communications System, a non-destructive ASAT device. SPACE SECURITY INDEX, supra note 1, at 100; WeEDEN, supra note 11, at 25. See generally Hendrickx, supra note 11. China also developed a groundbased laser capable of temporarily dazzling U.S. satellites. Heginbotham ET AL., supra note 5, at 246-48; NRO Confirms Chinese Laser Test Illuminated U.S. Spacecraft, SpaCe News (Oct. 3, 2006), http:// spacenews.com/nro-confirms-chinese-laser-test-illuminated-us-spacecraft/.

15. See A. Ferreira-Snyman, Selected Legal Challenges Relating to the Military Use of Outer Space, with Specific Reference to Article IV of the Outer Space Treaty, 18 Potchefstroomse EleKtroniese RegsBlad [PER] 488, 499-501 (2015), http://www.scielo.org.za/pdf/pelj/v18n3/03.pdf (differentiating between militarization and weaponization of space); Shimabukuro, supra note 7, at 14; Jinyuan Su, The "Peaceful Purposes" Principle in Outer Space and the Russia-China PPWT Proposal, 26 SPACE POL'y 81, 83 (2010); Fabio Tronchetti, Legal Aspects of the Military Uses of Outer Space, in HandBook of SpaCE Law 331, 333-34 (Frans von der Dunk ed., 2015); see also Heginbotham et al., supra note 5, at 248-49. 
lite Launch Center in Sichuan Province; it collided with a defunct FY-1C satellite at an altitude of 865 kilometers, shattering both spacecrafts. The resulting plume of fragments - over 3000 pieces large enough to be tracked from Earth (and large enough to pose a substantial hazard to other satellites) - is expected to remain aloft for decades as the single worst debriscreating incident in space history. ${ }^{16}$

The next year, the United States responded, shooting down one of its own failing satellites, in Operation Burnt Frost. There, the U.S.S. Lake Erie, a Navy guided missile cruiser, launched a Standard Missile-3, part of the Aegis Ballistic Missile Defense System, to ram into a non-functional National Reconnaissance Office satellite designated as USA-193 at 240 kilometers altitude several hundred miles northwest of Hawaii. Because of the lower altitude, the debris from this event fell back to Earth relatively quickly, posing much less hazard to space navigation-but nonetheless demonstrating the U.S. capability for neutralizing satellites. ${ }^{17}$

If those events served as a "wake-up call" about the renewal of ASAT activity, the alarms continued to sound (albeit without the concussive effect of satellite destructions) in the following years. China, for example, continued to test space interceptors, but without causing catastrophic collisions by targeting an ascending vehicle against an unoccupied pre-designated point in space or by gently "bumping" a target spacecraft at low relative speed. In 2010, 2013, and 2014, China conducted delicate maneuvers involving multiple satellite close approaches and a robotic arm, activities with both benign and weapons applications. Most vividly, in 2013, China ominously launched a similar experimental rocket to much higher altitude, almost reaching the special geosynchronous orbit at $36,000 \mathrm{~km}$, at which many of the most valuable reconnaissance and communications satellites are parked. ${ }^{18}$

16. See also Martin, supra note 3. See generally POllPETER ET AL., supra note 3, at 86-93; SPACE SECURITY INDEX, supra note 1 , at 100 (noting that China had conducted two earlier ASAT tests in 2005 and 2006, which did not result in collisions and the creation of debris); WEEDEN, supra note 11, at 1-19; Gregory Kulacki \& Jeffrey G. Lewis, Understanding China's Antisatellite Test, 15 NonProliferation Rev. 335 (2008); T.S. Kelso, Ctr. Space Standards \& Innovation, Analysis of the 2007 Chinese ASAT Test and the Impact of Its Debris on the Space Environment, 2007 Proc. Advanced Maui Optical \& Space Surveillance Tech. CONF.

17. WeEden, supra note 11, at 25-29. See generally USA-193: Selected Documents (P.J. Blount \& Joanne Irene Gabrynowicz eds., 2009); David Axe, When It Comes to War in Space, U.S. Has the Edge, REuters (Aug. 10, 2015) (asserting that the United States now deploys dozens of comparable missiles, capable of quickly wiping out Russian and Chinese satellites); Bhupendra Jasani, King's Coll. London, Space Assets and Emerging Threats 10-11, Presentation at the 10th United Nations Workshop on Space Law (Sept. 6, 2016), http://www.unoosa.org/pdf/SLW2016/Panel2/1_Jasani_-_Space_assets_and_threats _06082016.pdf (summarizing U.S. ASAT programs).

18. See Coats, supra note 5, at 9 (assessing that China's ground-based ASAT missile system "might be nearing operational service"); CORDESMAN, supra note 3, at 22-27; LAMBAKIs, supra note 5, at 19-26 (describing China's space modernization programs); Pollpeter ET AL., supra note 3, at 89-91; U.S.China Econ. \& Sec. Rev. Comm'n, supra note 5, at 292-98; Weeden, supra note 11, at 12-13; Maximilian Betmann, A Counterspace Awakening? (Part I), SpaCE Rev. (May 22, 2017), http://www.thespacereview.com/article/3247/1; Harsh Vasani, How China Is Weaponizing Outer Space, Diplomat (Jan. 19, 2017), https://thediplomat.com/2017/01/how-china-is-weaponizing-outer-space/; Brian Weeden, Dancing in the Dark Redux: Recent Russian Rendezvous and Proximity Operations in Space, Space Rev. (Oct. 5, 
Russia undertook a series of four launches in 2013 and 2014 that delivered maneuverable spacecraft into orbit, conducting covert "rendezvous and proximity operations" ("RPO"), testing the ability to execute deft approaches to other orbiters and employing a robotic arm. Similar, still-mysterious events in 2015 involved repeated, slow close approaches to targeted spacecraft, validating capabilities for inspection, servicing, or attack. Again in 2016, Russia conducted non-destructive interception tests in space. Russian officials have been ambiguous about their intentions, sometimes ascribing these events to anti-missile programs, but sometimes overtly acknowledging a dedicated ASAT-development enterprise. ${ }^{19}$

In each instance, the nature and motivation of these test flights remain obscure-in space, many of the techniques and much of the hardware are inherently dual-capable, adaptable for both benign scientific research and weapons applications. Even within the military sector, it is difficult for outside observers to discern whether a particular space enterprise is devoted to anti-satellite functions or to the refinement of an ability to defend against incoming ballistic missiles and warheads. ${ }^{20}$

Thus inspired (or panicked), U.S. space officials have responded with renewed concern about the safety of U.S. space assets, and they have redoubled their attention to corrective or offsetting actions. The Obama administration hurriedly added an extra $\$ 5$ billion to the Pentagon budget for unspecified space security enhancements and undertook to assess how best to protect the

2015), http://www.thespacereview.com/article/2839/1. Also note reports that in 2006, a Chinese laser "dazzled" a U.S. satellite, resulting in temporary degradation of its functionality. U.S.-CHINA ECON. \& SeC. Rev. Comm'N, supra note 5, at 298; China Jamming Test Sparks U.S. Satellite Concerns, Reuters, Oct. 5, 2006, Factiva, Doc. No. LBA0000020061005e2a5001v0; NRO Confirms, supra note 14. See generally Chow, supra note 9; Martin, supra note 3.

19. See Space Security Index, supra note 1, at 103-04, 106-07; Betmann, supra note 18; Weeden, supra note 18; Martin, supra note 3. See generally Coats, supra note 5, at 9 (summarizing Russian tests and statements regarding ASAT developments); LAMBAKIs, supra note 5, at 26-31 (describing Russia's growing investment in space and counter-space capabilities); Hendrickx, supra note 11; Bill Gertz, Russia Flight Tests Anti-Satellite Missile, Wash. Free BeACON (May 27, 2016), http://freebeacon.com/nationalsecurity/russia-flight-tests-anti-satellite-missile/; George Leopold, Russian Test Reported, But Was It ASAT?, Def. Systems (Dec. 22, 2016), https://defensesystems.com/articles/2016/12/22/russian.aspx; L. Todd Wood, Russia Tests Anti-Satellite Weapon, Wash. Times (Dec. 21, 2016), https://www.washingtontimes.com/news/2016/dec/21/russia-tests-anti-satellite-weapon-pl-19-nudol/.

20. See Space Security Index, supra note 1, at 99, 103, 105; Weber \& Drell, supra note 11, at 418 (observing that missile defense and ASAT "are intimately connected in both a technological and military-strategic sense”); WEEDEN, supra note 11, at 34-35; Ross Liemer \& Christopher F. Chyba, A Verifiable Limited Test Ban for Anti-Satellite Weapons, WASH. Q., July 2010, at 155-56 (comparing missile defense tests and ASAT tests); Mark A. Gubrud, Chinese and U.S. Kinetic Energy Space Weapons and Arms Control, 35 Asian Persps. 617, (2011) [hereinafter Gubrud, Chinese and U.S.]; Mark A. Gubrud, An "ASAT Test Ban" Is Not Arms Control, 1.0 Human (Aug. 13, 2014) thereinafter Gubrud, Not Arms Control], http://gubrud.net/?p=355; Vasani, supra note 18 (characterizing the difference between ASAT and missile defense tests as depending mainly on software variations); see also Mike Gruss, Russian Satellite Maneuvers, Silence Worry Intelsat, SpACE NEws (Oct. 9, 2015), http://spacenews.com/russian-satellite-maneuvers-silence-worry-intelsat/ (describing worried U.S. reaction to Russian satellite that maneuvered close to U.S. geosynchronous satellites without explanation). See generally James A. Vedda \& Peter L. Hays, Major Policy Issues in Evolving Global Space Operations, Mitchell InST. Pol'y PAPers, Dec. 2017, at 24-28. 
U.S. satellite architecture from surging threats. ${ }^{21}$ The United States launched two new observation satellites into geosynchronous orbits as sentinels against malicious activity, ${ }^{22}$ and it continued testing the mysterious $\mathrm{X}-37 \mathrm{~B}$ space plane, which could be capable of a plethora of dual-purpose operations. ${ }^{23}$ Some of the new funding has also been devoted to frankly offensive space control activities, about which less has been made public. ${ }^{24}$

Leaders in each of the three protagonist states have spoken with increased frankness about the prospect of a new arms race in space. ${ }^{25}$ From the United

21. See Colby, supra note 1 (citing "a noticeably more alarmed tone" inside the U.S. government concerning threats in space); Hitchens \& JoHnsON-FreEse, supra note 1, at 3; JoHnSON-FreESE, supra note 1, at 92-96; SPACE SECURITY INDEX, supra note 1, at 85-86, 97-98 (U.S. officials added \$5 billion to the budget for space protection activities over the next five years, and an additional $\$ 6$ billion for space surveillance through 2020); WEEDEN, supra note 11, at 39-40; Beard, supra note 1, at 338; Betmann, supra note 18 (quoting Sen. John McCain referring to a "counterspace awakening”); Amy Butler, No Sanctuary, Aviation WK. \& Space Tech., May 15, 2015, at 68; Martin, supra note 3.

22. See Fiscal Year 2017 National Defense Authorization Budget Request for National Security Space Activities: Hearing Before the Subcomm. on Strategic Forces of the H. Comm. on Armed Servs., 114th Cong. 5-6 (Mar. 15, 2016) (statement of Douglas Loverro, Deputy Assistant Secretary of Defense) (discussing "strategic portfolio review" of 2014 to assess U.S. space systems); Weeden, supra note 18 (noting that the United States had also launched two other observation satellites into geosynchronous orbit in 2014, ahead of their original schedule); Martin, supra note 3.

23. See Brian Weeden, Secure World Found., X-37B Orbital Test Vehicle Fact Sheet (2017), https://swfound.org/media/205879/swf_x-37b_otv_fact_sheet.pdf; Beard, supra note 1, at 338-39; Brian Weeden, U.S.-China Cooperation in Space, in ANTI-Satellite Weapons, supra note 8, at 113, 115-16; Martin, supra note 3.

24. See Reappointment of John E. Hyten To The Grade Of General And To Be Commander, United States Strategic Command: Hearing Before the S. Armed Servs. Comm., 114th Congress 17 (2016) (answers to advance questions for General John E. Hyten, USAF) (emphasizing a new emphasis on space control, battle management, and a "change [in] the warfighting culture of our space cadre”); U.S. DEP'T OF DEF., Directive No. 3100.10, Space Policy (2016); Heginbotham ET Al., supra note 5, at 234-37 (surveying U.S. dedicated counter-space systems); LAMBAKIS, supra note 5, at 49-51 (discussing recent U.S. space control initiatives); Mike Gruss, Hyten Tells Senate DoD Needs to Focus on Space Control, Battle Management System, Space News (Sept. 20, 2016), http://spacenews.com/hyten-tells-senate-dod-needs-to-focuson-space-control-battle-management-system/ (highlighting the $\$ 2$ billion to be spent on space control capabilities, including \$144 million for the Counter Communications System and \$158 million for the Space Security and Defense Program, which is thought to include offensive space capabilities). Much of the new funding has been devoted to the Counter Communications System, a ground-based mechanism for jamming or otherwise interfering with communications satellites. See U.S. AIR ForCE, RDT\&E Budget Item Justification, Exhibit R-2, PB 2017 (2016); U.S. Air Force, RDT\&E Budget Item Justification, Exhibit R-2, FY 2018 (2017).

25. See U.S.-China Econ. \& Sec. Rev. Comm'n, China's Position on a Code of Conduct in SPACE (2017); CoRdesman, supra note 3, at 4 (quoting a Chinese leader as saying that space is the "new commanding height for international strategic competition .. . [and] means having control of the ground, oceans, and the electromagnetic space, which also means having the strategic initiative in one's hands"); LAMBAKIS, supra note 5, at 29 (quoting Russian officials recommending resumption of efforts to "intercept absolutely everything that flies from space"); MACDONALD ET AL., supra note 1, at 17, 25 (quoting the commander of China's Air Force as saying that military operations in space are a "historical inevitability" and asserting that recent Chinese analysis concludes that "the superior military space power will enjoy decisive benefits"); POLLPETER ET AL., supra note 3, at 15-17 (reporting Chinese rhetoric about space control); Walt Conrad et al., Arms Control in the Third Space Age: Assessing International Efforts to Regulate Military Operations in Outer Space in the "3 C's" Era, 6 SpACE \& Def. 4, 8 (2017) (quoting Russian Deputy Defense Minister commenting on other countries' ASAT developments and stating that "we can't sit back and quietly watch others doing that; such work is [also] being conducted in Russia"); Shimabukuro, supra note 7, at 17 (quoting a Chinese analyst asserting that China "no longer wishes to leave the U.S. unchallenged in the use of space in any potential conflict or war in the Taiwan 
States, much of the rhetoric sounds in inevitability and "normalization"depicting space as just another military operational environment, akin to land, sea, and air, in which armed competition is to be expected sooner or later. From that viewpoint, a prudent defense must anticipate hostilities from all azimuths and prepare to respond to (or to anticipate) an adversary's pursuit of the special advantages of operating in the "new high ground." 26

Other states, too, are expressing new interest in military operations in space, including pursuit of ASAT capabilities. They-including Russia and China-may feel that they are not "starting" a new arms race but are merely attempting belatedly to follow the space weaponization lead pioneered by the United States. ${ }^{27}$

Straits, nor in any other conflict it may become involved in"); Zak, Hidden History, supra note 11. But see Joan Johnson-Freese \& Theresa Hitchens, Stop the Fearmongering Over War in Space: The Sky's Not Falling, Part 1, Breaking Def. (Dec. 27, 2016, 4:00 AM), https://breakingdefense.com/2016/12/stop-thefearmongering-over-war-in-space-the-skys-not-falling-part-1/ (arguing that the inflated rhetoric overhypes the dangers).

26. See United States Strategic Command: Hearing Before the S. Comm. on Armed Services, 115th Cong. 10 (Apr. 4, 2017) (statement of John E. Hyten, Commander of U.S. Strategic Command) ("Space is a warfighting domain just like the air, ground, maritime, and cyber domains . . . [W] must normalize how we think of space, how we operate in it, and how we describe it to each other. It is unique for many reasons, but the concepts that govern other military operations . . . apply just the same."); SPACE SECURITY INDEX, supra note 1, at 106 (noting that the U.S. National Defense Authorization Act for FY 2016 called upon the Department of Defense to have the capability to, "if necessary, deny adversaries the use of space capabilities”); U.S. DeP'T of Def., supra note 24; Michael Krepon, Space and Nuclear Deterrence, in Anti-Satellite Weapons, supra note 8, at 15, 35-36; Heather Wilson, Why I'm Directing the Air Force to Focus on Space, Def. One (June 16, 2017), http://www.defenseone.com/ideas/2017/06/why-im-directing-air-force-focus-space/138744/ (Secretary of the Air Force asserting that "we must develop space airmen who have the tools, training, and resources to fight when-not if - war extends into space"); U.S. Air Force, AFNow The Future of Space, YouTubE (June 16, 2017), https://www.youtube.com/ watch? $\mathrm{v}=$ hyuqdDwdoXM ("Should a war extend into space, the Air Force will lead the debate on how to normalize space as a warfighting domain.").

27. See, e.g., Cordesman, supra note 3, at 27 (concluding that "China's pursuit of advanced capabilities is an attempt to replicate the space infrastructure the United States has already built"); DIA, supra note 5, at 36-37 (describing Russia's counter-space efforts); Grego, supra note 11, at 9-12; HitcHENS \& JoHnSON-FreEse, supra note 1, at 25-26; LAMBAKIs, supra note 5, at 18-19, 31-35 (discussing space and counter-space programs of Iran and North Korea); MACDONALD ET AL., supra note 1, at 17-19 (noting that China sees itself as inferior to, and under threat from, the space capabilities of the United States); SPACE SECURITY INDEX, supra note 1, at 87, 100; WEEDEN, supra note 11, at 39 (noting that "ASAT [missile] systems are proliferating around the world"); Anderson et al., supra note 3, at 9-11 (discussing India's pursuit of ASAT capability); Axe, supra note 5; Lynn, supra note 3, at 10-11 ("Counterspace weapons are no longer the weapon of last resort in a geo-strategic conflict. Instead, they are becoming tools that advanced nations and sub-regional powers alike are incorporating into conventional military doctrine. Even non-state actors have found utility in employing jammers and manipulating communications satellites."); Raghuvanshi, supra note 5 (discussing India's interest in ASAT capabilities); Harsh Vasani, India's Anti-Satellite Weapons, Diplomat (June 14, 2016), https://thediplomat .com/2016/06/indias-anti-satellite-weapons/; Martin, supra note 3; Weeden, supra note 18 (noting that not long ago, "it was primarily the United States that was testing and developing these [ASAT] capabilities years or decades ahead of any potential rivals"). But see Brian Weeden, Insight: Building Stronger U.S. China Relations in Space, Secure World Found. (Feb. 1, 2017), https://swfound.org/news/all-news/ 2017/02/insight-building-stronger-us-china-relations-in-space (noting that China's test of a direct-ascent ASAT system to near geosynchronous altitudes would constitute a new capability that neither the United States nor Russia has operationalized in the past). 
In any event, the "mantra" of the U.S. space defense community has come to focus on the " $3 \mathrm{Cs}$ "- the description of space as being "congested" (crammed with an ever-increasing number of operational satellites and uncontrolled debris); "contested" (with more countries initiating military activities designed to challenge other states' abilities to conduct space operations); and "competitive" (with multiple users crowding into finite orbital slots and employing scarce radio frequencies for communications). In this context, if outer space was ever a true "sanctuary," removed from the burdens of traditional terrestrial military competition and threat, it is no longer so privileged, and the prospect looms of a particularly parlous military space race. ${ }^{28}$

Underpinning these dangers is the observation that space is an environment in which the offense enjoys distinct advantages. That is, the task of attacking a satellite is technically easier and cheaper than the task of defending against those onslaughts. Many of the current satellites that constitute the backbone of the national security space capabilities incorporate numerous inherent vulnerabilities: they are often large and conspicuous, following known trajectories with little maneuverability, making them "sitting ducks" for attack. They are expensive and few in number, without backup inventories of spare replacements that could be rapidly launched to substitute for any damaged in conflict. They are not "hardened" or shielded against attack, and adding protective cladding would impose weight penalties that could raise costs and degrade performance. ${ }^{29}$

Future generations of small or micro-satellites might redress many of these vulnerabilities, and efforts are underway to develop a more resilient satellite architecture, better able to withstand possible hostilities. Adaptations could include dispersing satellite functions among many, smaller satellites-instead of relying so extensively upon a few exquisite behemothsand leveraging the growing space capabilities of the private sector and of U.S. allies. Learning, or relearning, how to fight without access to the full

28. See U.N. Secretary-General, Report of the Group of Governmental Experts on Transparency and Confidence-Building Measures in Outer Space Activities, I 6, U.N. Doc. A/68/189* (July 29, 2013) (adopting the phrase that space is increasingly "congested, contested, and competitive"); U.S. Dep'T OF DeF. \& U.S. Dir. of Nat'l Intelligence, National Security Space Strategy, Unclassified Summary 1-3 (2011); Hitchens \& Johnson-Freese, supra note 1, at 15-23; Johnson-Freese, supra note 1, at 26-55 (analyzing the content of the terms "congested, contested, and competitive"); MACDONALD ET AL., supra note 1, at 10-13; SPACE SECURITY INDEX, supra note 1, at 28-30 (discussing congestion of radio frequencies and orbital slots); Lynn, supra note 3, at 8-14.

29. See Subcomm. on Strategic Forces of the H. Armed Services Comm., supra note 22, at 7 (observing that offense is cheaper than defense in space); CoLBY, supra note 1, at 7-8, 11 (opining that the U.S. satellite architecture is delicate and fragile because it was not designed with military threats in mind, and accordingly, in space, "the job of attackers is, generally speaking, going to be easier than the defender's, and considerably less expensive."); MACDONALD ET AL., supra note 1, at 15, 36 ("Space is largely an offensedominant domain."); NRC REPORT, supra note 1, at 23-24; SPACE SECURITY INDEX, supra note 1, at 91-94 (vulnerability of satellite communications); Martin, supra note 3. But see Edward Ferguson \& John Klein, The Future of War in Space is Defensive, SpaCE Rev. (Dec. 19, 2016), http://www.thespacereview .com/article/3131/1 (arguing that defensive measures in space can be effective). 
suite of satellite services, such as by reinvesting in some old-fashioned terrestrial alternatives, is part of the emerging picture, too. The newfound goal is to create a more responsive and diverse structure, capable of persistence and reconstitution in the event of an attack-one that could fail gracefully, rather than catastrophically, when things go wrong. But for now-and until the United States and others are able to reconfigure their satellite portfolios-space is a realm in which the potential offense remains dominant. ${ }^{30}$

One possible U.S. response to these emerging provocations, therefore, would be mimicry: creating or enhancing ASAT systems of its own, matching or exceeding whatever advances Russia and China can accomplish. As noted above, there could be multiple venues for this extraterrestrial competition, including kinetic, directed-energy, cyber, and other technologies, with components based on Earth, in the air, or in space. Proliferating such weaponry might create a deterrence relationship in space, perhaps akin to the uneasy interplay of offsetting threats and counter-threats that (sometimes) constrains inter-state violence on Earth. Each side would know that if it initiated anti-satellite attacks, it would suffer corresponding harm to its own orbiters, and each might be definitively reluctant to go there. ${ }^{31}$

But that structure is unreliable and uncomfortable, for all the reasons that deterrence doctrine suffers in more traditional contexts. ${ }^{32}$ Moreover, in space, a profound asymmetry exacerbates the problems: the United States

30. See Subcomm. on Strategic Forces of the H. Armed Services Comm., supra note 22, at 3, 5, 7-9; Assistant Sec'y of Def. for Homeland Def. \& Glob. Sec., Space Domain Mission Assurance: A RESILIENCE TAXONOMY (2015) (describing different approaches to reducing system vulnerability); U.S. Dep't of Def. \& U.S. Dir. of NAT'L InTElligence, supra note 28, at 10-11; Colby, supra note 1, at 14 (discussing advantages and disadvantages of disaggregating satellite functions); HITCHENS \& JoHNSON-FreEse, supra note 1, at 37-41; MACDONALD ET AL., supra note 1, at 65-79 (discussing methods to increase resilience of space assets); NRC REPORT, supra note 1, at 22-23; SPACE SECURITY INDEX, supra note 1, at 26-27 (discussing the emergence of small satellites), 94-95 (dealing with reconstitution and resilience of space systems); Chow, supra note 9, at 88-93; Lynn, supra note 3, at 12 (asserting the need to make U.S. "space systems more resilient, and our combat power less reliant upon their full functioning.”); Sydney J. Freedberg, Jr., Maps E Jammers: Army Intensifies Training vs. Russian-Style Jamming, Breaking Def. (Mar. 18, 2016, 4:00 AM), https://breakingdefense.com/2016/03/fighting-blind-armyintensifies-training-vs-russian-style-jamming/.

31. See HARrison ET AL., supra note 10, at 19-34; LAMBAKIS, supra note 5, at 64-71 (stressing the importance of a U.S. capability to respond in kind to hostile use of ASATs); MACDONALD ET AL., supra note 1, at 43-46 (comparing the principles of deterrence in different military domains); FORREST E. Morgan, Deterrence and First-Strike Stability in Space 26-30 (2010); Pollpeter et al., supra note 3, at 112 (noting the danger that a U.S.-China space competition could create destabilizing incentives for each side to strike first, to seize the initiative during a crisis); Chow, supra note 9, at 92; Shea et al., supra note 10, at 63-65; Karl Mueller, The Absolute Weapon and the Ultimate High Ground: Why Nuclear Deterrence and Space Deterrence Are Strikingly Similar-Yet Profoundly Different, in ANTI-SATEllite WeAPONS, supra note 8, at 41, 41-48; Vedda \& Hays, supra note 20, at 32-35; Stone, supra note 10.

32. Laura Grego \& David Wright, Securing the Skies, Union of Concerned Scientists 15-16 (2010); Krepon, supra note 26, at 31-32; Mueller, supra note 31, at 52; Karl P. Mueller, Six Propositions About Offense, Defense, and Crisis Stability in Space, in MACDONALD ET AL., supra note 1, at 52, 52-64; Brian Chow, Avoiding a Space War Needs a New Approach, Def. News (Sept. 16, 2015), https:// www.defensenews.com/opinion/commentary/2015/09/16/avoiding-space-war-needs-a-new-approach/; Brian Chow, Fund Pre-Emptive Self-Defense in Space, DeF. News (Oct. 20, 2015), https://www.defensenews .com/opinion/commentary/2015/10/20/fund-pre-emptive-self-defense-in-space/. 
extracts far more benefits from its satellites than do other countries, and the U.S. satellite constellations are therefore more exposed and endangered than others'. If a shooting war were to start in, or move to, space, the United States would have far more to lose, and even if the U.S. ASAT capabilities were greater than those of its rivals, the United States would run out of targets to shoot at fairly quickly, long before its potential adversaries had exhausted their ASAT magazines. ${ }^{33}$

In sum, the contemporary and emerging dangers are multifaceted. First, and most obviously, any substantial use in combat of anti-satellite weapons would be catastrophic: the damage to military capabilities and to the civilian economy could be both vast and irreparable. Even the peacetime testing or demonstration of an evolving ASAT musculature could generate an untenable quantity of debris, ruining all states' aspirations for effective, economical use of space. Moreover, an international arms race in developing competing mechanisms for asserting space control could deter optimal patterns of peaceful exploitation of space, and even the current amplifying rhetoric about weaponization of space may make some wary potential space actors hesitate about investing in new space capabilities.

The central premise of this Article-and a core postulate for much of the standard U.S. national security policy-is that reliance upon measures of deterrence and defense alone is insufficient and unsound. Arms-control measures-if well-crafted, with adequate assurances of verification of compliance and robust enforcement-would provide a valuable complementary posture. Instead of simply emulating and offsetting the undesired counter-space deployments by our potential enemies, it would be more advantageous to prevent those weapons from being developed and fielded in the first place. Wise U.S. policy, therefore, should undertake to divert the leading spacefaring states from ASAT competition, rather than lead (or even follow) an arms race in that catastrophe-prone direction. ${ }^{34}$

33. See Dean Cheng, Heritage Found., Prospects for Extended Deterrence in Space and Cyber: The Case of THE PRC (2016) (contrasting U.S. and Chinese concepts of deterrence); Colby, supra note 1, at 27 (concluding that, because the United States relies far more on space than its adversaries do, "[i]t therefore does not make sense for the United States to confine itself to responses solely in the space domain since U.S. opponents are for the foreseeable future likely to be willing to forfeit their own use of space in exchange for compromising the U.S. ability to exploit it."); HARRISON ET AL., supra note 10, at 33; Hitchens \& Johnson-Freese, supra note 1, at 42; Lewis, supra note 8, at 75; Bruce W. MacDonald, Deterrence and Crisis Stability in Space and Counterspace, in ANTI-SATEllite Weapons, supra note 8, at 81; MACDONALD ET AL., supra note 1, at 14 (discussing the perverse alignment of interests and threats in space that could generate an incentive to strike first during a time of crisis); Morgan, supra note 31, at 26-30 (discussing the limits of punishment-based deterrence in space); see also Sergey Sukhankin, Russian Electronic Warfare in Ukraine: Between Real and Imaginable, REAL ClEAR Def. (May 26, 2017), https://www.realcleardefense.com/articles/2017/05/26/russian_electronic_warfare_in_ukraine_11 1460.html (describing Russia's use of cyber and space weapons in Ukraine). But see Kulacki, supra note 8 (arguing that China may be more vulnerable than the United States in space).

34. See generally MACDONALD ET AL., supra note 1, at 33 (concluding that China does not seek a conflict with the United States in space, but wants to be prepared in case conflict someday appears inevitable); Shimabukuro, supra note 7, at 21-22 (pondering why it has been so difficult to arrange arms control in space, when it appears to serve mutual interests); Maximillion Betmann, A Counterspace Awak- 


\section{The Failure of Contemporary Law and Diplomacy}

Unfortunately, despite the manifest need for an additional quantum of arms control in outer space, the current international institutions and procedures for articulating the necessary arrangements are dysfunctional. This Section assesses the reasons for that enduring and lamentable diplomacy deficit.

The story begins, however, with a much more optimistic observation. The first decade or two of the Space Age were astonishingly successful in generating new law-indeed, that period provides a textbook illustration of how effective and adroit the international prescriptive process can be, if the affected states demand it. ${ }^{35}$

The 1967 Outer Space Treaty ("OST") ${ }^{36}$ — concluded less than ten years after Sputnik's revolutionary first flight-established the central postulates that still underpin human extraterrestrial activities: the exploration and use of space "shall be carried out for the benefit and in the interests of all countries"; 37 space "shall be free for exploration and use by all States"; 38 space "is not subject to national appropriation"; 39 and parties shall carry out their space activities "in accordance with international law, explicitly including the Charter of the United Nations." ${ }^{40}$ Regarding weapons specifically, article IV of the OST prohibits parties from placing nuclear weapons or other weapons of mass destruction in orbit or on the moon or other celestial bodies, and it provides that the moon and other celestial bodies shall be used "exclusively for peaceful purposes," forbidding the establishment of military bases, the testing of weapons, and the conduct of military maneuvers there. ${ }^{41}$

ening? (Part 2), SPACE Rev. (May 30, 2017), http://www.thespacereview.com/article/3250/1 ("US officials also continue to stress that the US has no interest in taking a fight into space, as it would have the most to lose in such an event.").

35. See Francis Lyall \& Paul B. Larsen, Space Law (2009); Handbook of Space Law, supra note 15; Michael N. Schmitt, International Law and Military Operations in Space, in 10 MaX PlanCK Y.B. United Nations L. 10, (2006); Soft Law in Outer Space (Irmgard Marboe ed., 2012); Alexander Soucek, 1 Space Law Essentials (2016); Space Law Treaties E Principles, U.N. Office for Outer SPACE AfFaIRs, http://www.unoosa.org/oosa/en/ourwork/spacelaw/treaties.html (last visited Nov. 17, 2017); What Is the MILAMOS Project?, MCGILL UNIV., http://www.mcgill.ca/milamos/home (last visited Nov. 17, 2017).

36. Treaty on Principles Governing the Activities of States in the Exploration and Use of Outer Space, Including the Moon and Other Celestial Bodies, Jan. 27, 1967, 18 U.S.T. 2410, 610 U.N.T.S. 205 [hereinafter OST].

37. Id. art. I.

38. $I d$.

39. Id. art. II.

40. Id. art. III; see Ram S. Jakhu et al., Conflicts in Space and the Rule of Law, SPACE PoL'y (forthcoming Spring 2016), https://papers.ssrn.com/sol3/papers.cfm?abstract_id $=2722245$ (identifying bodies of international law relevant to space).

41. OST, supra note 36, art. IV; see also LyALL \& LARSEN, supra note 35, at 499-532; Raymond L. Garthoff, The Outer Space Treaty: 1967 to the Present, in Encyclopedia, supra note 11, at 877; Stephen Gorove, Arms Control Provisions in the Outer Space Treaty, 3 Ga. J. InT'L \& Comp. Law 114 (1973); Peter Jankowitsch, The Background and History of Space Law, in HandBOOK OF SPACE Law, supra note 15, at 1, 14-20 (discussing space arms control); Schmitt, supra note 35, at 100-05; Fabio Tronchetti, Legal Aspects of the Military Uses of Outer Space, in HandBook OF Space Law, supra note 15, at 331, 335-41. 
The OST quickly found widespread acceptance and has now been joined by 105 parties, including all the leading spacefaring states; ${ }^{42}$ much of its content has even passed into universally-applicable customary international law. 43

In short order, the OST was supplemented by three other critical treaties: the 1968 Agreement on the Rescue and Return of Astronauts; ${ }^{44}$ the 1972 Liability Convention; ${ }^{45}$ and the 1975 Registration Convention. ${ }^{46}$ Although these instruments had little to say directly about military operations, collectively they did rapidly flesh out the legal infrastructure supporting space operations. ${ }^{47}$ They, too have enjoyed pervasive support, attracting, respectively, 95, 94, and 63 parties. ${ }^{48}$

But the cavalcade of successful space-related agreements abruptly ended in 1975. The Moon Treaty, ${ }^{49}$ concluded in 1979 largely to deal with questions regarding the potential future recovery of minerals and other assets from the moon, has attracted only seventeen parties, conspicuously not including the United States, Russia, China, and other leading interested actors. ${ }^{50}$

Regarding space weapons in particular, the United States and the Soviet Union trudged through three rounds of negotiations on a potential ASAT treaty from 1978 to 1979, but found themselves stymied by discord over

42. Comm. on the Peaceful Uses of Outer Space, Status of International Agreements Relating to Activities in Outer Space as at 1 January 2017, U.N. Doc. A/AC.105/C.2/2017/CRP.7, at 12 (Mar. 23, 2017).

43. See Restatement (Third) Foreign Relations Law of the United States $\S 102 \mathrm{cmt}$ n.2 (Am. Law InSt. 1987); Lyall \& LaRsen, supra note 35, at 53-80; Bin Cheng, United Nations Resolutions on Outer Space: 'Instant' International Customary Law?, 5 INDIAN J. INT'L LAW 23, 36 (1965).

44. Agreement on the Rescue of Astronauts, the Return of Astronauts, and the Return of Objects Launched into Outer Space, Apr. 22, 1968, 19 U.S.T. 7570, 9574 U.N.T.S. 120. This treaty requires parties to render necessary assistance to astronauts, and to return them and spacecraft to the launching state.

45. Convention on International Liability for Damage Caused by Space Objects, Mar. 29, 1972, 24 U.S.T. 2389, 961 U.N.T.S. 187 [hereinafter Liability Convention]. Under this treaty, a launching state has absolute liability for damage inflicted on Earth by its spacecraft, and liability for fault if its spacecraft causes harm to another state's satellites.

46. Convention on the Registration of Objects Launched into Outer Space, Jan. 14, 1975, 29 U.S.T. 695,1023 U.N.T.S. 15. This treaty requires each party to maintain a national registry of objects it launches into space and to report basic information promptly to the United Nations.

47. Lyall \& LARSEN, supra note 35, at 81-127; Schmitt, supra note 35, at 108-11; Steer, supra note 5 , at 10 .

48. Comm. on Peaceful Uses of Outer Space, supra note 42, at 12.

49. Agreement Governing the Activities of States on the Moon and Other Celestial Bodies, UN Doc. A/34/664, Nov. 12, 1979 [hereinafter Moon Treaty]; G.A. Res. 34/68, annex, Agreement Governing the Activities of States on the Moon and Other Celestial Bodies Annex, UN Doc. A/RES/34/68, at 77 (1979).

50. Comm. on Peaceful Uses of Outer Space, supra note 42, at 12. The Moon Treaty also restates, and perhaps somewhat enlarges, the Outer Space Treaty's prohibition against nuclear weapons and selected other military activities on the moon. Moon Treaty, supra note 49, art. 3; LyALl \& LARSEN, supra note 35 , at $181-83,518$. 
fundamentals such as the definition of the to-be-prohibited activities and objects. No agreed text was ever produced. ${ }^{51}$

The leading international forum that is supposed to serve as the midwife for multilateral arms-control initiatives is the Conference on Disarmament, a sixty-five-member body in Geneva, Switzerland, affiliated with the United Nations. ${ }^{52}$ It has succeeded over the years in tackling some of the most challenging topics in arms control, including nuclear proliferation, biological weapons, and chemical weapons. ${ }^{53}$ But an ASAT agreement has consistently eluded its grasp-in fact, irreconcilable visions about a new order in space and other disarmament controversies have proven so contentious that the Conference on Disarmament has been unable even to agree on an active agenda for its proceedings or to initiate any serious negotiations since $1995 . .^{54}$

Other space-related elements of the U.N. family have been more productive, but they have confined themselves to aspects dealing exclusively with non-military functions. The eighty-four-member Committee on Peaceful Uses of Outer Space ("COPUOS"), ${ }^{55}$ for example, has contributed impressively to international collaboration regarding the safety and sustainability of space operations, the coordination of various states' activities, and the

51. See U.S. Dep't of State, XXVI Foreign Relations of the United States, 1977-1980: Arms Control and Nonproliferation (Chris Tudda \& Adam M. Howard eds. 2015), (documents from the 1978-79 ASAT negotiations); James Clay Moltz, Crowded Orbits: Conflict and CoopERATION IN SPACE 147-67 (2014) (surveying efforts at space diplomacy); Pike \& Stambler, supra note 11, at 995; STARES, supra note 11, at 180-200; Weber \& Drell, supra note 11, at 407-12; John Wertheimer, The Antisatellite Negotiations, in Superpower Arms Control: Setting the Record Straight 139-63 (Albert Carnesale \& Richard N. Haass eds., 1987); Eisenhower Ctr. for Space \& Def. Studies, Space Verification, 7 SPACE \& DEF. 55, 59-60 (2014). In addition, the START negotiations, beginning in 1982, focused on nuclear weapons, but also included a component that addressed space issues; however, that sub-negotiation soon bogged down. See Thomas Graham, Jr. \& Damien J. LaVera, Cornerstones of Security: Arms Control Treaties in the Nuclear Era 885 (2003) (observing that the space talks "never went anywhere."); Dan Caldwell, from SALT to START: Limiting Strategic Nuclear Weapons, in ENCYCLOPEDIA, supra note 11, at 895, 908-09.

52. An Introduction to the Conference, U.N. OfFICE AT GENEva, https://www.unog.ch/80256EE6 00585943/(httpPages)/BF18ABFEFE5D344DC1256F3100311CE9?OpenDocument (last visited Nov. 17, 2017); see Ben Baseley-Walker, Outer Space, Geneva and the Conference on Disarmament: Future Directions, 28 SPace Pol'y 45 (2012).

53. U.N. OfFice at Geneva, supra note 52.

54. U.N. Conference on Disarmament, Report of the Conference on Disarmament to the General Assembly of the United Nations, 11-12, U.N. Doc. CD/2080 (Sept. 22, 2016). The Conference on Disarmament ("CD") ordinarily operates by a strict consensus rule, enabling even one determined resister to block action by the group. See MolTZ, supra note 51, at 157-58; SPACE SECURITY INDEX, supra note 1, at 115, 117; Baseley-Walker, supra note 52; Mischa Hansel, The USA and Arms Control in Space, 26 SPACE PoL'y 91, 92-93 (2010) (describing U.S. opposition to CD negotiation of an arms-control treaty for space during the early 2000s, on the basis that there was then no arms race in space that needed resolution); Proposed Prevention of an Arms Race in Space (PAROS) Treaty, NuClear Threat InITIATIVE, http://www .nti.org/learn/treaties-and-regimes/proposed-prevention-arms-race-space-paros-treaty/ (last updated Sept. 29, 2017).

55. Committee on the Peaceful Uses of Outer Space, U.N. OfFiCE FOr OUTER Space AfFairs, http://www .unoosa.org/oosa/en/ourwork/copuos/index.html (last visited Nov. 17, 2017); see also Christopher Johnson, Insight: The United Nations, COPUOS, and Space in 2017, SECUrE World Found. (Aug. 1, 2017), https://swfound.org/news/all-news/2017/08/insight-the-united-nations-copuos-and-space-in-2017. 
minimization of space debris, but it has not dared to venture into the turf of arms control. ${ }^{56}$ The U.N. General Assembly has been somewhat more amenable, adopting annual resolutions that exhort countries to pursue a broader range of peaceful options for enhancing space cooperation, use, and $\mathrm{law}^{57}$ and twice sponsoring a "Group of Governmental Experts" on space law and policy, ${ }^{58}$ but the General Assembly has only limited power to nudge the treatymaking process forward. ${ }^{59}$

In this sorry stasis, two recent diplomatic initiatives stand out as representing at least bona fide efforts to articulate some of the needed security measures for space-but the unambiguous failure of both now simply underscores the global inability to come to grips with the emerging problems. ${ }^{60}$

The first such enterprise is a joint Russian and Chinese venture to propound a Treaty on the Prevention of the Placement of Weapons in Outer Space, and the Threat or Use of Force against Outer Space Objects

56. See U.N. Office for Outer Space Affairs, 2016 Annual Report, U.N. Doc. ST/SPACE/70 (2017). COPUOS has also sponsored the Inter-Agency Debris Coordination Committee (IADC), which has promulgated widely-recognized non-legally-binding guidelines on best practices to mitigate the creation of new space debris. See Secure World Found., The UN COPUOS Guidelines on the LongTerm Sustainability of Outer Space Activities (2017); Space Security Index, supra note 1, at 116 (reporting productive COPUOS work in elaborating a set of voluntary guidelines on Long-Term Sustainability of Outer Space Activities); Beard, supra note 1, at 382; Inter-Agency Space Debris Coordination Comm., 20 Years of IADC http://www.unoosa.org/pdf/pres/stsc2014/tech-32E.pdf (Feb. 2014); Christopher D. Johnson \& Victoria Samson, A Summer Update on the COPUOS Long-Term Sustainability Guidelines, Space Rev. (July 24, 2017), http://www.thespacereview.com/article/3291/1; History, U.N. OfFice FOR OUter SPACE AfFairs, http://www.unoosa.org/oosa/en/aboutus/history/index.html (last visited Nov. 17, 2017) ("Questions relating to the militarization of outer space are dealt with by the Conference on Disarmament ....."); Our Work, U.N. OfFICE FOR Outer SpaCE AfFairs, http://www .unoosa.org/oosa/en/ourwork/index.html (last visited Nov. 17, 2017) (describing activities of COPUOS).

57. See, e.g., G.A. Res. 71/90, International Cooperation in the Peaceful Uses of Outer Space, (Dec. 6, 2016); G.A. Res. 71/31, Prevention of an Arms Race in Space (Dec. 5, 2016); G.A. Res. 71/32, No First Placement of Weapons in Outer Space (Dec. 5, 2016).

58. See U.N. Secretary-General, supra note 28; Hitchens \& JoHnson-Freese, supra note 1, at 30; Paul Meyer, Dark Forces Awaken: The Prospects for Cooperative Space Security, 23 NonProliferation Rev. 495, 6-7 (2016). The Group of Governmental Experts collected international expertise on space law and policy but serves only to make limited findings and recommendations by consensus; it has no lawmaking authority.

59. See U.N. Inst. for Disarmament Research, Space Security Conference 2017 (reporting space activities of U.N. Institute of Disarmament Research); LYALL \& LARSEN, supra note 35, at 15-25, 43-52; Massimo Pellegrino \& Gerald Stang (Rapporteurs), Inst. for Sec. Studies, Issue RePORT No. 29, Space SECurity fOr Europe, at 53-60 (2016) (discussing United Nations and other international bodies for international space cooperation); SECURE World Found., supra note 56; SPACE SECURITY INDEX, supra note 1, at 111-18 (discussing the role of the United Nations and affiliated institutions in space governance); Space Law: Resolutions, U.N. OfFICE FOR Outer SPACE AfFaIrs, http:/ /www.unoosa.org/oosa/en/ourwork/spacelaw/resolutions.html (last visited Nov. 17, 2017).

60. See U.N. Inst. For Disarmament Research, supra note 59, at 25 ("In short, the future for space security diplomacy is fraught at the current stage. Differences among leading space powers are being accentuated, while threat perceptions and military programmes based on them are increasing. All of this can provide ready substantiation for a building up of national counterspace capabilities, which would in turn fuel an incipient arms race that the international community has pledged to prevent."); Vedda \& Hays, supra note 20, at 19-22. 
("PPWT"). ${ }^{61}$ Through a series of revised drafts, the PPWT would prohibit the placement of weapons in space, but would not address weapons based on Earth, sea, or air that could attack targets in space. It would ban "resort to the threat or use of force against outer space objects of States Parties,"62 but preserve the right of individual or collective self-defense, recognized by the U.N. Charter. ${ }^{63}$ It contains no specifications regarding verification of compliance, but it contemplates the future negotiation of an additional protocol to deal with that crucial element; it does include some voluntary transparency- and confidence-building measures. ${ }^{64}$ The United States has criticized the shortcomings of the PPWT vigorously and in detail, ${ }^{65}$ and there is little prospect that it can serve as the basis for productive negotiations. ${ }^{66}$

The second bid at new space law came from the European Union, which has promulgated a series of drafts of an International Code of Conduct for Outer Space Activities ("EU Code"). ${ }^{67}$ As envisaged, this instrument would not be legally binding, but would attempt to establish workable "rules of the road" to enhance the safety, security, and sustainability of space operations. ${ }^{68}$ The document drew lukewarm support from the United States and

61. Permanent Reps. of the Russian Federation and China to the Conference on Disarmament, Draft Treaty on the Prevention of the Placement of Weapons in Outer Space, the Threat or Use of Force against Outer Space Objects, U.N. Doc. CD/1985 (June 12, 2014) [hereinafter PPWT]. See generally U.S.-ChINA ECON. \& SEC. Rev. Comm'N, supra note 5; Su, supra note 15. Note that this Russian-Chinese proposal concerns "no first placement" of weapons in space, in contrast to the concept, discussed infra, of "no first use" of such weapons. See Robinson, supra note 10.

62. PPWT, supra note 61, art. II.

63. Id. art. IV.

64. Id. art. V.

65. See Delegation of the United States of America to the Conference on Disarmament, Analysis of the 2014 Russian-Chinese draft "treaty on the prevention of the placement of weapons in outer space, the threat or use of force against outer space objects," U.N. Doc. CD/1998 (Sept. 3, 2014); Permanent Rep. of China to the Conference on Disarmament \& Charge d'affaires a.i. of the Russian Federation, Follow-up comments by the Russian Federation and China on the analysis submitted by the United States of America of the updated Russian-Chinese draft PPWT, U.N. Doc. CD/2042 (Sept. 11, 2015); Frank A. Rose, Assistant Sec'y of State, Bureau of Arms Control, Verification and Compliance, Remarks to 3rd ARF Workshop on Space Security: Challenges to Arms Control in Space and Pragmatic Way Ahead (Nov. 30, 2015), https://2009-2017.state.gov/t/avc/rls/2015/250231.htm. Note that the U.N. General Assembly has endorsed at least the concept of banning the placement of weapons in space. See G.A. Res. 71/32, No First Placement of Weapons in Outer Space (Dec. 5, 2016).

66. See Moltz, supra note 51, at 158-59; Fabio Tronchetti, A Soft Law Approach to Prevent the Weaponization of Outer Space, in SOFT LAW IN OUTER SPACE, supra note 35, at 361, 369-71; SPACE SECURITY INDEX, supra note 1 , at 117.

67. European Union External action Service, Draft International Code of Conduct For Outer Space ACtivities (2014) [hereinafter EU Code] (also known as the International Code); see also Observer Research found., Awaiting Launch: Perspectives on the Draft ICOC for Outer Space ACtivities (Rajeswari Pillai Rajagopalan \& Daniel A. Porras eds., 2014); Beard, supra note 1, passim; Jinyuan Su \& Zhu Lixin, The European Union Draft Code of Conduct for Outer Space Activities, 30 SPaCe Pol'y 34 (2014).

68. EU CoDE, supra note 67, art. I.1.1. Under the EU Code, participating states would agree to implement specified transparency and confidence-building measures (art. I.1.3), to refrain from the threat or use of force against others (art. I.2, para. 2), to establish national procedures to minimize the risks of accidents, collisions, and interference (art. II.4.1), to refrain from actions that would damage or destroy space objects unless justified by specified exceptions (art. II.4.2), and to notify others before undertaking 
others, ${ }^{69}$ but many criticized both the substance of the draft (including both the confined scope of its ambitions and the extent to which it might seem to authorize, rather than to restrict, uses of force in space $)^{70}$ and the process through which it was developed (including its presentation as a "take it or leave it" draft, with little scope for international negotiation). ${ }^{71}$ Like the PPWT, the EU Code may not quite be "dead" as a diplomatic undertaking, but it now seems implausible that it will ever attract a substantial consensus among the most important potential participants. ${ }^{72}$

Conspicuously absent from the roster of recent undertakings for arms control in outer space have been any comprehensive initiatives from the United States. Indeed, even the Obama administration adopted an official policy under which it would listen to proposals and concepts for new measures of space arms control— provided they were equitable, effectively verifiable, and enhanced U.S. and allied national security interests-but U.S. officials would not exercise any forward-leaning leadership on point or sponsor any overtures of their own. ${ }^{73}$ Reinforcing that self-restraint, congressional skep-

specified space activities (art. III.5); see also Beard, supra note 1, at 357; Su \& Lixin, supra note 67, at 35-36.

69. See Beard, supra note 1, at 392-93; Conrad et al., supra note 25, at 12-19; Michael Listner, U.S. Rebuffs Current Draft of EU Code of Conduct, SpACE REv. (Jan. 16, 2012), http://www.thespacereview.com/ article/2006/1 (discussing U.S. reversal of position on the acceptability of the EU Code); Meyer, supra note 58, at 499 (characterizing the United States as "a persistent if tepid backer" of the EU Code); Michael Krepon, Space Code of Conduct Mugged in New York, Arms Control Wonk (Aug. 4, 2015), http://www.armscontrolwonk.com/archive/404712/space-code-of-conduct-mugged-in-new-york/.

70. Conrad et al., supra note 25, at 15-19; Michael Krepon, Will Gravity Lift the Space Code of Conduct?, Arms Control Wonk (Nov. 11, 2013), https://www.armscontrolwonk.com/archive/403944/ will-gravity-lift-the-space-code-of-conduct/ (comments by Mark Gubrud); Listner, supra note 69 (citing substantive concerns raised by several countries); see also Mohamed Hatem Elatawy, ICoC: Recommendations for Further Elaboration, in Awaiting Launch: Perspectives on the Draft ICOC for Outer Space ACtivities 45, 49-50 (Rajeswari Pillai Rajagopalan \& Daniel A. Porras eds., 2014); Kazuto Suzuki, ICoC and the Right of Self Defence, in Awaiting Launch, supra, at 87, 89-92.

71. See Gerard Brachet, E.U. Nonproliferation Consortium, The Security of Space Activities, 1, 6-7 (2016); U.S.-China Econ. \& Sec. Review Comm'n, supra note 5; Space Security Index, supra note 1, at 117-18; Anderson et al., supra note 3, at 12-13; Beard, supra note 1, at 390-91; Su \& Lixin, supra note 67, at 35; Krepon, supra note 69.

72. BRACHET, supra note 71 , at 6 (assessing that the EU project "seems to be in the doldrums"); Beard, supra note 1, at 390; Timothy Farnsworth, Space Code Process Called "Unsuccessful," Arms CONTroL ToDAy, Mar. 2016, at 5 (quoting State Department official as saying that the effort to negotiate the EU Code was unsuccessful); Meyer, supra note 58, at 499-500. But see MolTz, supra note 51, at 160-62 (expressing somewhat greater optimism that the EU Code might represent a path forward for space diplomacy).

73. See The White House, National Space Policy of the United States of America 7 (2010) ("The United States will pursue bilateral and multilateral transparency and confidence-building measures to encourage responsible actions in, and the peaceful use of, space. The United States will consider proposals and concepts for arms-control measures if they are equitable, effectively verifiable, and enhance the national security of the United States and its allies."); U.S. Dep't of Def. \& U.S. Dir. of NAt'L INTELLIGENCE, supra note 28, at 10; Beard, supra note 1, at 424; Michael Krepon, Is Space the Final WarFighting Frontier?, Arms Control Wonk (July 26, 2017), http://www.armscontrolwonk.com/archive/ 1203399/is-space-the-final-war-fighting-frontier/ (judging that the Obama administration had other arms-control priorities besides outer space, and did not want to stir up additional political opposition); Frank A. Rose, Assistant Sec'y, Bureau of Arms Control, Verification, and Compliance, Remarks at the International Symposium on Ensuring Stable Use of Outer Space: Using Diplomacy to Advance the 
ticism over any arms control in space remains intense-even including expressing outrage at the relatively unassuming provisions of the EU Code. ${ }^{74}$ It is still too early to know whether the Trump administration will prove to be more forthcoming regarding legal restraints to preserve the safety and security of outer space, but at this writing, there is little reason to be optimistic that the world's collective passivity regarding the emerging dangers will be addressed in any meaningful diplomatic fashion in the foreseeable future. $^{75}$

Faced with this unpleasant contradiction-an insistent need to do something effective to mitigate an emerging arms race in space, coupled with a failure of traditional arms-control mechanisms to rise to the occasion-the Article now proposes a series of suggestions. It is important not to overpromise here: Parts II (no first use), III (limited test ban), and IV (shared space situational awareness) each proffers only ideas of tightly circumscribed scope and is wholly insufficient to ward off all the incipient dangers. But perhaps their modesty is a virtue; they should be promptly doable, enabling participants to register some near-term accomplishments, even while they

Long-Term Sustainability and Security of the Outer Space Environment, (Mar. 3, 2016), https://geneva.usmission.gov/2016/03/07/using-diplomacy-to-advance-the-long-term-sustainability-and-securityof-the-outer-space-environment/ (affirming that "the United States is not opposed to space arms control in principle," and supporting the development of confidence-building measures).

74. See Beard, supra note 1, at 400-04; Shimabukuro, supra note 7, at 19; Listner, supra note 69; Michael Listner, Separation of Powers Battle Continues over the Code of Conduct, SPACE Rev. (Jan. 7, 2013), http://www.thespacereview.com/article/2215/1. See Jeff Kueter \& John B. Sheldon, Heritage Found., An Investment Strategy for National Security Space, Special Report No. 129, at 10 (2013) http://www.heritage.org/research/reports/2013/02/an-investment-strategy-for-national-securityspace (arguing that the EU Code of Conduct "is not in the interests of the United States and can leave U.S. national security space capabilities needlessly vulnerable”); John R. Bolton \& John C. Yoo, Opinion, Hands Off the Heavens, N.Y. Times (Mar. 9, 2012), http://www.nytimes.com/2012/03/09/opinion/handsoff-the-heavens.html; see also National Defense Authorization Act for Fiscal Year 2013, Pub. L. 112-239, $\S 913,126$ Stat. 1632, 1874-76 (Congressional restrictions on international agreements concerning outer space activities, including the EU Code).

75. See Reinvigorating America's Human Space Exploration Program, 82 Fed. Reg. 59,501 (Dec. 11, 2017); Space SeCurity Index, supra note 1, at 7-8 ("While there is widespread international recognition that the existing regulatory framework is insufficient to meet the current challenges facing the outer space domain, the development of an overarching normative regime has been slow. Space actors have been unable to reach consensus on the exact nature of a space security regime."); Jakhu et al., supra note 40 , at 22 (concluding that it is "undoubtedly clear" that the adoption of a new space treaty in the nearor medium-term "does not seem possible."); Jankowitsch, supra note 41, at 26-28; Dr. Scott Pace, Exec. Sec'y, Nat'l Space Council, Space Development, Law, and Values, Address at the International Institute of Space Law Galloway Space Law Symposium (Dec. 13, 2017), https://spacepolicyonline.com/wp-content/uploads/2017/12/Scott-Pace-to-Galloway-Symp-Dec-13-2017.pdf; Bill Gertz, Pentagon Gearing Up for Space Warfare, FreE BEACON (Mar. 8, 2018, 5:00 AM), http://freebeacon.com/national-security/pentagon-gearing-space-warfare/; President Donald J. Trump Is Unveiling an America First National Space Strategy, White House (Mar. 23, 2018), https://www.whitehouse.gov/briefings-statements/president-donald-jtrump-unveiling-america-first-national-space-strategy/; see also The White House, National SEcurity Strategy of the United States of America 31 (2017) ("The United States must maintain our leadership and freedom of action in space."). 
seek to reinvigorate progress toward larger, more controversial subsequent steps.

\section{No First UsE}

This Part deals with the notion of an international agreement to avoid a first use of space weapons. It first defines the proposition in more detail and discusses a number of variations and options to consider; then it identifies what the proposal can, and cannot, essay to accomplish; and finally it describes precedents from elsewhere in the history of arms control that may provide some support for the viability and utility of the concept.

\section{A. The NFU Proposal and Its Variations}

The core conceit of a "no first use" ("NFU") scheme is simple: participating states would each undertake not to be first to violate the taboo against employing a specified weapon, here an ASAT device, in combat. Behind that nostrum, however, lies a host of sub-options.

For example, the NFU commitment could be entrenched in legally-binding form, through a treaty or similar undertaking; ${ }^{76}$ in a non-legally-binding (or politically-binding) document; or in a series of orchestrated, parallel, revocable, self-declared unilateral statements of intention. In general, the accoutrements of black letter international law should provide a greater degree of formality and seriousness of purpose, but it is hard to demonstrate that legally-binding instruments are categorically more important, more enduring, or more fully complied with than mere political "soft law" documents. ${ }^{77}$

In either case, the defined scope of an NFU undertaking would be subject to negotiation, in multiple dimensions. It could deal exclusively with kinetic-energy devices or embrace directed-energy and cyber weapons, too. ${ }^{78}$ Likewise, it could bar only "destruction" of a target, or also extend to mechanisms that would inflict only partial, or only temporary, suspensions of normal satellite operations. The coverage could be further modulated to pro-

76. In principle, a legally-binding NFU commitment could be established through other routes, such as a resolution of the U.N. Security Council, customary international law, or unilateral undertakings. For present purposes, the focus will be on treaty possibilities.

77. For example, recent U.S. international practice has seen important, high-visibility international arrangements established via multiple routes, including by treaty, see, e.g., 2017 Treaties and Agreements, U.S. DeP't of State, https://www.state.gov/s/1/treaty/tias/2017/index.htm, by executive agreement, see, e.g., 2015 Paris Agreement, Apr. 22, 2016, U.N. Framework Convention on Climate Change, http:// unfccc.int/files/essential_background/convention/application/pdf/english_paris_agreement.pdf, and by non-legally-binding agreement, see, e.g., Joint Comprehensive Plan of Action, July 14, 2015, U.S. DeP'T. OF STATE, http://www.state.gov/e/eb/tfs/spi/iran/jcpoa/ (regarding Iran's nuclear program). See MACDONALD, supra note 9, at 81, 82-83; SOFT LAW IN OUTER SPACE, supra note 35; Beard, supra note 1, at 346-53, 411-13; Hansel, supra note 54, at 93-95; Jankowitsch, supra note 41, 20-26.

78. See supra text accompanying note 10 (describing different physical principles for ASAT mechanisms). 
tect only the satellite or extend to its associated ground stations and the links between them. The self-restraint could apply categorically to all satellites, or it could preferentially protect only specified types, such as those that were central to states' strategic nuclear operations, while leaving unprotected the satellites that support tactical or conventional warfare.

In addition, the participants would have to decide whether to protect only satellites of those states that had joined the agreement, or to express a promise not to employ weapons first against anyone, even those who did not commit themselves to reciprocal undertakings. If the more restricted version of an ASAT ban were adopted, negotiators would then have to decide how best to attribute a particular satellite to a particular state (or states), a problem growing in complexity during an era in which space objects are increasingly owned and operated by private actors or by public/private consortia with ties to multiple countries. ${ }^{79}$

Obviously, the most comprehensive version of an NFU pledge-legally binding, applying to all forms of systems and extending to all stateswould be the strongest, and provide the most arms control value. But it is quite possible that the political dynamics of the day would compel the negotiators to begin with a relatively temperate version of the undertaking, hoping it would grow over time. ${ }^{80}$

\section{B. What an NFU Agreement Could, and Could Not, Accomplish}

The primary direct contribution of an ASAT NFU agreement would be to attempt to delegitimize counter-space operations, to reinforce the international taboo against employing military force in that way. It could help define use of these weapons as unacceptable, something that civilized countries simply do not do (or, at least, do not do unless their enemies have already done it first). ${ }^{81}$

In a more pragmatic vein, this type of commitment would rein in some of the provocative rhetoric that countries occasionally employ in their public statements about their military operations and in their defense doctrine and manuals. For example, it would inhibit truculent comments that "all op-

79. See IDA, supra note 1, at 4.20; POllPeter ET AL., supra note 3, at 22-40 (describing China's various cooperative arrangements in space with many countries); SPACE SECURITY INDEX, supra note 1, at 76-80 (discussing the growth in public-private collaboration in space); Elizabeth Seebode Waldrop, Integration of Military and Civilian Space Assets: Legal and National Security Implications, 55 A.F. L. REV. 157, 157 (2004) (noting the increased U.S. military reliance upon commercial satellites owned by foreign and domestic entities).

80. See MacDonald, supra note 9, at 7 (reporting that some Chinese writings suggest that China is considering adopting a space NFU policy).

81. See Colby, supra note 1, at 21 (endorsing the concept that the United States should promote the principle that "being the first to carry war into space is escalatory and irresponsible"); William Burr \& Jeffrey Kimball, Seven Decades after Hiroshima, Is There Still a Nuclear Taboo?, Bull. Atomic Scientists (Aug. 4, 2015), https://thebulletin.org/seven-decades-after-hiroshima-there-still-nuclear-taboo8591 (discussing the power of a taboo in international affairs). But see MACDONALD, supra note 9, at 41 ("There is no taboo against the use of many counter-space systems."). 
tions are on the table" in dealing with a particular crisis or problem. ${ }^{82}$ It would likewise affect the justifications for funding space weapons and the training routines and war games that military space forces conduct. ${ }^{83}$

In this vein, a useful adjunct to an NFU agreement could be a joint statement-parallel to President Reagan's famous assertion regarding nuclear weapons-to the effect that a war in space "cannot be won and must never be fought." ${ }^{44}$ Acknowledging the potentially catastrophic effects of multiplying space debris, national leaders could commit themselves to avoiding such pyrrhic encounters.

Admittedly, the practical effect of an NFU undertaking is confined. In particular, this sort of verbal declaration or agreement does not categorically prohibit or restrict the development, testing, production, or deployment of space weapons, because virtually all of the same hardware and many of the other preparations for a (legal) second use of a weapon would be indistinguishable from those associated with an (illegal) first use. The NFU treaty or commitment would therefore exert only a modest suppression upon the retention or development of states' capabilities for engaging in space warfare. ${ }^{85}$

Furthermore, a state participating in an NFU accord, even a legally-binding document that was widely adopted by its potential opponents, would probably not feel sufficiently secure to let down its guard very much. That is, declaratory policies, even if codified in a treaty of this sort, could not provide much guarantee that some rogue state will not, in fact, use its system first. There is no assurance against a sudden "breakout" from the treaty - the ban could be fully complied with until the sudden moment when it was completely violated, and the cheater might be able to seize a substantial military advantage via its instantaneous breach. Verification of compliance with an NFU treaty could be another issue; perhaps it would ordinarily be possible to identify a first ASAT strike and to attribute it to a particular state, but it is certainly conceivable that in other circumstances it might be difficult to establish responsibility for the attack. ${ }^{86}$

82. Hitchens \& Johnson-Freese, supra note 1, at 5-6 (discussing the effect of "muscular rhetoric" on U.S. space security); Burr \& Kimball, supra note 81 (noting instances of President Bush asserting that "all options are on the table" in hinting at possible use of nuclear weapons); Justin McCurry, Trump Tells Japan "All Options on the Table" in Face of North Korea Provocation, GuARdian (Apr. 6, 2017), https://www .theguardian.com/world/2017/apr/06/trump-japan-all-options-north-korea-provocation.

83. See NRC REPORT, supra note 1, at 30-32 (discussing contrasting views about the wisdom of employing more frank and direct language in discussing threats to space security and possible military responses).

84. Ronald Reagan, President, State of the Union Address (Jan. 25, 1984), https://www.reaganlibrary.archives.gov/archives/speeches/1984/12584e.htm.

85. Cf. Paul Ingram, BASiC Briefing Paper: Renewing Interest in Negative Security AsSURANCES (2017) (underscoring the importance of declaratory policies in nuclear nonproliferation); ALberto Perez Vadillo, Basic, Beyond the Ban: The Humanitarian Initiative of Nuclear Disarmament and Advocacy of No-First-Use Nuclear Doctrines 10-11 (2016) (stressing the practical consequences of adopting an NFU policy regarding nuclear weapons).

86. See JohnSON-FreEse, supra note 1, at 182-84; Nayak, supra note 4, at 2, 7 (discussing the problem of attributing an ASAT attack to a particular country, and whether an attacker could preserve 
Moreover, the retained permission to use a weapon second, after the proscription has been shattered by some other actor, could raise complicated questions of interpretation. If country $\mathrm{A}$ uses a device against country $\mathrm{B}$, then surely it would be legitimate for $\mathrm{B}$ to respond in kind against $\mathrm{A} .{ }^{87} \mathrm{But}$ could state $\mathrm{C}$ also take the opportunity to shoot at A's satellites (assuming either that there is some sort of alliance relationship between $\mathrm{B}$ and $\mathrm{C}$, or not)? For that matter, once A has shattered the NFU prohibition, are all limitations removed, so it would be permissible for $\mathrm{C}$ to fire a weapon against state D's satellites (again, alternatively assuming there is, or is not, any special connection between $A$ and $D)$ ? ${ }^{88}$

\section{Precedents for NFU in Arms Control}

Demonstrating a clear provenance for a controversial idea does not, of course, establish its wisdom or prove its adaptability to different circumstances, but the history can be illuminating nonetheless. In the case of an NFU pledge, there are ample precedents available, and they have achieved considerable success in other zones of arms control.

The most direct prior expression of NFU comes from the realm of chemical and biological weapons. Under the 1925 Geneva Protocol, participants eschew the use of "asphyxiating, poisonous or other gases, and of bacteriological methods of warfare." 89 Through a network of reservations, this categorical prohibition was converted essentially into a commitment not to use such weapons first, and only with respect to other states assuming reciprocal

plausible deniability); Ahsan Ali Zahid \& Hasan Ehtisham, The Enduring Hypocrisy of Nuclear No First Use, Mod. Dipl. (Aug. 22, 2017), https://moderndiplomacy.eu/2017/08/22/the-enduring-hypocrisy-of-nuclear-no-first-use/ (arguing that other countries cannot trust an NFU pledge and that despite Russia making an NFU declaration in 1982, it was secretly prepared to use nuclear weapons first if necessary); infra text accompanying notes 158-81 (regarding proposals to enhance space situational awareness, to provide greater certainty in identifying and attributing an ASAT attack).

87. Note that any legal use of force in space would be bound by the corpus of jus in bello. See Peter Hulsroj \& Anja Nakarada Pecujlic, Space Through the Lens of Neutrality, in MONOGRaPH SERIES V: CoNFlicts in Space and the Rule of Law, 437 (Maria Manoli \& Sandy Belle Habchi eds., 2018); Tronchetti, supra note 66, at 350-59; Dale Stephens \& Cassandra Steer, Conflicts in Space: International Humanitarian Law and Its Application to Space Warfare (Univ. of Adelaide Law Sch., RUMLAE Research Paper No. 16-18, 2015), https://papers.ssrn.com/sol3/papers.cfm?abstract_id=2767980.

88. See Steven Starr et al., New Terminology to Help Prevent Accidental Nuclear War, Bull. Atomic Scientists (Sept. 29, 2015), https://thebulletin.org/new-terminology-help-prevent-accidental-nuclearwar8773 (discussing ambiguity about what counts as a "first" use of a weapon in near-combat situations).

89. Protocol for the Prohibition of the Use in War of Asphyxiating, Poisonous or Other Gases, and of Bacteriological Methods of Warfare, June 17, 1925, 26 U.S.T. 571, 94 L.N.T.S. 65 [hereinafter Geneva Protocol]. 
obligations. ${ }^{90}$ The treaty was very widely accepted and remains in force today (although largely superseded, as elaborated, infra). ${ }^{91}$

Unsurprisingly, despite the global support for the Geneva Protocol (and despite the universal revulsion at the shocking humanitarian consequences that chemical weapons had inflicted during World War I), many countries continued to build up their chemical and biological weapons inventories. In fact, new generations of even more deadly nerve agents were crafted to supplement or replace the mustard gas, phosgene, and other horrors of the earlier conflict. As World War II raged, combatants armed themselves with massive chemical ordnance, and most grimly anticipated that these arsenals would again be used on a grand scale..$^{92}$

Still, President Franklin D. Roosevelt sought to avoid that cataclysm, by employing the device of an NFU undertaking. Although the United States had not yet ratified the Geneva Protocol, he publicly asserted that the United States would refrain from employing its chemical weapons if the Axis powers would do likewise. ${ }^{93}$ Remarkably, even without any additional formal legal commitment-and in the midst of a global conflagration that knew few other humanitarian restraints-these special arms were not employed by the opposing forces in the central battlefields of the European Theater. ${ }^{94}$ It is, of course, impossible to prove how much the Geneva Protocol and the Roosevelt reciprocity statement, in concert with the deterrent threat of retaliation in kind, were responsible for that unanticipated non-use, but it does appear that the NFU commitments made important contributions.

In fact, the pattern regarding chemical and biological weapons over the following decades revealed only rare international usage, accompanied by a profound sense that any country that resorted to these reviled weapons was

90. W. Seth Carus, Ctr. for the Study of Weapons of Mass Destruction, A Short HisTORY OF Biological Warfare 14 (2017); Graham \& LaVera, supra note 51, at 8; John Ellis van Courtland Moon, Controlling Chemical and Biological Weapons Through World War II, in ENCYClopediA, supra note 11, at 657, 664-66.

91. Protocol for the Probibition of the Use in War of Asphyxiating, Poisonous or Other Gases, and of Bacteriological Methods of Warfare, U.N. OfFICE FOR Disarmament AfFAIRs, http://disarmament.un.org/treaties/ t/1925 (last visited Nov. 17, 2017) (listing 140 current parties to the Geneva Protocol). See infra text accompanying notes 96-99 for a discussion of the 1993 Chemical Weapons Convention, which largely displaced the Geneva Protocol.

92. Moon, supra note 90, at 666-73.

93. Franklin D. Roosevelt, President, The Axis Is Warned Against the Use of Poison Gas (June 8, 1943), in 1943 The Public Papers and Addresses of Franklin D. Roosevelt 242, 243 (Samuel I. Rosenman ed., 1950); Barton J. Bernstein, America's Biological Warfare Program in the Second World War, 11 J. Strategic Stud. 3, 292 (1988) (noting that Roosevelt's NFU undertaking applied to chemical weapons but not to biological weapons); Moon, supra note 90, at 669 .

94. Chemical weapons were used by Italy against Ethiopia, by Japan against China, and by Germany against Jews in concentration camps. Moon, supra note 90, at 666, 669; Glenn Cross, Long Ignored: The Use of Chemical and Biological Weapons Against Insurgents, WAR ON Rocks (Aug. 14, 2017), https:// warontherocks.com/2017/08/long-ignored-the-use-of-chemical-and-biological-weapons-against-insurgents/ (analyzing the use of chemical and biological weapons against targets that were poorly equipped or trained to resist, especially non-state insurgent groups). 
behaving as a pariah. States mostly did not disarm their chemical and biological weapons, but they did not often engage those capacities in conflict. ${ }^{95}$

Formal elaboration of the NFU commitments, and advancement beyond them, required additional decades. The 1972 Biological Weapons Convention $^{96}$ and the 1993 Chemical Weapons Convention ${ }^{97}$ established broad, widely-accepted prohibitions-parties undertook not to develop, produce, stockpile, or otherwise acquire the stigmatized weapons; not to use them (first or second); and, in the case of chemical weapons, to destroy not only the arms but also the facilities that had been used to create them. ${ }^{98}$ Both the Biological Weapons Convention and the Chemical Weapons Convention expressly acknowledge the Geneva Protocol as the legal genesis for their much more ambitious undertakings. ${ }^{99}$

Another important precedent for NFU commitments comes from the world of nuclear weapons, where the history is more checkered. During the Cold War, for example, when massive NATO and Warsaw Pact forces were entrenched across Central Europe, the Soviet Union advocated that the countries possessing nuclear weapons should agree never to use them first, so any conflict on the continent would be at least somewhat confined. At that time, however, the United States and its allies feared they might not be able to contain a massive westward aggression by conventional forces. They concluded that it was valuable for deterrence to retain a measure of strategic ambiguity, including the possibility that the West might breach the nuclear barrier to repel an attack. No NFU agreement was reached. ${ }^{100}$

Years later, following the dissolution of the Warsaw Pact, the collapse of the Soviet Union, and the precipitous cratering of the Russian economy, the military calculations were reversed. The United States and its newly-expanded collection of allies grew more confident about their ability to resist

95. Charles C. Flowerree, Chemical and Biological Weapons and Arms Control, in ENCYCLOPEDIA, supra note 11, at 999, 1002-04; Moon, supra note 90, at 668-73; Milton Leitenberg, China's False Allegations of the Use of Biological Weapons by the United States During the Korean War 7 (Woodrow Wilson Int'l Ctr. for Scholars, Working Paper No. 78, 2016) (quoting secret U.S. policy documents in force from 1950 to 1956 stating that "chemical, biological and radiological weapons will not be used by the United States except in retaliation"). But see Cross, supra note 94 (discussing instances of the use of chemical and biological weapons against non-state actors).

96. Convention on the Prohibition of the Development, Production and Stockpiling of Bacteriological (Biological) and Toxin Weapons and on Their Destruction art. I, Apr. 10, 1972, 26 U.S.T. 583, 1015 U.N.T.S. 163 [hereinafter Biological Weapons Convention or BWC].

97. Convention on the Prohibition of the Development, Production, Stockpiling and Use of Chemical Weapons and on Their Destruction art. XXI, Jan. 13, 1993, S. Treaty Doc. No. 103-21 (1993), 1974 U.N.T.S. 45 (entered into force Apr. 29, 1997) [hereinafter CWC]. The CWC largely supersedes, but explicitly does not derogate from, the Geneva Protocol. Id. art. XVI.

98. Id. art. I; BWC, supra note 96, art. I; see GRAHAM \& LAVERA, supra note 51, at 292-95, 1168-70; Flowerree, supra note 95, at 1004-14.

99. CWC, supra note 97, pmbl. para. 3, art. XIII; BWC, supra note 96, pmbl. para. 2, art. VIII.

100. Fen Osler Hampson, "No-First-Use" Nuclear Policy, in ENCYCLOPEDIA, supra note 11, at 1069; Nuclear Declaratory Policy and Negative Security Assurances, Arms Control Ass'N (June 30, 2016), https:// www.armscontrol.org/factsheets/declaratorypolicies [hereinafter NSA Fact Sheet] (citing U.S.S.R.'s 1982 nuclear NFU pledge). 
aggression, and they were more favorably disposed toward a nuclear NFU agreement for the continent. This time, however, the newly disempowered Russia declined. ${ }^{101}$

More generally, a nuclear NFU commitment-in the form of a "negative security assurance"- has become an important tool in the global campaign for nuclear non-proliferation. ${ }^{102}$ Under the 1968 Nuclear Non-Proliferation Treaty ("NPT"), ${ }^{103}$ most countries agreed to give up any right to possess nuclear weapons of their own, but they have sought guarantees from the countries that continue to possess those arms that they will not use them against the non-nuclear states. In response, each of the five nuclear weapons possessors who are parties to the NPT have extended some form of negative security assurance in various vocabulary over the years. ${ }^{104}$ These statements run beyond the concept of NFU in constituting commitments not to use nuclear weapons at all against the countries that have foresworn them, but the assurances are typically laden with exceptions or limitations that make a negative security assurance functionally quite similar to an NFU statement. ${ }^{105}$ Notably, pressures continue to emerge from the "recipients," who press for the assurances to be expanded into a more comprehensive, unqualified, and clearly legally-binding form, seeking to diminish the value of nuclear weapons as "the coin of the realm" in national security debates and as the badge of "first-class citizenship." Conversely, the nuclear weapons states' failure to satisfy those demands, and their insistence that nuclear weapons remain "usable," have emerged as significant dangers to the continued integrity and viability of the NPT regime. ${ }^{106}$

101. Hampson, supra note 100, at 1073-75; NSA Fact Sheet, supra note 100 (describing Russia's various partial NFU policy statements in 1993 and 1995).

102. NSA Fact Sheet, supra note 100; see also InGRAM, supra note 85 (discussing negative security assurances); Ray Acheson \& Beatrice Finn, Reaching Critical Will, Negative Security AssurANCES, http://www.reachingcriticalwill.org/images/documents/Resources/Factsheets/nsa.pdf (last visited Mar. 18, 2018); Beatrice Fihn, U.N. InSt. For Disarmament Research, The Conference on Disarmament and Negative Security Assurances (2011); Marc Finaud, Why New Thinking Is Needed on Negative Security Assurances, 47 Arms Control Today, Oct. 2017, at 12; Ali Zahid \& Ehtisham, supra note 86 (discussing Indian and Pakistani approaches to nuclear assurances).

103. Treaty on the Non-Proliferation of Nuclear Weapons, July 1, 1968, 21 U.S.T. 483, 729 U.N.T.S. 169 [hereinafter NPT].

104. ACHESON \& FiHn, supra note 102.

105. See NSA Fact Sheet, supra note 100; Proposed Internationally Legally-Binding Negative Security Assurances (NSAs), NuCLEAr Threat Initiative, http://www.nti.org/learn/treaties-and-regimes/proposed-internationally-legally-binding-negative-security-assurances/ (last updated May 1, 2017) (also noting "positive security assurances," that is, commitments to come to the assistance of a country victimized by a nuclear weapons attack; this concept, too, could be adapted for the space context).

106. See Graham \& LaVera, supra note 51, at 102-03; Ingram, supra note 85 (analyzing the importance of negative security assurances in the NPT); Finaud, supra note 102; James E. Cartwright \& Bruce G. Blair, Opinion, End the First-Use Policy for Nuclear Weapons, N.Y. Times (Aug. 14, 2016), https:// nyti.ms/2ktoSyD (asserting that a nuclear NFU policy would "further delegitimize nuclear weapons"); Alyn Ware \& Jean-Marie Collin, European Parliaments Demand "No-First-Use"-Obama's Nuclear Agenda Analysed, InDePTHNews (July 12, 2016), https:/www.indepthnews.net/index.php/nuclear-abolition/ 527-european-parliaments-demand-no-first-use-obama-s-nuclear-agenda-analysed. But see Michaela Dodge, Some Bad Ideas, Like Zombies, Never Die. A "No First Use" Nuclear Policy Is One of Them, DAILY SIGNAL (Aug. 16, 2017), http://dailysignal.com/2017/08/16/bad-ideas-like-zombies-never-die-no-first- 
Finally in this area, it is worth highlighting the controversy over the latest evolutions in the U.S. unilateral, non-legally-binding nuclear NFU statement. In the 2010 Nuclear Posture Review Report-a broad, fundamental reassessment of the foundations of nuclear weapons policy-the Obama Administration undertook to assess the prior U.S. public assurances, and to make a more definitive commitment, as part of its contribution to the global non-proliferation effort. ${ }^{107}$ Intense internal debate emerged within the government, resulting in an uneasy compromise. The Pentagon report declared: "[T] weapons against non-nuclear weapons states that are party to the Nuclear Non-Proliferation Treaty (NPT) and in compliance with their nuclear nonproliferation obligations." 108

In 2018, the Trump Administration released its own Nuclear Posture Review Report, ${ }^{109}$ which revised the NFU statement to expand the range of circumstances in which the United States would consider the employment of nuclear weapons. Now included in the roster of "extreme circumstances" justifying a first use are "significant non-nuclear strategic attacks ... on the U.S., allied, or partner civilian population or infrastructure, and attacks on the U.S. or allied nuclear forces, their command and control, or warning and attack assessment capabilities." ${ }^{110}$ Under this standard, a cyber attack, for example, could now trigger a nuclear response. ${ }^{111}$

In sum, there is to date no comprehensive NFU policy regarding nuclear weapons by the United States or others. But if the controversy and the backand-forth gyrations of public policy over the years prove anything, it is to establish the proposition that an NFU statement is not dismissed as "mere

use-nuclear-policy-one/ (contending that a U.S. nuclear NFU policy would spur nuclear proliferation). See generally Stephan Haggard, The Fourth Nuclear Test, North KorEa: Witness to Transformation BLOG (Jan. 6, 2016, 3:45 PM), https://piie.com/blogs/north-korea-witness-transformation/fourth-nuclear-test (describing North Korea's official nuclear NFU posture and dismissing it as "almost entirely disingenuous").

107. U.S. Dep't of Def., Nuclear Posture Review Report (2010); Amy F. Woolf, Cong. Research Serv., U.S. Nuclear Weapons Policy: Considering "No First Use," (2016), https:// fas.org/sgp/crs/nuke/IN10553.pdf; Bruce Blair, How Obama Could Revolutionize Nuclear Weapons Strategy Before He Goes, PoliTico (June 22, 2016), https://www.politico.com/magazine/story/2016/06/barackobama-nuclear-weapons-213981; NSA Fact Sheet, supra note 100; Keith B. Payne, Once Again: Why a "NoFirst-Use" Policy Is a Bad, Very Bad Idea, NAT'L Rev. (July 6, 2016), http://www.nationalreview.com/ article/437510/it-would-reduce-potential-cost-using-conventional-chemical-and-biological-attacks.

108. U.S. Dep't of Def., supra note 107, at 15. In the Report, the United States also reserved the right to adjust the assurance, if required by developments in and proliferation of biological weapons. The Report also emphasized that although the United States was not then prepared to adopt a comprehensive NFU statement, it "will work to establish conditions under which such a policy could be safely adopted." Id. at 16; see also Finaud, supra note 102, at 13-14; NSA Fact Sheet, supra note 100 (identifying key elements in U.S. NFU posture).

109. Office of the Sec’y of Def., Nuclear Posture Review (2018).

110. Id. at 21 .

111. David E. Sanger \& William J. Broad, Pentagon Suggests Countering Devastating Cyberattacks with Nuclear Arms, N.Y. Times (Jan. 16, 2018), https://nyti.ms/2FLHxl0. 
words." People, government departments, and leading nations care a great deal about even the nuances of NFU policy. ${ }^{112}$

A proposed NFU statement about anti-satellite weapons, in a similar fashion, would not magically re-order the field, but it would be consequential nevertheless; it would make a difference in global security calculations that would be worth struggling to get right.

\section{Limited TeSt BAN}

The second proposal runs an important step beyond the NFU sphere of public posture statements and undertakes to constrain (again, in a humble, beginning way) the physical behavior of counter-space operations. Specifically, this Article advocates restrictions upon the testing in space of specified types of ASAT systems. Again, the discussion is divided into consideration of the idea and its variations; the advantages and disadvantages it might carry; and the precedents from elsewhere in arms control.

\section{A. The Test Ban Proposal and Its Variations}

The core concept here is for the relevant states to agree to restrict their developmental testing of certain types of ASAT systems; the key operational question is how "limited" vs. "comprehensive" that test-ban structure should become.

Prominent among the variants to consider is the question (as noted in Part II, dealing with NFU declarations ${ }^{113}$ ) whether the test-ban undertaking should be cast in legally-binding or politically-binding form. Also up for grabs is the matter of duration: whether the commitment would be for a fixed (long or short) period of time, of indefinite length, or permanent. ${ }^{114}$

112. See Dominic Tierney, Refusing to Nuke First, ATLANTIC (Sept. 14, 2016), https://www.theatlantic .com/international/archive/2016/09/nuclear-obama-north-korea-pakistan/499676/ (reviewing the controversy over possible adoption of a U.S. nuclear NFU posture, and concluding that such a doctrine is not merely idealistic, but is a strategy available to the strongest states, who try to shift the focus of a possible future conflict onto the terms most advantageous to themselves); Cartwright \& Blair, supra note 106 (stressing the operational consequences of an NFU declaration; it is not just words); Josh Rogin, Opinion, U.S. Allies Unite to Block Obama's Nuclear "Legacy," Wash. Post (Aug. 14, 2016), http://wapo.st/ 2DHwiYh (describing opposition from close U.S. allies to possible adoption of a nuclear NFU policy); Franklin C. Miller, The Dangers of No-First-Use, Bull. Aтомic SCIENTiSTs (Aug. 22, 2016), https:// thebulletin.org/dangers-no-first-use 9790 (describing dangers of a nuclear NFU declaration).

113. See supra text accompanying notes 76-77.

114. As noted in infra note 144, the first voluntary moratorium on explosive testing of nuclear weapons lasted for three years. The treaties limiting nuclear weapons testing have been of permanent duration, although for much of the negotiation of the Comprehensive Nuclear-Test-Ban Treaty, the most comprehensive treaty, the United States favored a treaty that would be operational for only ten years. See, e.g., Comprehensive Nuclear-Test-Ban Treaty art. IX, I 1, Sept. 24, 1996, S. Treaty Doc. No. 105-28 (1997), 35 I.L.M. 1439 (not yet in force) [hereinafter CTBT]; 1963 Treaty Banning Nuclear Weapon Tests in the Atmosphere, in Outer Space and Under Water art. IV, Aug. 5, 1963, 14 U.S.T. 1313, 480 U.N.T.S. 6964 [hereinafter Limited Test Ban Treaty or LTBT]; John M. SHALIKASHVIli, RePORT ON the Findings and Recommendations Concerning the Comprehensive Nuclear Test Ban TrEATY 13-14 (2001), https://fas.org/nuke/control/ctbt/text/shalictbt.htm (noting that the most contro- 
Another crucial issue would be which states would participate in the test ban regime. Obviously, the affiliation by the three leading space actors would be of utmost importance, but universal adherence would also be highly desirable. It is possible, perhaps, for the agreement to initially include only a relatively small roster of states and then to grow over time, as many arms control instruments have done. ${ }^{115}$

The definition of a prohibited "test" could be quite complicated here, as it sometimes has been in prior applications. ${ }^{116}$ Because, as noted above, many military operations in outer space are dual-capable, contributing to both the ASAT mission and to the development of missile defense capabilities (as well as to peaceful exploration and exploitation of space), the linedrawing could be particularly contentious. ${ }^{117}$ Likewise, negotiators for a space test-ban agreement would have to address provisions for verification of compliance, a task that might be relatively straightforward, but not automatic, in this context. ${ }^{118}$

The proposal here is unpretentious-simply to bar tests in space of any ASAT system in a mode that generates significant amounts of long-lasting space debris. Admittedly, there is considerable ambiguity in the words "significant" and "long-lasting." Virtually all space activities result in some debris, and accidents or plain bad luck can greatly magnify the pollution. ${ }^{119}$ But the intention is at least to preclude a rerun of the disastrous Chinese 2007 event, which spawned an unprecedented cluster of enduring hazardous

versial aspect of the initial U.S. negotiating position regarding the CTBT was the proposal that the initial duration of the treaty should be only ten years, after which a country could easily exit; the treaty was ultimately concluded as a permanent agreement).

115. The NPT, supra note 102, for example, was opened for signature in 1968, and thirty-eight states had ratified it by 1970. Many more parties drifted in later, and the treaty currently boasts 191 parties. See Treaty on Non-Proliferation of Nuclear Weapons, U.N. OfFICE fOR Disarmament Affairs, http://disarmament.un.org/treaties/t/npt (last visited Nov. 15, 2017) (complete list of current parties to the NPT). Entry into force of the Limited Test Ban Treaty, supra note 114, required ratification only by the Soviet Union, the United Kingdom, and the United States, who were designated as the "Original Parties." In practice, the LTBT drew many adherents promptly after its 1963 opening for signature, but there were many latecomers among its 125 current parties. See LTBT, supra note 114, art. III, I 3; Treaty Banning Nuclear Weapon Tests in the Atmosphere, in Outer Space and Under Water, U.N. OfFICE FOR Disarmament AfFAIRs, http://disarmament.un.org/treaties/t/test_ban (listing all current parties to the LTBT).

116. See, e.g., John Burroughs, Key Issues in Negotiations for a Nuclear Weapons Probibition Treaty, 47 Arms Control Today, June 2017, at 6, 8 (discussing the difficulty of defining terms such as "test," "research," and "design" in the negotiation of a treaty banning nuclear weapons).

117. See supra text accompanying note 20 for a discussion of the overlap between ASAT and missile defense technology and testing.

118. Liemer \& Chyba, supra note 20, at 153.

119. Space SECURITY INDEX, supra note 1, at 9 (conceding that all space missions generate some quantity of debris). 
material. ${ }^{120}$ Other space activities, even those resulting in a "normal" dispersal of debris, would be unaffected. ${ }^{121}$

\section{B. What a Test Ban Agreement Could-and Could Not-Accomplish}

Here, it is convenient to start the discussion by highlighting what the proposal does not restrict. As presented, this version of a test ban would not affect the continued possession of ASAT systems of any variety; no numerical cap on the numbers of such weapons would be imposed, and no elimination of weapons would be required. Moreover, the contemplated agreement would not affect the testing of directed-energy systems, such as high energy laser weapons, provided they do not result in an explosion or other mass fragmentation of the target. ${ }^{122}$ In addition, a party would be allowed to test even its kinetic ASAT mechanisms in a non-impact mode: firing an interceptor against a pre-specified but vacant point in space. In like vein, rendezvous-and-proximity tests and operations would be allowed, even if they do contribute to the development of ASAT capabilities, because they do not generate indiscriminate debris and have many other benign applications, too. ${ }^{123}$

An event such as the 2008 U.S. Burnt Frost downing of the failing USA193 satellite would represent a borderline case. It would probably be permitted, principally because it did not generate "long-lasting" debris. Most of the detritus from that collision fell back to Earth relatively promptly, without substantial hazards to other spacecraft. ${ }^{124}$ Likewise, this proposal

120. See supra text accompanying note 16 (describing China's 2007 kinetic-energy ASAT test); see also GREGO \& WRIGHT, supra note 32, at 18-19 (advocating a moratorium on destructive ASAT weapons testing); Hitchens \& Johnson-Freese, supra note 1, at 30 (recommending a ban on testing and use of ASATs); Beard, supra note 1, at 416-19 (identifying a ban on ASAT testing as the "best target" for an initial multilateral agreement); Liemer \& Chyba, supra note 20, at 149.

121. See supra note 56 (discussing the international guidelines from the IADC concerning best practices for mitigating creation of new debris). Cf. Liemer \& Chyba, supra note 20, at 154 (proposing to prohibit testing of debris-producing ASATs above a designated altitude, but to allow testing in lower orbits).

122. A directed-energy ASAT weapon that permanently disabled its target would render that satellite "debris," but at least it would be one large item of debris, relatively easy for others to track and avoid. If a high-energy ASAT laser caused the target to explode (such as by hitting a fuel supply), it would create far more chaos in space; such a test would be barred by this proposal.

123. Under the Outer Space Treaty, a party that believes a planned space activity by another party would cause "potentially harmful interference" with its own activities in the peaceful exploration and use of outer space may request consultation. OST, supra note 36, art. IX; see also Liemer \& Chyba, supra note 20, at 154-55; Gubrud, Chinese and U.S., supra note 20, at 617 (criticizing the concept of an ASAT test ban); Gubrud, Not Arms Control, supra note 20; Krepon, supra note 11 (evaluating a prohibition on only those ASAT tests that resulted in collisions and debris).

124. See supra text accompanying note 17 for a discussion of Burnt Frost. Note that the United States characterized the Burnt Frost activity as not constituting an ASAT "test" and as not being a response to China's 2007 ASAT test, but, instead, as an operation intended to reduce an imminent hazard to Earth, because the failing satellite might crash intact, inflicting damage on people and property underneath. See Gene Stansbery et al., A Comparison of Catastrophic On-Orbit Collisions, 2008 Proc. Advanced Maui Optical \& Space Surveillance Tech. Conf. (comparing debris generated by various ASAT tests). 
would not inhibit most missile-defense testing, because the usual collisions from those events occur at low altitudes. ${ }^{125}$

Turning now to the positive attributes of the proposal, this test-ban regime would pursue two principal purposes, in addition to the general overall goal of seeking to reinvigorate the long-moribund international dialog on space security and arms control.

The first objective is to inhibit the development of at least one type of ASAT technology. The concept here rests upon the "test-ban theory of arms control": countries will be reluctant to rely upon weapons that have not been thoroughly tested, so the most effective mechanism for inhibiting the next spin in an arms race is to deprive them of the opportunity to assure themselves that the new evolving prototypes will, in fact, operate as intended. In this view, blocking future qualitative improvements in a weapon may be even more important than capping the sheer numbers of those devices, and a test ban can be the key governor against innovations. ${ }^{126}$

This theory is not iron-clad; states sometimes do invest in weapons that have not survived the crucible of rigorous testing. ${ }^{127}$ But prudence strongly guides them in the opposite direction: a cautious budget office will be reluctant to devote scarce resources to procurement of unproven systems, and conservative military and civilian leaders will hesitate to rely upon arms of unproven effect. The history of weapons development is littered with illustrations of conspicuous and expensive failures resulting from decisions to forego customarily exhaustive testing, especially where new technology is pushing the envelope of prior experience. ${ }^{128}$

In addition to helping retard the proliferation of ASAT capabilities, this test-ban regime could, over time, reduce the confidence of countries that have already completed their testing of debris-creating ASAT systems. That is, even a proven military strength can atrophy if it is not regularly exer-

125. See supra text accompanying note 20 for a discussion of the overlap between ASAT and missile defense technology and testing.

126. See, e.g., Benjamin S. Loeb, Test Ban Proposals and Agreements, in Encyclopedia, supra note 11, at 827, 844-45; Alan Neidle, Nuclear Test Bans: History and Future Prospects, in U.S.-Soviet Security CoOPERATION, supra note 11 , at 175, 184, 189-90.

127. Conspicuously, South Africa was able to develop nuclear weapons, probably without conducting any explosive tests. See Nuclear Disarmament South Africa, Nuclear Threat Initiative, http://www.nti .org/analysis/articles/south-africa-nuclear-disarmament/ (last updated July 2017); Nuclear Weapons: Who Has What at a Glance, Arms Control Ass'N, https://www.armscontrol.org/factsheets/Nuclearweaponswhohaswhat (last updated Mar. 2018).

128. See J. Michael Gilmore, U.S. Dep’t. of Def., FY 2016 Annual Report (2016) (describing rigorous test and evaluation procedures for new weapons and characterizing the process as essential to sound procurement decisions); WEEDEN, supra 11, at 18, 20 (concluding that a dedicated ASAT system would likely undergo substantial testing of increasing complexity and difficulty); Kingston Reif, Congress Puts Bipartisan Arms Control Policies at Risk, 9 Arms Control Ass'N Issue Briefs (July 17, 2017), https://www.armscontrol.org/issue-briefs/2017-07/congress-puts-bipartisan-arms-control-policies-at-risk; David Willman, The Pentagon's \$10 Billion Bet Gone Bad, L.A. Times (Apr. 5, 2015), http://graphics.latimes.com/missile-defense/; see also MACDONALD, supra note 9, at 18 (arguing that if debris-creating ASAT tests were banned, a country could still benefit from conducting "near miss" or fly-by tests, but "China would not enjoy the confidence that normal testing would give it"). 
cised, ${ }^{129}$ and space weapons would be no exception. The U.S. and Soviet legacy kinetic-energy interceptor systems that were deemed operational in the 1980s, for example, largely deteriorated through desuetude in the subsequent decades, and their more recent ASAT enterprises had to start more or less from scratch. ${ }^{130}$

The second objective for this partial test-ban regime is to avoid the generation of unnecessary space debris, via effectively channeling any ASAT competition into the somewhat less damaging modes. That is, if countries are going to continue, at least for now, in their headlong pursuit of ASAT capabilities, at least they might agree to forego the most destructive algorithms. ${ }^{131}$

China's 2007 test was a true watershed, highlighting the catastrophic harm of massive, long-lived debris creation, and perhaps inspiring the global community to avoid further self-destructive fouling of our own communal orbital nest. ${ }^{132}$ In one sense, this new awareness may already be too latesome theorize that there is already so much debris in space that widespread collisions are now unavoidable, and these impacts would create additional plumes of debris that would cascade through space in a destructive, unend-

129. In the context of nuclear weapons testing, controversy has surrounded the fact that the CTBT would prohibit all nuclear weapons testing; the Science-Based Stockpile Stewardship program was designed to ensure that the weapons would remain secure and reliable indefinitely even without full explosive confirmation. See Hugh Gusterson, A New Push for the Comprehensive Nuclear Test Ban Treaty?, BuLl. Атоміс Scientists (Oct. 29, 2015), https://thebulletin.org/new-push-comprehensive-nuclear-test-bantreaty8830 (comparing nuclear weapons science and space science); Neidle, supra note 126, at 188; Ernest J. Moniz, U.S. Sec'y of Energy, Editorial, A Comprehensive Nuclear Test Ban, 354 SCIENCE 1081, 1081, Nov. 30, 2016; Harold P. Smith \& Richard S. Soll, Challenges of Nuclear Stockpile Stewardship under a Comprehensive Test Ban, Arms Control Today (Mar. 1998), https://www.armscontrol.org/act/1998_03/ ctbmr; Press Release, National Nuclear Security Administration, 20th Anniversary of U.S. Commitment to Science-Based Stockpile Stewardship (Aug. 14, 2015), https://nnsa.energy.gov/mediaroom/pressreleases/20th-anniversary-ssp-commitment. A test ban does privilege the states that have already undertaken extensive testing; even if their confidence in the continuing integrity of the weapon will diminish over time, those states will retain an experiential advantage over states that have never tested at all.

130. Grego, supra note 11, 7-8; LAmbakis, supra note 5, at 27; Anatoly Zak, Russian Anti-Satellite Systems, Russian SPACE WEB, http://www.russianspaceweb.com/naryad.html (last updated Nov. 30, 2017).

131. See Jinyuan Su, The Environmental Dimension of Space Arms Control, 29 SPACE POL'y 58, 61-62 (2013); Michael J. Listner, The Account of NORAD 40258 and U.S. Options Under Article IX, SPACE ThOughts BlOG (Oct. 10, 2015), https://spacethoughtsblog.wordpress.com/2015/10/10/the-account-ofnorad-40258-and-u-s-options-under-article-ix/ (discussing the availability of consultations under art. IX of the Outer Space Treaty, and the non-use of that provision by states); Douglas Loverro, Why the U.S. Must Lead Again, SpACE Rev. (Aug. 14, 2017), http://www.thespacereview.com/article/3307/1 (arguing that the United States should lead the effort to prohibit indiscriminate space weapons).

132. See Space Security Index, supra note 1, at 11 (asserting that "[s]pace debris poses a significant, constant, and indiscriminant threat to all spacecraft"); id. at 19-21 (assessing the existing volume of debris, the history of collisions, and the international effort to restrict the creation of new debris); Wade Boese, Chinese Satellite Destruction Stirs Debate, Arms Control Today (Mar. 1, 2007), https://www.armscontrol.org/act/2007_03/ChinaSatellite; Theresa Hitchens, U.S.-Sino Relations in Space, ChINA SEC., Winter 2007, at 12; Richard Weitz, U.S. Allies Criticize China's Anti-Satellite Weapon Test; Media Notes Concerns About U.S. Space Policies, WMD Insights, Mar. 2007, at 2; Fritz Lodge, Orbital Debris Crisis Could Wreak Havoc on Earth, CipHer Brief (Aug. 25, 2017), https://www.thecipherbrief.com/orbitaldebris-crisis-wreak-havoc-earth. 
ing chain reaction. ${ }^{133}$ As there is, at present, no operational capacity for actively removing debris from space, ${ }^{134}$ the world's space community has come to place a greater emphasis upon avoiding the creation of new space junk, especially reviling the most long-lasting debris injected into the most popular and useful orbital slots. ${ }^{135}$

The United States, China, and Russia already seem to be moving their ASAT ambitions in this direction, choosing to pursue non-destructive weapons approaches over the traditional interceptors. The American position explicitly adopts this orientation: General John E. Hyten, the commander of U.S. Strategic Command and responsible for oversight of the ASAT program, has emphasized, "[T]o me, the one limiting factor is no debris. Whatever you do, don't create debris." 136 China and Russia have to date been more circumspect about renouncing debris-creating ASATs, but neither state has repeated anything like the catastrophic 2007 test. ${ }^{137}$ Some

133. European Space Agency, Space Operations: Space Debris 6 (Mar. 2017) (discussing ESA's policy of mitigating the creation of additional space debris in missions); IDA, supra note 1, at 7.5-7.7; SPACE SECURITY INDEX, supra note 1, at 20-22 (anticipating future trends in growth of space debris and collisions between space objects); J.-C. Liou \& N.L. Johnson, Risks in Space from Orbiting Debris, ScIENCE, Jan. 20, 2006, at 340; Darren McKnight \& Donald Kessler, We've Already Passed the Tipping Point for Orbital Debris, IEEE SPECTRum (Sept. 26, 2012), http://spectrum.iee.org/aerospace/satellites/weve-already-passed-the-tipping-point-for-orbital-debris; Tereza Pultarova, Experts Call for Legislation and Improved Tracking to Deal with Orbital Debris, SpaCE News (Apr. 21, 2017), http://spacenews.com/expertscall-for-legislation-and-improved-tracking-to-deal-with-orbital-debris/ (discussing the "Kessler Syndrome," whereby space debris becomes so prevalent that collisions are unavoidable, resulting in a chain reaction of additional collisions and the generation of still more debris).

134. See Space Security Index, supra note 1, at 26 (reporting on orbital debris mitigation research and early-stage prototype debris sweeping satellite); Lodge, supra note 132 (citing the concept of removal as "the holy grail of space debris"); Vedda \& Hays, supra note 20, at 12-14; Al Anzaldua \& Dave Dunlop, Overcoming Non-Technical Challenges to Cleaning Up Orbital Debris, SpaCE Rev. (Nov. 9, 2015), http://www.thespacereview.com/article/2863/1; Al Anzaldua \& Dave Dunlop, Why the US and Russia Should Work Together to Clean Up Orbital Debris, SpACE REv. (Jan. 30, 2017), http://www.thespacereview .com/article/3156/1 (arguing for enhanced international cooperation in removing space debris); Tracking Trash in Space Requires Global Cooperation, CipHer BrIEF (Aug. 25, 2017), https://www.thecipherbrief .com/tracking-trash-space-requires-global-cooperation (discussing concepts for removal of debris in interview with Johann-Dietrich Woerner).

135. See Brachet, supra note 71, at 4-6; European Space Agency, supra note 133; Space SecurITY INDEX, supra note 1, at 21; Beard, supra note 1, at 382-83; supra note 56 (discussing IADC guidelines for reducing the creation of space debris).

136. Lee Billings, War in Space May Be Closer Than Ever, SCI. Am. (Aug. 10, 2015), https://www.sci entificamerican.com/article/war-in-space-may-be-closer-than-ever/; see also U.S. DEP'T OF DEF., BudGET Justification: Space Control Technology, Fiscal Year 2004/2005 (2004) (stating that U.S. military policy is to "focus only on negation technologies which have temporary, localized, and reversible effects.”); Betmann, supra note 34 (reporting Gen. Hyten's assertion that the United States would pursue only ASAT capabilities that would not create space debris); Seven Questions: Space Weapons, Part II, ForEIGN PoL'y (Aug. 1, 2005, 12:00 AM), http://www.foreignpolicy.com/articles/2005/07/31/seven_ques tions_space_weapons_part_ii (interview with Lt. Gen. Daniel P. Leaf, vice commander of U.S. Air Force Space Command, who stated, "Our first priority is to use means that are temporary and reversible means").

137. See Pollpeter ET Al., supra note 3, at 17, 88-89 (contending that even before the 2007 test, Chinese analysts preferred non-destructive and temporary ASAT mechanisms to avoid debris and limit escalation of a conflict, but there are still times when a hard kill method is valuable); SPACE SECURITY INDEX, supra note 1 , at 25 (observing that recent ASAT tests by China and Russia have not produced large amounts of space debris, but experts disagree whether this reflects a lasting policy change by those 
other spacefaring states have not yet overtly entered the ASAT race, or they have not clearly defined their technological preferences; perhaps they, too, would recognize the virtues of avoiding the types of tests that could lead to reduced availability of the orbital resources for all. ${ }^{138}$

This aspect of the test-ban regime, therefore, sounds as much in environmental protection as in arms control-it does not, by itself, do much to prevent the development of warfighting ASAT capabilities, but it tries to prevent a bad debris problem from becoming much worse. For states that have invested in selected types of counter-space capabilities, or for states that have not yet committed themselves, a test-ban regime might help channel their efforts in the preferred direction. ${ }^{139}$

\section{Precedents for Test Bans in Arms Control}

Many arms-control agreements have incorporated limitations on testing as a key element in the regime of restrictions. As noted, the Outer Space Treaty bans "the testing of any type of weapons" on the Moon or other celestial bodies. ${ }^{140}$ The 1959 Antarctic Treaty contains a comparable limitation for the southern continent, ${ }^{141}$ and treaties establishing "nuclearweapon-free zones" in selected geographic regions similarly obligate their parties to refrain from nuclear testing. ${ }^{142}$ More pointedly, the 1979 Strategic Arms Limitation Talks ("SALT") II Treaty restricted the United States and the Soviet Union from, inter alia, developing more than one new type of intercontinental ballistic missile each, and it enforced that limitation by allowing each party to conduct flight testing of only one new such weapon. ${ }^{143}$

The most expansive illustration of this principle comes from the realm of nuclear weapons testing, in which a series of both legally-binding and politically-binding agreements has inhibited the conduct of developmental explosions. First, in 1958, both the United States and the Soviet Union undertook voluntary moratoria against test explosions, albeit without ex-

states); Mike Gruss, U.S., China Will Meet This Year to Talk Space Debris, Space News (Sept. 22, 2016), http://spacenews.com/u-s-china-will-meet-this-year-to-talk-space-debris/ (quoting U.S. diplomat as saying that China now takes the problem of space debris "very seriously," and that United States and China have agreed that debris can be catastrophic).

138. Supra text accompanying note 5 (discussing other states interested in ASATs).

139. See Group of Seven [G7], Statement on Non-Proliferation and Disarmament I 61 (Apr. 11, 2017) (calling on all states "to refrain from irresponsible intentional destruction of space objects, including by anti-satellite tests"); Su, supra note 131.

140. OST, supra note 36, art. IV.

141. Antarctic Treaty art. I.1, Dec. 1, 1959, 12 U.S.T. 794, 402 U.N.T.S. 71.

142. See, e.g., Treaty for the Prohibition of Nuclear Weapons in Latin America and the Caribbean art. 1.1(a), Feb. 14, 1967, 634 U.N.T.S. 326 (entered into force Apr. 22, 1968); Graham \& LaVera, supra note 51, at 41-97 (discussing current and proposed nuclear-weapon-free zones); John R. Redick, NuclearWeapon-Free Zones, in ENCYCLOPEDIA, supra note 11, at 1079.

143. Treaty Between the United States of America and the Union of Soviet Socialist Republics on the Limitation of Strategic Offensive Arms art. IV.9, U.S.-U.S.S.R., June 18, 1979, U.S. DeP'T of State, https://www.state.gov/t/isn/5195.htm [hereinafter SALT II] (not in force). 
plicitly defining precisely what activities would, and would not, be suspended, and without specifying the duration of the self-restraint. The interlude persisted for three years (even though France conducted its first nuclear tests in the interval) until it was abruptly shattered by the Soviet Union in 1961; the United States immediately responded with its own vigorous series of explosions. ${ }^{144}$

The 1963 Limited Test Ban Treaty ("LTBT") was the first legally-binding instrument of its type. It was "limited" in the sense of prohibiting tests in the atmosphere, in outer space, and under water, while allowing them to be conducted without restriction in deep underground chambers that would confine the release of hazardous radioactive materials. ${ }^{145}$ Originally negotiated among three states (the United States, the Soviet Union, and the United Kingdom) the treaty was opened for adherence by all others, and it has attracted 125 parties (although not France or China, who have nevertheless both conformed to its restrictions). ${ }^{146}$ The LTBT deserves great credit for staunching the production of strontium-90 and other dangerous radioactive atmospheric pollutants, a boon for global public health. It has also contributed to impeding proliferation and the nuclear arms race by making the explosive testing of new nuclear weapons more expensive and cumbersome, but countries soon found ways to accommodate its restrictions into their testing practices. ${ }^{147}$

For comparison to the world of ASAT testing, it is further noteworthy that some of the relevant states had begun to migrate toward underground nuclear testing even before the LTBT was concluded, in acknowledgment of the emerging global awareness of the environmental hazards of aboveground explosions. ${ }^{148}$ With space weapons, the United States (and perhaps

144. Graham \& LaVera, supra note 51, at 30; Loeb, supra note 126, at 829-32; Nuclear Testing and Comprehensive Test Ban Treaty (CTBT) Timeline, ARMs ConTrol Ass'N, https://www.armscontrol.org/factsheets/Nuclear-Testing-and-Comprehensive-Test-Ban-Treaty-CTBT-Timeline (last visited Nov. 17, 2017); Treaty Banning Nuclear Weapon Tests in the Atmosphere, in Outer Space and Under Water, Narrative, U.S. DeP't State, https://www.state.gov/t/isn/4797.htm (last visited Nov. 17, 2017).

145. LTBT, supra note 114, art. I. This treaty is also sometimes cited as the Partial Test Ban Treaty. See generally James E. Goodby, Hoover Inst., The U.S. Arms Control and Disarmament Agency IN 1961-63 (2017); Loeb, supra note 126, at 833-35; Graham \& LAVERA, supra note 51, at 29-31.

146. See supra note 115 (noting the three "original parties" to the LTBT and the number of parties today).

147. The preamble to the LTBT, reflecting the parties' collective object and purpose in the negotiations, cites both a determination to pursue a comprehensive test ban and a desire to end the contamination of the environment by radioactive substances. LTBT, supra note 114, pmbl. para. 2; TERRENCE R. Fehner \& F.G. Gosling, U.S. Dep't of Energy, Atmospheric Nuclear Weapons Testing, 1951-1963, at 199 (2006) (observing that the LTBT banned atmospheric testing, "but legitimized underground testing" - and made it politically respectable - by avoiding the worst public health controversies); SHALIKASHVILI, supra note 114, at 4 ("Restrictions on nuclear testing have figured prominently in efforts to slow the development and spread of nuclear weapons."); Neidle, supra note 126, at 178 (stressing the LTBT as an important but limited step toward greater constraints on nuclear weapons); Su, supra note 131 , at 60 .

148. Fehner \& GosLING, supra note 147, app. (listing U.S. nuclear tests, showing the transition from atmospheric to underground testing); Nuclear Testing, 1945-Today, PreParatory Commission For Comprehensive Nuclear-Test-Ban Treaty Org. [CTBTO], https:/www.ctbto.org/nuclear-testing/ 
Russia and China) are similarly moving from an emphasis on kinetic interceptors toward a preference for more deft technologies, such as directedenergy systems, in part because of the persistent, indiscriminate environmental harm inflicted by debris-creating events. That transition does not imply that a treaty codifying an agreement to refrain from debris-creating ASAT tests would be superfluous, any more than the LTBT is redundant. Writing the unilateral self-restraint policies into the discipline of law makes a difference, and an affirmative act of treaty-making may draw more states more tightly into the restraint regime.

Subsequently, the two superpowers also found it expedient to conclude two additional, interim test ban treaties on a bilateral basis. The 1974 Threshold Test Ban Treaty ${ }^{149}$ and the 1976 Peaceful Nuclear Explosions Treaty ${ }^{150}$ confined the size of the underground detonations to 150 kiloton yield; they, too, may have inhibited the refinement of the most colossal weapons. ${ }^{151}$

Decades later, the interaction between politically-binding national moratoria against testing and legally-binding treaties played out again, with each device usefully reinforcing the other. The culmination of the step-by-step growth in the constraints was the 1996 Comprehensive Test Ban Treaty ("CTBT"), ${ }^{152}$ which would categorically and permanently prohibit all nuclear explosive testing in any environment. In capping the qualitative improvement in nuclear weapons, the CTBT would establish a most telling restriction; President Bill Clinton referred to it as "the longest-sought, hardest-fought prize in the history of arms control." 153 The CTBT has not yet entered into force, due to not being ratified by several key states, including the United States. ${ }^{154}$ Nonetheless, pending the treaty's implementation, the leading powers have each suspended further testing, pursuant to offi-

history-of-nuclear-testing/nuclear-testing-1945-today/ (last visited Mar. 28, 2018) (noting U.S. underground testing prior to the conclusion of the LTBT, while France and China continued atmospheric testing through the 1970s).

149. Treaty on the Limitation of Underground Nuclear Weapon Tests, U.S.-U.S.S.R., July 3, 1974, 1714 U.N.T.S. 217 [hereinafter TTBT]. The TTBT preamble recalls the LTBT commitment to pursue a comprehensive test ban and notes that the TTBT would contribute to that objective. $I d$. pmbl. paras. $2-3$.

150. Treaty on Underground Nuclear Explosions for Peaceful Purposes, U.S.-U.S.S.R., May 28, 1976, 1714 U.N.T.S. 432.

151. Graham \& LaVera, supra note 51, at 372; Loeb, supra note 126, at 836-37; Neidle, supra note 126, at 179-81, 184 (assessing how much the 150 kiloton ceiling contributed to arms control). In the TTBT, the two parties committed to continuing their negotiations toward a comprehensive test ban treaty. TTBT, supra note 149 , art. I.3.

152. CTBT, supra note 114 .

153. William J. Clinton, President, Remarks by the President to the 52nd Session of U.N. General Assembly (Sept. 22, 1997), https://clinton4.nara.gov/WH/New/html/19970922-20823.html.

154. Pursuant to art. XIV, the CTBT will not enter into force until it has been ratified by all fortyfour states identified by name in the treaty's Annex 2. To date, thirty-six of the required states, and 130 other countries, have ratified the treaty, but the United States, China, India, Pakistan, and some other key players have not. CTBT, supra note 114, art. XIV.1; CTBTO, https://www.ctbto.org/ (last visited Nov. 17, 2017). 
cially declared national moratoria or tacit practice. ${ }^{155}$ The United States has not conducted any nuclear tests since 1992; Russia has been similarly inactive since 1990. ${ }^{156}$ Even though the treaty has lingered for more than two decades without entering into force, many speculate that, with the exception of rogue North Korea, the era of nuclear testing is, de facto, finished, unless some very major, unforeseen adverse circumstance intervenes. ${ }^{157}$

Again, this chain of precedents does not guarantee future success in the very different sphere of outer space. But it is nonetheless instructive to note that from unpretentious beginnings - a temporary, non-legally-binding suspension of nuclear testing by only some of the affected states-has grown a much more robust regime. Moreover, some of the incremental steps toward a complete test ban regime were quite humble; some contributed as much to environmental protection as to arms control. Even more, the process has consumed six decades, and the culminating step-the entry into force of the CTBT-has not yet been achieved, but the illustration of the value of a test ban is impressive.

\section{Cooperative Space Situational Awareness}

The Article's third proposal is of a different character and somewhat harder to explain. In a nutshell, the hypothesis is that spacefaring countries should unite to pool their resources in monitoring outer space and sharing the data about the location, trajectory, and attributes of space objects. This enhanced "space situational awareness" ("SSA") would enable all interested states to use space more effectively by avoiding collisions and by clarifying the nature of untoward events, and it could also form the basis of a verification regime to support the two previous measures.

155. See 1994-96, Debating the Basic Issues, CTBTO, https://www.ctbto.org/the-treaty/1993-1996treaty-negotiations/1994-96-debating-the-basic-issues/ (last visited Nov. 17, 2017) (recounting that the CTBT does not define a nuclear weapon "test," so controversy continued about the legitimacy of various "subcritical" experiments and "stockpile stewardship" programs).

156. Nuclear Testing 1945-Today, supra note 148 (also identifying the last nuclear tests by United Kingdom (1991), France (1996), China (1996), India (1998), and Pakistan (1998)). The leading countries have also affirmed that a nuclear weapon test by a CTBT signatory would violate international law as an act that would "defeat the object and purpose" of the treaty. S.C. Res. 2310, ๆ 4 (Sept. 23, 2016); Joint Statement on the Comprehensive Nuclear Test-Ban Treaty by China, France, the Russian Federation, the United Kingdom, and the United States (Sept. 15, 2016), https://newsroom.ctbto.org/2016/09/ 16/joint-statement-on-the-comprehensive-nuclear-test-ban-treaty-by-the-nuclear-nonproliferationtreaty-nuclear-weapon-states/; see also Vienna Convention on the Law of Treaties art. 18, May 23, 1969, 1155 U.N.T.S. 331.

157. Lassina Zerbo, The Challenges to Ratifying the CTBT-Can the No-Test Norm Be Maintained Indefinitely?, European LeAdership NeTwOrK (Sept. 10, 2013), http://www.europeanleadershipnetwork .org/the-challenges-to-ratifying-the-ctbt_can-the-no-test-norm-be-maintained-indefinitely_777.html [https://web.archive.org/web/20170314020141/http://www.europeanleadershipnetwork.org/the-challenges-to-ratifying-the-ctbt_can-the-no-test-norm-be-maintained-indefinitely_777.html]. 


\section{A. The SSA Proposal and Its Variations}

Some additional background is necessary in order to help frame this proposal. Space situational awareness refers to the ability to know what is going on in outer space: what space objects (both human-made and natural) are out there, where they are, where they are headed, what their approximate size and composition are, and to some extent what their capabilities, activities, and inherent nature might be. ${ }^{158}$

A wide variety of globally-distributed instruments and routines contributes to the SSA mission. Most notable is the dispersed U.S. array of groundbased optical telescopes, lasers, different genres of radar systems, and other sensors that regularly scan the skies for distant travelers; it incorporates eight dedicated and eighteen multi-mission establishments. Space-based sensors, too, persistently observe various altitudes and orbital inclinations. Altogether, the United States blends some 375 sensors and systems, drawing upon private as well as public sources. ${ }^{159}$

The United States has long maintained the world's best capability for monitoring space, and it is continuously improving the network-at a cost of approximately $\$ 1$ billion per year. The current upgrade effort, designated as erecting an enhanced "space fence," is intended to observe even quite small, obscure, and remote space traffic-reportedly, it will enhance the current observational power by ten times. The U.S. sensor grid is unusually farflung; it receives (or will soon receive) input from facilities in Australia, the Marshall Islands, the Indian Ocean, and elsewhere. ${ }^{160}$ The current system is generally capable of detecting objects larger than ten centimeters in diameter, depending upon the item's altitude and reflectivity. ${ }^{161}$ In 2016, the United States lofted two new sensors into the geosynchronous orbit, in order

158. Emily Nightingale et al., Evaluating Options for Civil Space Situational AwareNESS (SSA) 11-13 (IDA Paper NS P-8038, 2016); NRC RePort, supra note 1, at 39-40; SpACE SeCURITY INDEX, supra note 1, at 38 (defining SSA as "the ability to detect, track, identify, and catalog objects in outer space . . . ; observe space weather and [threatening near-Earth objects]; and monitor spacecraft and payloads for maneuvers and other events"); Brian WeEden, SECURE World Found., SPACE SituAtional Awareness Fact Sheet (2017); Stefan A. Kaiser, Legal and Policy Aspects of Space Situational Awareness, 31 Space Pol'y 5, 6 (2012); Brian Weeden et al., Global Space Situational Awareness Sensors, 2010 Proc. Advanced Maui Optical \& Space Surveillance Tech. Conf.

159. U.S. Gov't Accountability Office, Space Situational Awareness: Status of Efforts and Planned Budgets (2015) [hereinafter GAO]; Hitchens \& Johnson-Freese, supra note 1, at 33-37; Space Security Index, supra note 1, at 40; WeEden, supra note 158; Kaiser, supra note 158, at 7-9; Weeden et al., supra note 158, at 3-9.

160. GAO, supra note 159; Hitchens \& Johnson-FreEse, supra note 1, at 49; LAMBAKIs, supra note 5, at 45-47; SPACE SECURITY INDEX, supra note 1, at 12 (noting that the U.S. SSA capability is "far in advance of the rest of the world"), 40, 42 (describing the Space Fence, expected to be fully operational in December 2018, bringing greatly augmented observation power); WEEDEN, supra note 158; Weeden et al., supra note 158; Betmann, supra note 34.

161. SPACE SECURITY INDEX, supra note 1, at 19, 20 (commenting that because of the great distance to the geosynchronous orbit, an object there would usually have to be one meter in size to be detected currently). 
to provide more proximate and detailed watchfulness over that precious zone. ${ }^{162}$

The U.S. SSA network has identified an inventory of some 23,000 space objects and has catalogued over 17,000 of them. ${ }^{163}$ But many orbital items are so small as to remain essentially invisible; experts estimate that there are some 500,000 additional uncontrolled objects in space between one and ten centimeters in diameter and untold scores of millions smaller than that (but still capable of inflicting serious harm on a satellite in a collision). ${ }^{164}$

The United States disseminates much of its SSA data, in order to help satellite operators minimize interference, understand satellite anomalies, and avoid collisions. Sixty-three data-sharing agreements are already in place with foreign countries, international organizations, and commercial operations in several nations. ${ }^{165}$ In 2014 alone, the U.S. system provided 671,727 warnings to satellite managers about possible collisions, resulting in 120 avoidance maneuvers. ${ }^{166}$ The International Space Station, for example, conducted four sudden orbital adjustments in 2015, to dodge human-created space debris. ${ }^{167}$

Some space actors do not want to rely upon an SSA apparatus that is owned and controlled exclusively by the U.S. government, ${ }^{168}$ and they have pursued independent capabilities. ${ }^{169}$ Russia has the world's second-largest capacity, cataloging some 5000 space objects, and has announced plans to upgrade the system via deployment of ten next-generation ground sta-

162. LAMBAKIS, supra note 5, at 45-47; SPACE SECURITY INDEX, supra note 1, at 41, 42 (noting that the United States had also previously launched two new satellites into the geosynchronous orbit in 2014, in order to improve SSA there); Betmann, supra note 18; Mike Gruss, Space Surveillance Sats Pressed into Early Service, SPACE NEws (Sept. 18, 2015), http://spacenews.com/space-surveillance-sats-pressed-intoearly-service/; see also NigHTINGALE ET AL., supra note 158, at 5-7 (discussing the possibility of shifting to a civilian agency some of the functions currently performed by the U.S. military for maintaining the public catalog of space objects and for warning satellite operators about possible collisions).

163. Space Security Index, supra note 1, at 19, 23; Satellite Box Score, Orbital Debris Q. News, Aug. 2017, at 12 (listing 4,495 active payloads and 14,145 pieces of debris in space).

164. European Space Agency, supra note 133, at 2 (estimating 750,000 pieces of debris between one and ten centimeters in size and 166,000,000 smaller than that); SPACE SECURITY INDEx, supra note 1 , at 19,23 .

165. U.S. Dep't of Def., supra note 24, 9 4.j(1); Tiffany Chow, Secure World Found., Space Situational Awareness Sharing Program 1-18 (2011); Hitchens \& Johnson-Freese, supra note 1, at 17, 33-37; Nightingale ET AL., supra note 158, at 20-22; Space SECURITY IndeX, supra note 1, at 43; Beard, supra note 1, at 387; Frank A. Rose, Assistant Sec'y of State, Bureau of Arms Control, Verification and Compliance, Remarks at the Advanced Maui Optical and Space Surveillance Technologies Conference: Strengthening International Cooperation in Space Situational Awareness (Sept. 22, 2016), https://2009-2017.state.gov/t/avc/rls/262502.htm.

166. European Space AgEnCy, supra note 133, at 8 (reporting that the European Space Agency undertakes an average of twelve collision avoidance maneuvers annually); GAO, supra note 159, at 23; Nightingale ET AL., supra note 158, at 3; Space SeCurity InDeX, supra note 1, at 40.

167. Space Security Index, supra note 1 , at 24.

168. Hitchens \& Johnson-Freese, supra note 1, at 35-36; Charles Phillips, Time for Common Sense with the Satellite Catalog, SpACE Rev. (Apr. 10, 2017), http://www.thespacereview.com/article/3215/1 (explaining that the U.S. Air Force entity that maintains the satellite catalog used to be the Joint Space Operations Center; it has been redesignated as the 18th Space Control Squadron).

169. Hitchens \& Johnson-Freese, supra note 1, at 35-36; IDA, supra note 1, at 8.1-8.3. 
tions. ${ }^{170}$ The European Union and the European Space Agency have a limited but growing SSA capability, and China, India, and Canada have devoted increased resources to this effort, as well. ${ }^{171}$

The private sector, too, has invested in SSA mechanisms-part of what some observers label "the democratization of space" - and it is official U.S. policy to try to incorporate this commercial input into the governmental system. ${ }^{172}$ Space Data Association, founded by major commercial satellite operators, has become a focal point for sharing information about members' satellite positions, and additional entrepreneurs have undertaken to provide independent, timely, non-discriminatory data. ${ }^{173}$ Likewise, zealous amateur astronomers, university observatories, and other space enthusiasts comb the heavens and report their findings. ${ }^{174}$

This growing-and somewhat overlapping and redundant-investment in synoptic SSA capabilities provides multiple benefits. First, greater sensitivity can provide enhanced warning about possible collisions, which have already begun to plague space actors. ${ }^{175}$ Just as important, improved intelligence-gathering can reduce the frequency of false alarms, mitigating the number of occasions on which a satellite is forced to undertake an expensive, and ultimately unnecessary, evasion maneuver. ${ }^{176}$

More ominously, if something does go wrong with a satellite, SSA systems can help diagnose the cause. A sudden interruption in satellite functioning could be triggered by an internal malfunction, a collision with an undetected piece of natural space material, an accidental impact with another human-created object, or a deliberate attack by an enemy. Obviously,

170. Space Security Index, supra note 1, at 41, 44; WeEden, supra note 158; Weeden, et al., supra note 158 , at $5-6$.

171. European Space Agency, supra note 133; Pellegrino \& Stang, supra note 59, at 45-48; Space SeCurity Index, supra note 1, at 40, 45; Weeden et al., supra note 158, at 5-6; Victor Robert Lee, China Builds Space-Monitoring Base in the Americas, Diplomat (May 24, 2016), https://thediplomat .com/2016/05/china-builds-space-monitoring-base-in-the-americas/ (describing China's new space tracking facility in Argentina).

172. Hitchens \& Johnson-Freese, supra note 1, at 17, 34-36; IDA, supra note 1, at 8.1-8.3; The White House, supra note 73, at 7; Nightingale ET AL., supra note 158, at 26-28; Weeden, supra note 158; Beard, supra note 1, at 387-88; Dave Baiocchi \& William Welser IV, The Democratization of Space, Foreign AfF. (Apr. 20, 2015), https://www.foreignaffairs.com/articles/space/2015-04-20/democratization-space; Phillips, supra note 168 , at 3.

173. Space SeCURITY Index, supra note 1 , at 41, 43-44.

174. WeEden, supra note 158; Charles Phillips, Acknowledging Some Overlooked Satellites, SpaCE REv. (June 12, 2017), http://www.thespacereview.com/article/3259/1.

175. Space SeCurity INDEX, supra note 1, at 21 (listing major collisions between two spacecrafts, or between a spacecraft and human-caused space debris); COMM. FOR AsSESSMENT OF NASA's OrBITAL Debris Programs, Nat'l Research Council, Limiting Future Collision Risk to Spacecraft (2011), http://www.nap.edu/catalog.php?record_id $=13244$.

176. See Space Security Index, supra note 1, at 24 (noting that the International Space Station has undertaken twenty-five collision avoidance maneuvers since 1998; when the warning signal arrives too late for the station to maneuver, the crew has "sheltered in place" in an attached spacecraft that could be used for an emergency evacuation). 
the appropriate response would be quite different in the distinct scenarios, and it can be quite difficult to gauge the source and motivation remotely. ${ }^{177}$

Improved SSA can help identify the true nature of an incident and attribute its cause, enabling a condign response. If responsibility can be reliably assigned to another human agent-whether the explanation sounded in negligence or intention-legal liability can follow. That type of accountability and damage assessment can deter both sloppy and aggressive behavior, which inadequate SSA might otherwise mask. ${ }^{178}$

At the same time, it should be noted that there are costs to improved SSA, too. The United States and other countries conduct some "black" satellite operations, in which they intend that the location, orbital path, and functions - or even the mere existence-of the vehicle remain secret. The public U.S. satellite inventory, for example, does not include selected intelligence-gathering objects, and conjunction warnings are not issued about them. ${ }^{179}$ That covertness is more difficult to maintain when diverse SSA sources proliferate. Already, the satellite inventories made public by some states reveal data that others attempt to restrict, and even amateur astronomers are able to detect, track, and identify some classified systems - the race between the "hiders" and the "seekers" becomes more one-sided as SSA capabilities expand. ${ }^{180}$

As a final introductory point, it should be observed that the challenge of improving SSA, or even maintaining its current level, is likely to increase in the near future. Rapid technological change, in the form of "ultra low cost access to space" (that is, much less expensive mechanisms for launching satellites, pioneered by philanthrocapitalists and strategic investors) and miniaturized "cubesats" (that is, constellations consisting of hundreds or thousands of very small, unmaneuverable orbiters) will confound the

177. SpaCe SECURITY InDEX, supra note 1, at 12, 33-36 (discussing natural environmental hazards in space), 39 (discussing the importance of differentiating technical malfunctions, natural disruptions, and space negation attacks).

178. Note that under the Liability Convention, supra note 45, arts. II-III, a state that launches a satellite is obligated to pay compensation if its satellite causes damage on the surface of the Earth or to an aircraft (absolute liability) or causes damage to another satellite (for fault). But the victim must establish the national identity of the spacecraft that caused the damage, and acquiring that type of evidence can be difficult. Krepon, supra note 26, at 15, 28.

179. Space SeCURITy Index, supra note 1, at 40, 43; Phillips, supra note 168 , at 1 (asserting that the U.S. government "has excellent reasons for hiding the missions of certain satellites"); Brian Weeden, Time for the U.S. Military to Let Go of the Civil Space Situational Awareness Mission, Space News (Sept. 12, 2016), http://spacenews.com/time-for-the-u-s-military-to-let-go-of-the-civil-space-situational-awarenessmission/.

180. Phillips, supra note 168 , at 3 (discussing non-governmental satellite tracking systems, including those operated by commercial firms and amateurs); Russia to Reveal Location of US Military Satellites in Free Space Database-Report, RT (June 22, 2016), https:/www.rt.com/news/3477444-russia-satellites-databasenorad/ (observing that countries do not always maintain secrecy about each other's military satellites); Weeden, supra note 18 (noting that hobbyist astronomers are able to track a U.S. military satellite not included in the publicly-released governmental catalog). Also note the offensive aspect of SSA: improved knowledge about the location, trajectory, and nature of another country's satellites enhances the ability to attack those spacecraft; SSA can be used for aggressive as well as defensive purposes. 
monitors. There will soon be much more traffic in space-by one count, 3800 new satellites by 2020 — some of it very hard to identify and track. ${ }^{181}$

With that background, the proposal for enhanced international SSA now appears. The suggestion here is that countries would freely contribute equipment, data, and expertise to a shared global mechanism for monitoring space and broadly reporting the results. The apparatus would be more capable than any one country could achieve on its own, since it would draw upon the amalgamated resources from all over the world and assemble the best equipment and talent to process and disseminate the acquired data. Presumably, the United States, China, and Russia, as the predominant space actors, would take the lead in developing, outfitting, and staffing the consortium, but other states would be expected to contribute, too. The system would include space-based and ground-based sensors, together with rapid communications links and central processing, to ensure timely, global, and persistent observation of all orbital regions. The scheme would attempt to record and publicize "ephemeris data" (information about the current and predicted location) of all operational and defunct space craft and significant debris, as well as whatever information can be gleaned about the satellite's characteristics (for example, size, shape, and composition). ${ }^{182}$

Perhaps there would be international quality-control criteria applicable to qualify the radars and other sensors, and they would probably have to be standardized to report their data in a common format, and to ensure the accuracy, authenticity, and timeliness of the information. Negotiated international quotas could lead to equitable sharing of the responsibility and the costs, with each participating state accepting its portion of the burden. Perhaps some states or organizations would voluntarily commit additional resources as necessary to complement the system's other assets and to plug any perceived gaps in coverage. The ground-based and space-based collecting

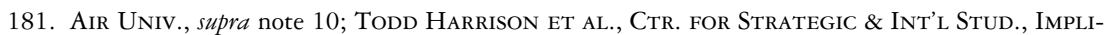
Cations of Ultra-Low-Cost Access to Space (2017); Nightingale et al., supra note 158, at 3 (citing one estimate that the number of near collisions in space will rise by a factor of seventy); Sean Cate \& Jesse Sloman, Operating Under Constant Surveillance, U.S. NAval Inst. Proc. Mag., May 2016, https:// www.usni.org/magazines/proceedings/2016-05/operating-under-constant-surveillance; Brian Weeden, Insight: Small Satellites and Space Situational Awareness, SEcure World Found. (Sept. 1, 2016), https:// swfound.org/news/all-news/2016/09/insight-small-satellites-and-space-situational-awareness (last updated Nov. 3, 2016) (estimating 3800 new satellites by 2020, which would almost quadruple the existing population). See generally Daniel Querejazu \& Lucien Randazzese, CTr. For Strategic \& Int'l Studies, Small Satellites, Big Missions: The Implications of the Growing Small Satellite Market for Launch and Key Applications (2017); Ting Wang, A Liability and Insurance Regime for Space Debris Mitigation, 24 SCI. \& Global SECurity 22 (2016) (assessing the challenge of microsatellites); Vedda \& Hays, supra note 20, at 9 (noting numerous plans for even larger satellite constellations).

182. Hitchens \& Johnson-Freese, supra note 1, at 36 (discussing proposals for collaborative SSA); SPACE SECURITY INDEX, supra note 1, at 40 (assessing that "a complete picture of the space environment and of activities in space is beyond the capability of any single actor at present," because complete SSA requires a global network of sensors and data sharing with satellite operators); Kaiser, supra note 158, at 7 (assessing that accuracy, comprehensiveness, and reliability of SSA can be assured only by pooling data from a wide range of sensors). 
stations might be financed and owned by individual states, private actors, or a new global organization. Some of the sensors might be designated to report all their data immediately and automatically, while others could be on tap on an as-needed basis. ${ }^{183}$

A new international data-fusion and -analysis center would be created to receive, process, interpret, and distribute the information. This could be an expensive undertaking, requiring contributions of top-level computer capabilities, human talent, and other resources. This center would have an international personality, not within the control of any one state or coalition. ${ }^{184}$

In principle, this contemplated system could be crafted simply by states undertaking mutually aligned, non-legally-binding behaviors, but the overall scheme does contemplate a degree of permanence, as well as a substantial and sustained financial investment. The plan would be more firmly grounded in a new treaty, creating responsibility for a shared "neighborhood watch" program in space, and embracing the enduring commitment and precise documentation, together with the elaboration of the status, privileges, and immunities of a new international organization. ${ }^{185}$

Some participating states may decide to continue to maintain, at least for a period of time, their own independent national SSA routines as an autonomous back-up check on, or supplement to, the international mechanism. ${ }^{186}$ But others might conclude that redundant fallbacks are unnecessarily expensive, and they could rely exclusively on the global collection and analysis.

183. Kaiser, supra note 158 , at 8 (discussing different levels of cooperation in SSA); Baiocchi \& Welser, supra note 172 (saying that it is time to centralize SSA data in one location, requiring governments to agree on policies and technologies for data sharing); Rose, supra note 65 (calling for enhanced international cooperation in SSA).

184. Cf. Hugh Chalmers \& Angela Woodward, Monitoring Space, 152 Trust \& Verify 7,7 (2016) ("It is timely for the international community to explore the desirability and feasibility of developing a multilaterally designed, constructed, and operated space-to-space surveillance and tracking system.”); Jasani, supra note 17, at 21 (suggesting the establishment of an International Data Centre to collect information about space objects' shapes, sizes, orbits, etc.); Comm. on the Peaceful Uses of Outer Space, Considerations on the Set of Prime Requirements and Factors That Should Shape the Policy of the International Information-Sharing Serving Safety of Space Operations, U.N. Doc. A/AC.105/L.303 (Mar. 16, 2016) (Russian proposal for additional international sharing of data regarding satellites).

185. It would also be desirable for a treaty establishing the global SSA program to address the question of immunity from legal liability, as the United States has done via statute, 10 U.S.C. $§ 2274(\mathrm{~g})$ (2016)

186. For comparison, in the realm of nuclear test monitoring, the United States maintains and continuously upgrades its own Atomic Energy Detection System, consisting of 3600 sensors distributed worldwide, supported by 1000 personnel, as an independent supplement to the CTBT verification system, see infra text accompanying notes 199-202. See also Air Force Technical Applications Center, 25TH AIR ForCE (Aug. 30, 2017), http://www.25af.af.mil/About-Us/Fact-Sheets/Display/Article/333995/air-force-technical-applications-center/; John Pike, AFTAC Introduction, FED'N AM. ScIENTISTs, http:/www.fas.org/irp/ agency/aftac/intro.htm [https://web.archive.org/web/20090107234719/http:/www.fas.org/irp/agency/ aftac/intro.htm]. In addition, the U.S. Global Seismographic Network includes 150 dispersed seismic monitoring stations. GSN_Global Seismographic Network, U.S. GeologICAL SuRV., https:/earthquake.usgs.gov/monitoring/gsn/ (last visited Apr. 3, 2018); see also SHALIKASHVILI, supra note 114, at 7 (discussing how the Atomic Energy Detection System will continue to operate in parallel with the CTBT's multilateral monitoring system). 


\section{B. What an SSA Agreement Could, and Could Not, Accomplish}

Notably, this proposal does not physically prevent a state from undertaking unfriendly or destructive behaviors in outer space, nor does it define additional offenses against the public order of outer space. Instead, by penetrating the cloak of invisibility that currently obscures some remote activities, enhanced global SSA would simply make it harder for a bad actor to get away with those adverse practices in secret. It relies upon greater transparency to elicit better behavior, since states would have less expectation of impunity. ${ }^{187}$ Moreover, the program might be capable of providing a degree of "early warning" about emerging threatening behaviors via observation of nascent or ambiguous activities, and it could provide internationally-accepted documentary evidence of countries' space activities, helping to satisfy global standards of objective proof.

An upgraded SSA capability could also provide spin-off benefits in enhancing awareness of space weather and related phenomena. These applications would be largely collateral to the system's security goals, but they could be quite valuable on a day-to-day basis in supporting satellite operations. ${ }^{188}$

Of course, even a greatly improved global observation capacity would still be imperfect, with enduring gaps in coverage; some unwelcome space acts could still proceed unseen. Moreover, in many cases, even an exquisite array of sensors and processors would generate only ambiguous data, susceptible to competing interpretations and explanations. Accordingly, the proposal cannot promise to resolve all potential ASAT controversies.

\section{Precedents for Shared SSA in Arms Control}

There are a great many at least partial precedents for this concept of shared monitoring in support of an arms-control agreement. Several treaties embrace some version of cooperative verification, through which participants collaborate in collecting and synthesizing relevant information. ${ }^{189}$ As a more general matter, outer space, in particular, has been a venue in which state-to-state cooperative ventures (and, for that matter, collaborations between public and private sector entities) have been spectacularly successful; ${ }^{190}$ perhaps those patterns could now be extrapolated.

187. Nayak, supra note 4 (stressing the value of a greater ability to detect hostile action in space).

188. Nat'l Sci. \& Tech. Council, National Space Weather Strategy (Oct. 2015).

189. See Eisenhower Ctr. for Space \& Def. Stud., supra note 51, at 63-64 (presenting a typology of arms-control verification regimes).

190. See Space Security Index, supra note 1, at 64-69, 90, 108 (discussing international cooperation as a "defining feature" of civil space activities, from the Apollo-Soyuz program to the International Space Station and noting numerous strategic partnerships between the United States and other countries on space exploration and exploitation). 
Familiar arms-control treaty tactics include data exchanges, ${ }^{191}$ on-site inspection, ${ }^{192}$ and the inauguration of new international organizations. ${ }^{193}$ Some treaties explicitly authorize the use of "national technical means" of verification (for example, satellite reconnaissance), accompanied by a prohibition upon interference with those operations or deliberate concealment of relevant activities. ${ }^{194}$ Other treaties authorize "multinational technical means" (joint verification enterprises of various sorts). ${ }^{195}$ Under the 1992 Open Skies Treaty, ${ }^{196}$ parties throughout Europe and North America have agreed to allow each other to overfly their sovereign territory with aircraft equipped with a suite of photographic, radar, and other sensors, to detect military-related sites and activities, and to do so on short notice and with few exclusions. ${ }^{197}$

A recurrent vision of an "International Satellite Monitoring Agency" has long animated dialog, as a vehicle for ensuring that all states-not only those that can afford the most elaborate space resources-could participate in remote sensing of specified terrestrial weapons-related activities. However, no such institution has yet been created. ${ }^{198}$

The best illustration of the concept, however, comes from the CTBT, for which an impressive International Monitoring System ("IMS") has been

191. See, e.g., Treaty Between the United States of America and the Union of Soviet Socialist Republics on the Elimination of Their Intermediate-Range and Shorter-Range Missiles, U.S.-U.S.S.R., Dec. 8, 1987, Memorandum of Understanding Regarding the Establishment of the Data Base for the Treaty, 1657 U.N.T.S. 1, SALT II Treaty, supra note 143, Memorandum of Understanding Regarding the Establishment of a Data Base on the Numbers of Strategic Offensive Arms.

192. See, e.g., CTBT, supra note 114, art. IV.D, Protocol, Part II; Antarctic Treaty, supra note 141, art. VII; CWC, supra note 97, art. IX.

193. See, e.g., CTBT, supra note 114, art. II; CWC, supra note 97, art. VIII; Treaty on the Limitation of Anti-Ballistic Missile Systems, U.S.-U.S.S.R., Common Understanding Regarding the Establishment of a Standing Consultative Commission, May 26, 1972, 23 U.S.T. 3435, 944 U.N.T.S. 13 (entered into force Oct. 3, 1972, no longer in force) [hereinafter ABM Treaty], Memorandum of Understanding Regarding the Establishment of a Standing Consultative Commission.

194. Treaty on the Reduction and Limitation of Strategic Offensive Arms, U.S.-U.S.S.R., art. IX, July 31, 1991, S. Treaty Doc. No. 102-20 [hereinafter START I Treaty]; see, e.g., ABM Treaty, supra note 193 , art. XII.

195. See, e.g., CTBT, supra note 114, art. IV (not using the term "multinational technical means," but containing similar provisions); Treaty on Conventional Armed Forces in Europe art. XV, Nov. 19, 1990, 30 I.L.M. 1 [hereinafter Conventional Forces in Europe Treaty or CFE Treaty] (entered into force July 17, 1992).

196. See generally Treaty on Open Skies, Mar. 24, 1992, S. Treaty Doc. No. 102-37 (1992).

197. See Graham \& LaVera, supra note 51, at 822; Amy Woolf, Cong. Res. Serv., The Open Skies Treaty (Aug. 10, 2017), https://fas.org/sgp/crs/nuke/IN10502.pdf; Treaty on Open Skies, U.S. DeP'T of STATE, https://www.state.gov/t/avc/cca/os/ (last visited Nov. 16, 2017).

198. See generally U.N. Secretary-General, Dep't. for Disarmament Affairs, The Implications of Establishing an International Satellite Monitoring Agency, U.N. Doc. A/AC.206/14 (Mar. 1983); U.N. Secretary-General, International Cooperation in Space Activities for Enhancing Security in the Post-Cold War Era, U.N. Doc. A/48/221 (July 1, 1993), http://www.un.org/events/unispace3/docs/sgrep.htm; A. Walter Dorn, Peacekeeping Satellites: The Case for International Surveillance and Verification, WALTER DoRN, http:// walterdorn.net/19-peacekeeping-satellites-the-case-for-international-surveillance-and-verification (last visited Apr. 3, 2018). 
elaborately crafted, even prior to that treaty's entry into force. ${ }^{199}$ When completed, the network will consist of 337 stations and laboratories, located in eighty-nine countries. ${ }^{200}$ The network exploits four complementary technologies to gather information about possible clandestine nuclear explosions on the land, under water, in the atmosphere, and in outer space. ${ }^{201}$ Data are transmitted via a dedicated satellite-based Global Communications Infrastructure to the International Data Centre in Vienna, Austria. ${ }^{202}$

The IMS stations must be certified as meeting state-of-the-art international standards. Construction and operational costs are usually borne by the CTBT's international organization, and the stations are operated by local institutions under contract. ${ }^{203}$

The International Data Centre processes and analyzes the incoming data streams, compiling bulletins about relevant events and swiftly and securely transmitting the information to states. ${ }^{204}$ The process has been operational since 2000 , and it has served to validate the capability of the system to detect, locate, and characterize events of concern, such as the North Korean nuclear tests. ${ }^{205}$

In addition, the IMS has provided additional value, in scientific research, and in detecting undersea earthquakes that could trigger dangerous tsunamis. This mechanism has enabled immediate warning to affected Pacific Rim countries and communities, saving countless lives. ${ }^{206}$ This spin-off benefit is perhaps analogous to the way an enhanced satellite monitoring system

199. Verification Regime, Preparatory Comm'n for the Comprehensive Nuclear-Test-Ban Treaty OrG., https://www.ctbto.org/verification-regime/ (last visited Nov. 16, 2017).

200. CTBTO, supra note 154 (noting 289 stations are currently operational and certified; the remainder are in the process of being certified, constructed, or planned); Overview of the Verification Regime, CTBTO, https://www.ctbto.org/verification-regime/background/overview-of-the-verification-regime/ (last visited Nov. 16, 2017) (monitoring stations in eighty-nine countries will contribute data).

201. Overview of the Verification Regime, supra note 200 (explaining that the CTBT International Monitoring System uses four complementary verification methods: seismic (to monitor underground events), hydroacoustic (oceanic), infrasound (atmospheric), and radionuclide (to detect radioactive debris)).

202. Global Communications Infrastructure, CTBTO, https://www.ctbto.org/verification-regime/theglobal-communications-infrastructure/page-1-gci/ (last visited Nov. 16, 2017).

203. Overview of the Verification Regime, supra note 200 (explaining that the building and operational costs are usually borne by the CTBTO, and stations are operated by local institutions under contract to the CTBTO).

204. Distribution of Data and Data Bulletins to Member States, CTBTO, https://www.ctbto.org/ ?id=1296 (last visited Nov. 16, 2017); History of the International Data Centre, CTBTO, https://www .ctbto.org/verification-regime/the-international-data-centre/history-of-theinternational-data-centre/ (last visited Nov. 16, 2017); Operations Centre and Computer Centre, CTBTO, https://www.ctbto.org/verification-regime/the-international-data-centre/operations-centreand-computer-centre/ (last visited Nov. 16, 2017).

205. DPRK Nuclear Tests, CTBTO, https://www.ctbto.org/the-treaty/developments-after-1996/2017sept-dprk/ (last visited Nov. 16, 2017).

206. Spin-Offs for Disaster Warning and Science, CTBTO, https://www.ctbto.org/verification-regime/ spin-offs-for-disaster-warning-and-science/ (last visited Nov. 16, 2017); The March 11 Japan Disaster, CTBTO, https://www.ctbto.org/verification-regime/the-11-march-japan-disaster/ (last visited Nov. 16, 2017). 
could contribute to global safety by flashing warnings about imminent satellite collisions or natural space hazards.

\section{CONCLUSION}

As emphasized throughout the analysis, this Article's three proposals are hardly revolutionary; they cannot be promoted as a true "problem-solving" approach, because even in concert they would be insufficient to completely redress the emerging security dilemmas regarding outer space. Many, no doubt, would prefer a more ambitious avenue, reasoning that if we are going to undertake the heavy lifting necessary to overcome the institutionalized resistance to any measures of arms control in space, we should aim for a bigger payoff. ${ }^{207}$

The Article presents its three proposals independently, for separate analysis and consideration, but there may also be noteworthy synergies among them. For example, if space situational awareness were to be enhanced via international sharing of data and resources (the third recommendation), it may become easier to verify states' compliance with a limited test ban (the second suggestion). Reciprocally, an effective test ban would help retard the generation of still more space debris, which should facilitate the task of monitoring the material that is already in orbit. Likewise, if the proffered no first use regime (the first concept) were in place, it might enhance confidence in states' benign intentions in space, paving the way for the other more ambitious, operational measures.

Still, a first step is needed, and the hope here is that modest but savvy incremental measures, especially when so firmly rooted in the successful precedents of arms control in other areas, can attract political support and catalyze subsequent enhancements.

Certainly, something needs to be done. The surging threats to the stability and security of the inherited space regime have brought us to an inflection point, and the United States has the most to lose from a deterioration in the usability and reliability of satellite resources. Even if American ingenuity and economic muscle could "win" an arms race in space, such competition would only propel the world more vigorously in a direction we do not want to go. A planet bristling with advanced counter-space capabilities in three or more states would be precarious, indeed, and perennial notions of deterrence would provide only weak assurance. Because of the current, and likely future, asymmetry in the exploitation of space-as the United States civilian economy and military forces continue to rely on satellites more heavily than our rivals do-the exposure and vulnerability are asymmetric, too. The constellation of policy objectives now should include efforts to re-

207. See Johnson-Freese, supra note 1, at 170 (discussing a potential "grand space bargain" to resolve several problematic issues simultaneously). 
duce and refine the offensive capabilities of our potential adversaries-and arms control offers the surest mechanism. A regime of reciprocal restraint from the pursuit of ASAT capabilities would both play to long-term U.S. strengths and promote a more durable international regime for all. ${ }^{208}$

Persistent diplomatic failures make it difficult to plot a course for success in space arms control. The Outer Space Treaty remains vital, but its few specific military-related provisions are old, barebones, and permissive. 209 The European Union's bland proffered Code of Conduct and the Russia-China tender of a loophole-laden PPWT have both conspicuously failed; the Conference on Disarmament has degenerated; and the general deterioration in global political relations makes this a tough time for reasoned measures of international arms restraint. ${ }^{210}$

Still, arms control has managed to flourish during tough times beforeindeed, many of the accords noted above were concluded during the darkest days of the Cold War-and it is precisely during the stressful epochs that diplomatic ingenuity is most necessary. ${ }^{211}$ Notably, going back to the Apollo-Soyuz mission in 1975, outer space has been especially valuable as a vehicle for continued cooperation, even when other modes are politically constricted. Some shreds of this "space exceptionalism" linger today, even in the midst of current U.S.-Russian antagonism. Perhaps humble measures designed to pursue mutual interests in preserving the utility of the space

208. ColBY, supra note 1 , at 17 ("[B]ecause some degree of vulnerability in space appears to be inevitable and because the United States is near certain to need to continue relying on space, the United States must find ways to protect its equities in space at least in part by persuading its adversaries not to exploit those vulnerabilities. More precisely, the United States needs to find ways to induce, convince, coerce, deter, dissuade, coax, incentivize, or otherwise persuade potential adversaries that can threaten U.S. space assets not to act on that ability or to limit the extent to which they do."); Krepon, supra note 26, at 38 (arguing for reassurance based on reciprocal restraint, rather than solely relying upon deterrence in space).

209. Hansel, supra note 54, at 91.

210. See Olga Oliker, U.S.-Russian Arms Control: The Stakes for Moscow, 47 Arms Control Today, May 2017, at 6.

211. GoodBY, supra note 145, at 3-4, 12 (observing that the successful negotiation of the LTBT followed a "terrible year" in East-West relations); Tatiana Anichkina et al., The Future of US-Russian Nuclear Deterrence and Arms Control, 73 Bull. Atomic Scientists 271 (2017) (concluding that dangerous threats will eventually provide new opportunities where international cooperation is both needed and politically feasible); Krepon, supra note 11 (regretting that "there are few diplomatic instruments and no diplomacy among major powers to serve as even a slight counterweight to the military competition now underway"); Maggie Tennis, Russia Suggests Revived Arms Talks, 47 Arms Control Today, May 2017, at 33 (noting Russian interest in resuming a "pragmatic" dialog on arms control); Frank A. Rose, Assistant Sec'y of State, Bureau of Arms Control, Verification and Compliance, Remarks at the International Symposium on Ensuring Stable Use of Outer Space: Using Diplomacy to Advance the Long-Term Sustainability and Security of the Outer Space Environment (Apr. 16, 2015), https://2009-2017.state.gov/t/ avc/rls/253947.htm (noting U.S.-U.S.S.R. progress on arms control during some dark periods of the Cold War, and commenting, "[I]f the United States and the Soviet Union could find areas of mutual interest in the realm of nuclear deterrence and chemical weapons - with the tensions and stakes as high as they were-then in today's climate we should be able to find areas of mutual interest among all space-faring nations regarding space security"). 
environment could help nudge the world an inch away from the present earthborn contention. ${ }^{212}$

The tradition of arms control is often to start with baby steps and to accelerate the process only when a measure of successful implementation has been achieved. The 1972 SALT I agreement, for example, was essentially only a temporary "freeze" or cap on U.S. and Soviet nuclear arsenals; SALT II in 1979 tried in a discreet way to begin the process of gradually reducing the inventories, and it failed to enter into force; it was only the Strategic Arms Reduction Treaty ("START") I in 1991 that imposed substantial cuts and New START in 2010 that chopped the arsenals in more meaningful ways. ${ }^{213}$

With even more timidity, sometimes arms control begins by recording states' solemn promises not to build or test weapons that they do not really want, need, or are not technologically capable of building anyway. Some elements of article IV of the Outer Space Treaty might fit that description, as well as the 1959 Antarctic Treaty ${ }^{214}$ and the 1971 Seabed Arms Control

212. Hitchens \& Johnson-Freese, supra note 1, at 29-33 (arguing in favor of "diplomacy first" in approaching space security); Krepon, supra note 26, at 33 (arguing that the major powers have managed to cooperate, as well as compete, on nuclear matters, and "[t]hey can do so in space, as well"); SPACE SECURITY INDEX, supra note 1, at 121 (observing "the shrinking opportunity to separate activities in space from geopolitical flashpoints on Earth"); David Filipov, Space, Nuclear Security, Polar Bears: Russia and the U.S. Still Agree on Some Things, WASH. Post (Aug. 25, 2017), http://wapo.st/2pw2fyT (observing that despite the generally strained relations, the United States and Russia still cooperate on certain matters, including space activities); David Dunlop, Applying Lessons from Apollo for a Smart Space Agenda at a Time of Increased International Tension, SPACE REv. (Sept. 18, 2017), http://www.thespacereview.com/ article/3328/1; Johnson-Freese \& Hitchens, supra note 25 (noting that the United States and Russia have managed to maintain a working relationship on the International Space Station, even when other aspects of their interactions are politically strained); Russia, U.S. Agree to Create 1st Lunar Space Station, PrESsTV (Sept. 27, 2017), http://www.presstv.ir/Detail/2017/09/27/536698/Russia-US-lunar-space-station-MarsNASA; Simon Saradzhyan, U.S.-Russian Space Cooperation: A Model for Nuclear Security, Bull. AтомIC SCIENTISTs (Mar. 7, 2017), https://thebulletin.org/us-russian-space-cooperation-model-nuclear-security10600 (describing how the United States and Russia have been "continuing to work together in exploring the cosmos," and suggesting using that example to help reestablish a productive partnership in other areas).

213. Treaty on Measures for the Further Reduction and Limitation of Strategic Offensive Arms, U.S.Russ., Apr. 8, 2010, S. Treaty Doc. No. 111-5 [hereinafter New START Treaty] (entered into force Feb. 5, 2011); Treaty on the Reduction and Limitation of Strategic Offensive Arms, U.S.-U.S.S.R., July 31, 1991, S. Treaty Doc. No. 102-20; SALT II Treaty, supra note 143; Interim Agreement Between the United States of America and the Union of Soviet Socialist Republics on Certain Measures with Respect to the Limitation of Strategic Offensive Arms, U.S.-U.S.S.R., May 26, 1972, 23 U.S.T. 3462 [hereinafter SALT I Interim Agreement] (entered into force Oct. 3, 1972); GraHam \& LAVERA, supra note 51, at 306-09, 336-37, 343-47, 883-89.

214. Antarctic Treaty, supra note 141. The Antarctic Treaty records the parties' agreement to use Antarctica "for peaceful purposes only," and to prohibit "any measures of a military nature," such as the establishment of military bases, the conduct of military maneuvers, and the testing of weapons. Id. art. I; see Graham \& LaVera, supra note 51, at 13 (describing the Antarctic Treaty "as an example of nations exercising foresight and working in concert to prevent conflict before it develops," on the premise that "to exclude armaments is easier than to eliminate them once they have been introduced"); Christopher C. Joyner, The Antarctic State Treaty, in ENCYClOPEDIA, supra note 11, at 817, 821 ("The Antarctic Treaty merits appreciation for its preventive character."). 
Treaty. ${ }^{215}$ Perhaps that quixotic legacy can be drawn upon for quarantining destructive ASAT systems, too.

In one sense, the proposals of this Article could be categorized as confidence-building (or confidence-, transparency-, and security-building) measures, rather than as genuine arms control, since they do not directly limit or reduce the armed forces or armaments of the participants. ${ }^{216}$ There is a long record of success in confidence-building approaches, including for outer space, and a complicated relationship between those instruments and true disarmament. ${ }^{217}$ The parallel structures of the non-legally-binding Helsinki, Stockholm, and Vienna Documents, ${ }^{218}$ intertwined with the legally-binding 1990 Conventional Forces in Europe Treaty, ${ }^{219}$ illustrate how different types of approaches can reinforce each other, as long as political circumstances permit. ${ }^{220}$

215. Treaty on the Prohibition of the Emplacement of Nuclear Weapons and Other Weapons of Mass Destruction on the Seabed and the Ocean Floor and in the Subsoil Thereof, Feb. 11, 1971, 23 U.S.T. 701 (entered into force May 18, 1972) [hereinafter Seabed Arms Control Treaty]. The treaty prohibits the emplacement of nuclear weapons on the ocean floor outside a narrow coastal zone. Id. art. I; see GrAHAM \& LAVERA, supra note 51, at 283 (noting that, like the Antarctic Treaty, the Seabed Arms Control Treaty "sought to prevent the introduction of international conflict and nuclear weapons into an area previously free of them"); see also Convention on the Prohibition of Military or Other Hostile Use of Environmental Modification Techniques art. I, May 18, 1977, 1108 U.N.T.S. 152, (prohibiting the use of certain environmental modification techniques for military or hostile purposes). Graham and LaVera observe that tactics of that type have "not played a major role in military planning for many years," but might do so in the future. Supra note 51 , at 464 .

216. See generally U.N. Office for Disarmament Affairs, Transparency and ConfidenceBuilding Measures in Outer Space Activities (2013); U.N. Secretary-General, supra note 28, at 12-18; Jakhu et al., supra note 40, at 12-14; Xiaodan Wu, China and Space Security: How to Bridge the Gap Between Its Stated and Perceived Intentions, 33 SPACE Pol'y 20, 24-28 (2015); Rose, supra note 65.

217. U.N. Secretary-General, Prevention of an Arms Race in Outer Space, Study on the Application of Confidence-Building Measures in Outer Space, U.N. Doc. A/48/305 (Oct. 15, 1993); Robert Friedman, Dep't of State, Office of the Legal Advisor, Remarks at the 3rd ARF Workshop on Space Security in Beijing, in Digest of United States Practice in International Law 547, 549-50 (CarrieLyn D. Guymon ed., 2015), (supporting non-legally-binding confidence building measures as an important, expeditious mechanism for strengthening the rule of law in space).

218. The Organization for Security and Cooperation in Europe ("OSCE”), as well as its predecessor structures, has generated a series of non-legally-binding agreements over more than thirty years to strengthen European security by implementing a variety of confidence-building measures. See GrAHAM \& LAVEra, supra note 51, at 1272-73; James MacIntosh, Confidence-Building Measures in Europe: 1975 to the Present, in ENCYClOPEDIA, supra note 11, at 929; Arms Control, OSCE, http://www.osce.org/arms-control (last visited Nov. 16, 2017); Overview of Vienna Document 2011, U.S. DeP'T of StATE, https://www.state .gov/t/avc/cca/c43837.htm (last visited Nov. 16, 2017).

219. CFE Treaty, supra note 195. The CFE Treaty attempts to reduce the danger of conventional warfare in Europe by limiting the holdings of most of the states in Europe and North America in several categories of military equipment, including tanks, aircraft, and attack helicopters. See GraHAM \& LAVEra, supra note 51, at 592-98; Treaty on Conventional Armed Forces in Europe (CFE), NuClEAR THREAT INITIATIVE, http://www.nti.org/learn/treaties-and-regimes/treaty-conventional-armed-forces-europe-cfe/ (last visited Nov. 16, 2017); The Conventional Armed Forces in Europe (CFE) Treaty and the Adapted CFE Treaty at a Glance, Arms ConTrol Ass'N, https://www.armscontrol.org/factsheet/cfe (last visited Nov. 16, 2017).

220. The CFE Treaty is facing serious challenges today, as Russia has suspended its implementation of its treaty requirements, and the United States has responded by ceasing to carry out certain of its own obligations. The Conventional Armed Forces in Europe (CFE) Treaty, supra note 219; Treaty on Conventional Armed Forces in Europe, supra note 219. 
Overall, there are many options for diplomats to exercise. The proposals of this Article could be cast in legally- or politically-binding form; they could be expressed in a written, signed text or in parallel but unilateral national statements of intention; they could be instituted as temporary, short-term vehicles, or endowed with generous initial durations. To be most meaningful, any accord would require initial buy-in at least from the United States, China, and Russia-the three major players moving most zealously toward greater military engagement in space. But there are multiple other stakeholding countries, and their interests must be accommodated, too, at least to ward off a potential flood of other entrants into the space-weapons race.

A major contention in this Article is that precedent matters. Sometimes, it is easier to sway potential doubters or resisters by demonstrating that we are not proposing anything that is too new or different-that the current ideas are just modern applications of familiar, tried-and-true tactics that have succeeded in other milieus. There is no guaranty, of course; sometimes familiarity breeds contempt, and sometimes opponents will still resist repeating either a perceived failure or a mechanism that did, indeed, succeed in taking the world in a particular disarmament direction. Moreover, many of the precedents cited in this Article initially arose decades ago, in the context of bilateral U.S.-Soviet (or Russia) relations, but today it is China that is widely perceived as posing the most fateful challenge to U.S. space superiority. ${ }^{221}$ But it should nonetheless be instructive to review the relevant history, to understand more fully how the deliberations of prior generations led to the crafting of rules, institutions, and procedures that can now be fruitfully applied in new contexts.

What could come next in space arms control, if these initial steps were to succeed? The crystal ball is hazy, but there are numerous tantalizing ideas and proposals. Surely, any efforts to negotiate a more meaningful bite out of an ASAT arms race would quickly encounter severe difficulties. Negotiations might well founder over the definition of an anti-satellite weapon (when so many space vehicles are inherently multi-purpose); the definition of a test (and how to deal with the overlap between ASAT-development and missile-defense tests); and the provisions for verification of compliance (because states so jealously guard their space programs and would resist opening themselves to meaningful inspection).222 But there is nothing

221. MacDonald ET AL., supra note 1, at 14 (concluding that "China presents the most prominent military space challenge to the United States."); Bill Gertz, STRATCOM Worried by Slow Pace of U.S. Nuclear Modernization, WASH. Free BeACON (July 31, 2017, 5:00 AM), http://freebeacon.com/nationalsecurity/stratcom-worried-slow-pace-u-s-nuclear-modernization/ (quoting Gen. Hyten as ranking "China a little bit ahead of Russia" in developing threatening space warfare capabilities).

222. Beard, supra note 1, at 414-23 (suggesting future steps for arms control in space); Rose, supra note 65; see Nancy Gallagher \& John D. Steinbruner, Am. Acad. of Arts \& Scis., ReconsiderING The Rules for Space Security (2008); Grego \& Wright, supra note 32; Richard A. Bruneau \& Scott G. Lofquist-Morgan, Verification Models for Space Weapons Treaties, in BuILding the ArChitecture for Sustainable Space Security, Conference Report 73 (2006). 
"inevitable" about an arms race in space; still less is armed conflict outside the atmosphere foreordained and inescapable. ${ }^{223}$

If the EU Code and the PPWT are inadequate and defective, the United States should not just criticize and exhibit passive-aggressive slow-rolling; instead, it is incumbent upon the United States to seize the initiative and develop better, more efficacious concepts. The United States should not just "consider" arms-control proposals for space (as the Obama administration's Space Policy apathetically stated the posture). ${ }^{224}$ Instead, it should exercise active leadership commensurate with its civilian and military investment in space.

This Article emphatically does not advocate simple unilateral self-restraint by the United States. The three ideas assessed here are not based on passivity and a naïve hope for enlightened reciprocity by others. Instead, the call is for aggressive diplomacy, seizing the occasion to exercise international leadership in attempting to forge a more satisfactory and complete space law regime. The United States cannot concoct global arms control on its own, but a strong American influence and sustained engagement are essential to build international consensus and generate concerted action. ${ }^{225}$

To emphasize, this is not "arms control for the sake of arms control," nor are the three proposals designed simply to be more conducive to the misty goal of preserving space as a mythically special place. Instead, the objective is to pursue global stability and U.S. national security by retarding the incipient slide toward a space arms race that would be distinctly disadvantageous. Unless decisive action is undertaken soon, the retrograde erosion of the freedom and usability of space will likely accelerate, with the United States having the most to lose.

The world has repeatedly alternated between arms racing and mutual restraint in ASAT testing and development; exploration of modalities for space control and negation seems to come in erratic waves, punctuated by moments of moderation. Now is the time to entrench the self-discipline, establishing effective, durable international discipline.

To echo the title of this Article, the problem is not that arms control in outer space is inherently so much more complicated or difficult than arms control in other areas. Certainly, the challenges of capping the incipient race

223. Krepon, supra note 11. But see Betmann, supra note 34 (observing that the inevitability of future space war is a broadly shared conclusion among the key national security space actors in the United States); Jakhu et al., supra note 40, at 9 (citing POLLPETER ET AL., supra note 3) (observing that some experts conclude that China believes that space war is inevitable). See generally JoHnson-FreEse, supra note 1 , at $57-68$.

224. See The White House, supra note 73 , at 7.

225. See Am. Inst. of Aeronautics \& Astronautics, Ensuring U.S. Leadership in Space (2016) (arguing for continued U.S. leadership in space); GREGO \& WRIGHT, supra note 32, at 13-14, 28; Loverro, supra note 131; see also Weber \& Drell, supra note 11, at 393, 397 (calling for the United States to exercise "contingent restraint" in the development of ASAT capabilities). See generally RoNALD O'Rourke \& Michael Moodie, Cong. Research Serv., U.S. Role in the World (2017) (highlighting questions about U.S. international leadership under the Trump administration). 
to establish counter-space capabilities will be profound, but other security realms have posed seemingly intransigent hurdles, too. No, the problem is human politics-both domestic and international-not the domain in which the controversies play out. Since the Outer Space Treaty in 1967, the world has witnessed major disarmament advances within the purview of nuclear arms (for example, START I under President Ronald Reagan, New START under President Barack Obama); chemical weapons (the Chemical Weapons Convention under Presidents George H.W. Bush and Bill Clinton); and biological weapons (the Biological Weapons Convention under President Richard Nixon). None of those accomplishments was easy or automatic; at multiple points, it seemed that success was far from assured-but the negotiators pressed forward.

Today, the resistance to effective arms control in outer space seems especially entrenched; even modest measures provoke a strong allergic reaction. Still, as Shakespeare's Cassius advised Brutus, objective circumstances can make some tasks extremely difficult-but fate and "the stars" do not control our destiny. ${ }^{226}$ Instead, the fault is in ourselves; humans can overcome the frustrations and the challenges of governance-and we now have the occasion, the provocation, and the responsibility to try.

226. William Shakespeare, Julius Caesar, act 1, sc. 2 ("Men at some time are masters of their fates; The fault, dear Brutus, is not in our stars, But in ourselves, that we are underlings."). 